\title{
Optimization of Advanced Filter Systems
}

\author{
Base Contract Topical Report
}

\author{
By \\ R. A. Newby, G. J . Bruck, M. A. Alvin, T. E. Lippert
}

April 1998

Work Performed Under Contract Number DE-AC26-97FT33007--03

August 20, 1997 - April 1998

For

U. S. Department of Energy

Office of F ossil Energy

Federal Energy Technology Center

P.O. Box 880

Morgantown, West Virginia 26507-0880

Prepared by

Westinghouse Science \& Technology Center

1310 Beulah Road

Pittsburgh, Pennsylvania 15235-5098 


\section{TABLE OF CONTENTS}

ABSTRACT. viii

1. SUMMARY AND CONCLUSIONS $1-1$

1.2 The Optimization of Advanced Filter Systems Program ............. 1-5

1.3 PFBC Ceramic Barrier Filter Conclusions ................................. 1-6

1.4 IGCC Ceramic Barrier Filter Conclusions.................................... 1-8

1.5 Technical Issues and Option I Program Plan ............................. 1-9

2. PROGRAM INCENTIVES AND GOALS ......................................... 2-1

3. CERAMIC CANDLE FILTER SYSTEM TECHNICAL ISSUES ............... 3-1

3.1 Westinghouse Commercial Candle Filter Description .................. 3-1

3.2 Technical Issues................................................................... 3-3

4. ADVANCED CERAMIC BARRIER FILTER CONCEPTS .................... 4-1

4.1 Ceramic Filter Element Types ............................................... 4-1

4.2 Ceramic Filter Element Support Arrangement Concepts............. 4-5

5. BASIS FOR ADVANCED CERAMIC BARRIER FILTER

EVALUATION ……................................................................... $5-1$

5.1 Advanced Power Plant Selection................................................. 5-1

5.2 Reference IGCC and PFBC Operating and Design Conditions... 5-4

5.3 Design and Performance Estimation Procedures..........................5-4

5.4 E conomic Premises and Cost Estimation Procedures ................... 5-6

6. CERAMIC BARRIER FILTER CHARACTERISTICS AND FEATURES

6.1 Standard Ceramic Candle Filter Configurations 6-1

6.2 Inverted Candle Filter

6.3 Sheet Filter 6-5

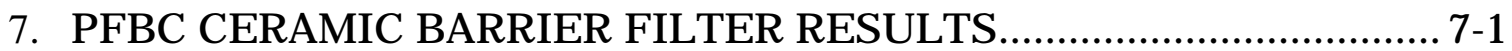

7.1 Design, Performance, and Cost.................................................... 7-1

7.2 Availability Estimates........................................................... 7-6

7.3 PFBC Ceramic Barrier Filter Conclusions .............................. 7-18

8. IGCC CERAMIC BARRIER FILTER RESULTS ................................. 8-1

8.1 Design, Performance, and Cost................................................ 8-1

8.2 Availability Estimates........................................................... 8-7

8.3 IGCC Ceramic Barrier Filter Conclusions................................ 8-12

9. OPTION I PROGRAM ENGINEERING AND TEST PLANS …............. 9-1

9.1 Technical Issues ........................................................................ 9-1

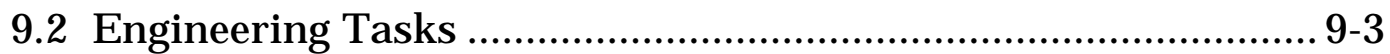

9.3 Test Program Tasks ................................................................ 9-4

9.4 Description of Testing ............................................................ 9-8 
9.5 Data Interpretation and Success Criteria................................. 9-14

9.6 Option I Program Schedule .................................................. 9-17

10. REFERENCES .......................................................................... 10-1

APPENDIX A - Sheet Filter Mechanical Design Assessment ..................... A-1 


\section{LIST OF FIGURES}

Figure 1.1 - Inverted candle and sheet filter geometry ................................... 1-2

Figure 1.2 - I nverted candle configuration concept.......................................... 1-4

Figure 1.3 - Sheet filter configuration concept ............................................... 1-4

Figure 3.1 - Westinghouse Standard Candle Filter Cluster Configuration........3-2

Figure 4.1 - Inverted candle and sheet filter geometry ....................................4-3

Figure 4.2 - Ceramic filter element pressure drop characteristics .....................4-3

Figure 4.3 - I nverted candle configuration concept.......................................... 4-7

Figure 4.4 - Sheet filter configuration concept ................................................. 4-7

Figure 6.1 - Standard candle cluster arrangement ....................................... 6-4

Figure 6.2 - Inverted candle individual-encl osure cluster arrangement ............ 6-6

Figure 6.3 - Inverted candle complete-encl osure cluster arrangement ............... 6-7

Figure 6.4 - I nverted candle complete-encl osure cluster with external support pipe arrangement

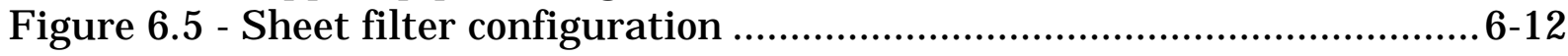

Figure 9.1 - Option I Program Schedule ..................................................... 9-18

Figure A1 - Maximum Sheet Filter Stress with Internal Rib Construction .......A-4 


\section{LIST OF TABLES}

Table 5.1 - Ceramic Barrier Filter Design and Operating Conditions .............5-5

Table 6.1 - Standard Candle Cluster and Single-Plenum Cluster Dimensions and Features

Table 6.2 - Inverted Candle with Individual-Enclosures - Cluster Dimensions and Features

Table 6.3 - Inverted Candle with Complete-Enclosure - Cluster Dimensions and Features

Table 6.4 - I nverted Candle with Compl ete-Enclosure and External Support Pipe - Cluster Dimensions and Features

Table 6.5 - Sheet Filter Internals Dimension and F eatures....

Table 7.1 - Filter System Characteristics for PFBC (314 MWe) Standard Candle Filter Configurations - 60-mm OD, 1.5-m Long Candles..7-4

Table 7.2 - Filter System Characteristics for PFBC (314 MWe) Inverted Candle (60-mm OD, 1.5-m Long) and Sheet Filter Configurations

Table 7.3 - Filter System Characteristics for PFBC (314 MWe) Inverted Candle (60-mm OD, 2.0-m Long) Filter Configurations

Table 7.4 - Filter System Characteristics for PFBC (314 MWe) Inverted Candle (60-mm OD, 1.5 and 2.0-m Long) Complete-E nclosure Clusters with External Support Pipe Filter Configurations

Table 7.5 - Reliability Factor Ranking for Advanced Ceramic Filter Systems in PFBC

Table 7.6 - Availability Estimates for Standard Candle Cluster Filter in PFBC

Table 7.7 - Availability Estimates for Single-Plenum Candle Cluster Filter in PFBC

Table 7.8 - Availability Estimates for Inverted Candle Cluster Filter in PFBC

Table 7.9 - Availability Estimates for Sheet Filter in PFBC

Table 8.1 - Filter System Characteristics for IGCC (406 MWe) Standard Candle Filter Configurations - 60-mm OD, 1.5-m Long Candles ..8-3

Table 8.2 - Filter System Characteristics for IGCC (406 MWe) Inverted Candle (60-mm OD, 1.5-m Long) and Sheet Filter Configurations.

Table 8.3 - Filter System Features for IGCC (406 MWe) Inverted Candle (60-mm OD, 2.0-m Long) Filter Configurations. 
Table 8.4 - Filter System Features for IGCC (406 MWe) Inverted Candle (110-mm OD, $1.5 \&$ 2.0-m Long) Filter Configurations

Table 8.5 - Filter System Features for IGCC (406 MWe) Inverted Candle (60 \& 110-mm OD, 1.5 \& 2.0-m Long) In Complete-Enclosures with External Support Pipe Filter Configurations

Table 8.6 - Reliability Factor Ranking for Advanced Ceramic Filter Systems in IGCC Application

Table 8.7 - Availability Estimates for Standard Candle Cluster Filter in IGCC

Table 8.8 - Availability Estimates for Single-Plenum Candle Cluster Filter in IGCC

Table 8.9 - Availability Estimates for Inverted Candle Cluster Filter in IGCC

Table 8.10 - Availability Estimates for Sheet Filter in IGCC .......................8-17

Table 9.1 - I nverted candle cold flow test matrix ........................................9-9

Table 9.2 - I nverted candle high-temperature test matrix ............................9-12

Table 9.3 - Sheet filter cold flow test matrix ................................................9-15

Table 9.4 - Sheet filter high-temperature test matrix.....

Table A1 - Sheet filter stress as a function of plate dimensions, thickness and pulse pressure.

Table A2 - Variation of Maximum Stress with Rib and Fin Features A-4

Table A3 - Sheet Filter Representative Material Mechanical Properties... A-5 


\section{DISCLAIMER}

This report was prepared as an account of work sponsored by the United States Government. Neither the United States nor the U nited States Department of Energy, nor any of their employees, makes any warranty, expressed or implied, or assumes any legal liability or responsibility for the accuracy, completeness or usefulness of any information, apparatus, product, or process disclosed, or represents that its use would not infringe privately owned rights. Reference herein to any specific commercial product, process, or service by trade name, mark, manufacturer, or otherwise, does not necessarily constitute or imply its endorsement, recommendation, or favoring by the United States Government or any agency thereof. The views and opinions of authors expressed herein do not necessarily state or reflect those of the United States Government or any agency thereof.

Available to the public from the National Technical Information Service, U.S. Department of Commerce, 5285 Port Royal Road, Springfield, VA 22161; phone orders accepted at (703) 487-4650.

\section{PATENT STATUS}

This technical report is being transmitted in advance of DOE patent clearance and no further dissemination or publication shall be made of the report without prior approval of the DOE Patent Counsel.

\section{TECHNICAL STATUS}

This technical report is being transmitted in advance of DOE review and no further dissemination or publication shall be made of the report without prior approval of the DOE Project/Program Manager. 


\begin{abstract}
Reliable, maintainable and cost effective hot gas particulate filter technology is critical to the successful commercialization of advanced, coal-fired power generation technologies, such as IGCC and PFBC. In pilot plant testing, the operating reliability of hot gas particulate filters have been periodically compromised by process issues, such as process upsets and difficult ash cake behavior (ash bridging and sintering), and by design issues, such as cantilevered filter elements damaged by ash bridging, or excessively close packing of filtering surfaces resulting in unacceptable pressure drop or filtering surface plugging. This test experience has focused the issues and has hel ped to define advanced hot gas filter design concepts that offer higher reliability.

Westinghouse has identified two advanced ceramic barrier filter concepts that are configured to minimize the possibility of ash bridge formation and to be robust against ash bridges should they occur. The "inverted candle filter system" uses arrays of thin-walled, ceramic candle-type filter elements with inside-surface filtering, and contains the filter elements in metal enclosures for complete separation from ash bridges. The "sheet filter system" uses ceramic, flat plate filter elements supported from vertical pipe-header arrays that provide geometry that avoids the buildup of ash bridges and allows free fall of the back-pulse released filter cake.

The Optimization of Advanced Filter Systems program is being conducted to evaluate these two advanced designs and to ultimately demonstrate one of the concepts in pilot scale. In the Base Contract program, the subject of this report, Westinghouse has devel oped conceptual designs of the two advanced ceramic barrier filter systems to assess their performance, availability and cost potential, and to identify technical issues that may hinder the commercialization of the technologies. A plan for the Option I, bench-scale test program has also been developed based on the issues identified. The two advanced barrier filter systems have been found to have the potential to be significantly more reliable and less expensive to operate than standard ceramic candle filter system designs. Their key development requirements are the assessment of the design and manufacturing feasibility of the ceramic filter elements, and the small-scale demonstration of their conceptual reliability and availability merits.
\end{abstract}




\section{SUMMARY AND CONCLUSIONS}

Reliable, maintainable and cost effective hot gas particulate filter technology is critical to the successful commercialization of advanced, coal-fired power generation technol ogies, such as IGCC and PFBC. While ceramic barrier filters have reached a near-commercial status for IGCC and PFBC applications, their reliability and maintainability is still a concern. In pilot plant and demonstration plant testing, the operating reliability of ceramic barrier filter systems have been periodically compromised by process issues, such as process upsets and difficult ash cake behavior (ash bridging and sintering), and by design issues, such as cantilevered filter elements damaged by ash bridging, or excessively close packing of filtering surfaces resulting in unacceptable pressure drop or filtering surface plugging. This test experience has focused the issues and has hel ped to define advanced hot gas filter design concepts that offer higher reliability and availability.

\subsection{ADVANCED CERAMIC BARRIER FILTER SYSTEM CONCEPTS}

Westinghouse has identified two advanced ceramic barrier filter concepts that are configured to minimize the possibility of ash bridge formation and to be robust against ash bridges should they occur. The "inverted candle filter system" uses arrays of thin-walled, ceramic candle-type filter elements with inside-surface filtering, and contains the filter elements in metal enclosures for complete separation from ash bridges. The "sheet filter system" uses ceramic, flat plate filter elements supported from vertical pipe-header arrays that provide geometry that avoids the buildup of ash bridging and allows free fall of the back-pulse released filter cake.

The general features of these advanced ceramic filter elements are illustrated in Figure 1.1. The possible range of filter element dimensions are shown in the figure, and these dimensions are parameters in the evaluation. The inverted candle element is a thin-walled (5-10-mm), advanced ceramic candle having a membrane skin on the inside surface. For durability, the inverted candle design is expected to be very similar in its flange and other features to conventional ceramic candle filter elements, though its manufacturing feasibility (with thin walls, inside membrane, and possibly larger diameter and length than standard candles) and durability has not been demonstrated. 


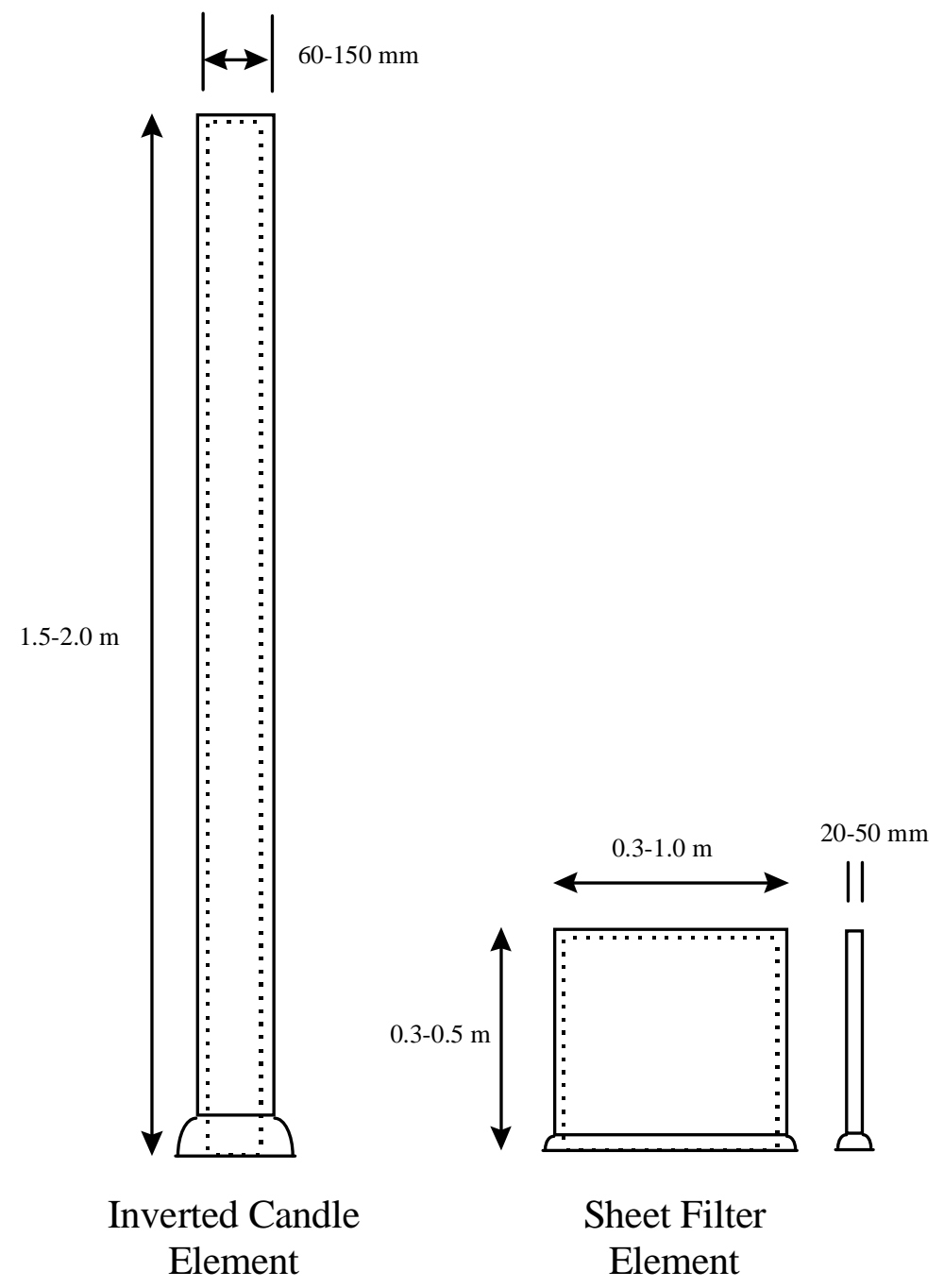

Figure 1.1 - I nverted candle and sheet filter geometry 
Advanced sheet filter elements are relatively simple structures, being parallel flat plate filtering surfaces that are closed on the edges except for one flanged face. The sheet elements must be designed to be rugged with respect to IGCC and PFBC environments. As shown in Figure 1.1, the sheet filter el ement dimensions might result in a surface area slightly smaller than a conventional ceramic candle, but the sheet design is very amiable to achieving high surface area packaging. The use of lightweight ceramics and/or ceramic composites offers the potential for lower weight sheet elements that enhance economics and maintainability. The details of the sheet filter construction (materials, thicknesses, need for internal ribs, flange and holder design, fixture to permanently capture the element) and manufacturing feasibility have not been determined and are the subject of the Option I program. Appendix A reports the results of preliminary estimation of the sheet filter plate thickness and need for internal ribs to minimize stresses resulting during pulse cleaning.

In the inverted candle filter concept illustrated in Figure 1.2, dirty gas is filtered on the inside of each filter element. Each individual inverted candle (Figure 1.2a) or each array of candles (Figure 1.2b) is contained in a metal housing that protects the elements from cantilevered ash bridging. Each filter element is fixed at its bottom, flanged end, and guides are used to maintain the candle in fixed positions within the housing. The holders are designed to allow removal of the candle elements from beneath the plenum, into the dirty-side of the vessel. Two major advantages of this configuration are that all of the filter elements are directly accessible without removal of any equipment or neighboring filter elements, and they are free from the possibility of ash bridging and the potential damage caused by bridging. Because of this, the candles may be as closely packed as is mechanically feasible. F urthermore, with the inverted candle concept, should a filter element develop a crack, it is almost certain to stay contained in its housing, a may even continue to provide effective filtering. The inverted filter elements cannot drop out of their position if they are damaged, so cannot impact and damage other filter elements. Damaged inverted candles al so cannot plug the ash drain nozzle or jam the ash removal system. Should the filter vessel be overfilled with ash during operation, little or no damage should occur to the ceramic filter elements. The capital cost of the inverted candle filter support structure may be slightly higher than that of the standard ceramic candle filter system, but the life cycle cost of the entire system should be lower.

The sheet filter configuration concept is shown in Figure 1.3. The sheet elements are placed on parallel, vertical, clean-gas pipe manifolds, arranging the sheet elements to have uniform face-to-face spacing and providing clear pathways for released ash to drop to the vessel hopper. The configuration is potentially more 


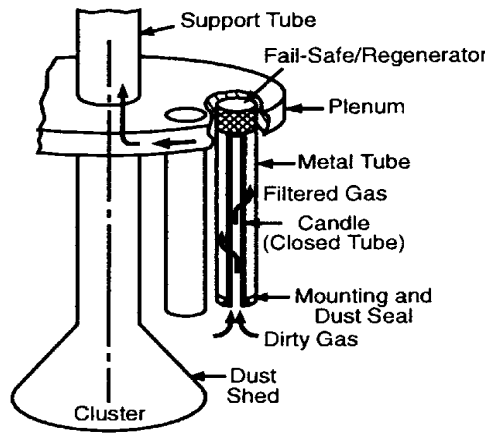

a. Individual Tubes

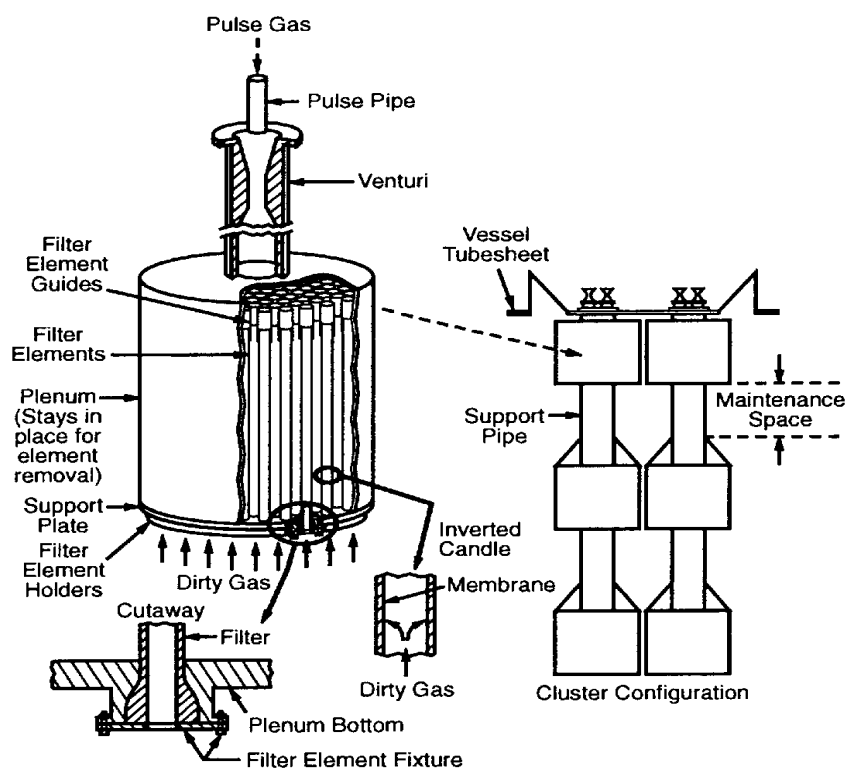

b. Array of Tubes

Figure 1.2 - Inverted candle configuration concept
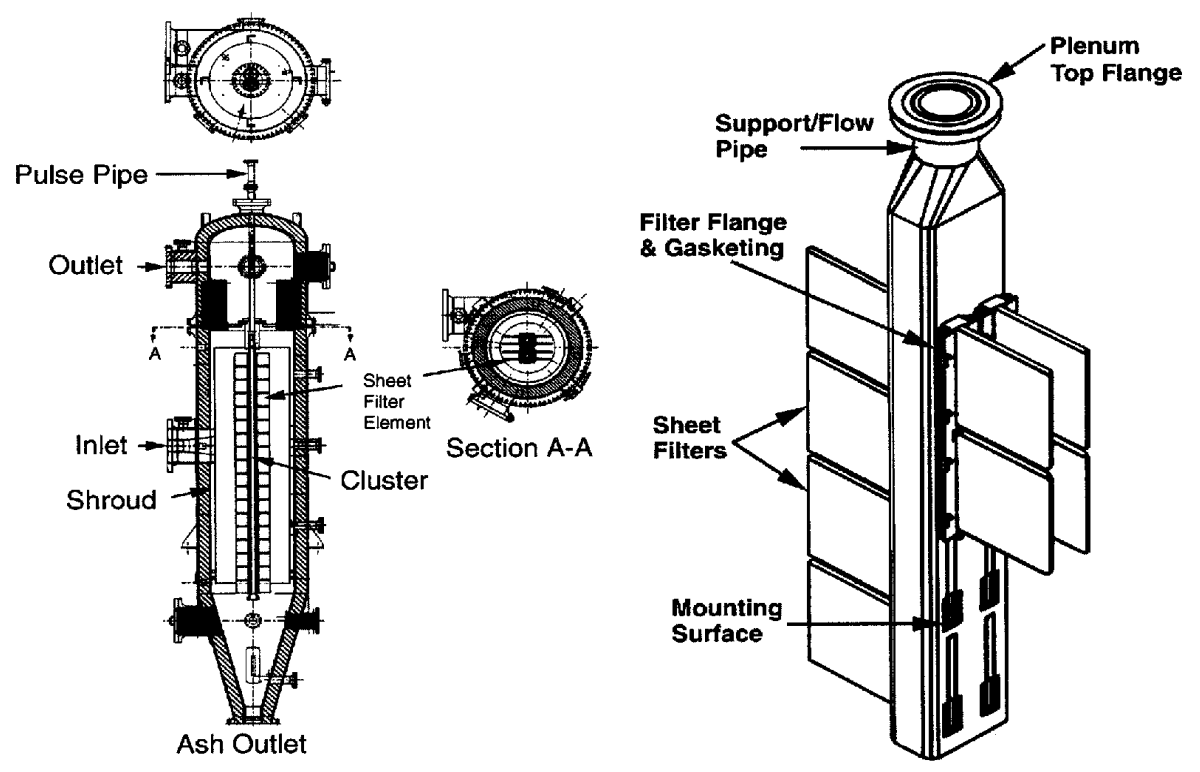

Figure 1.3 - Sheet filter configuration concept 
compact than the conventional ceramic candle filter configuration. The opportunity for ash bridge formation is minimized by the unobstructed path for ash cake discharge. A key sheet filter design issue is the development of a durable and manufacturable sheet element. Also, the sheet filters must be fixed to the plenum pipes so that damaged elements cannot drop off to impact and damage other sheet elements in a cascading fashion, or to block the ash drain nozzle of jam the ash removal system. The sheet filter configuration maintenance is performed within the vessel similarly to that of the standard candle filter system. The sheet filter has the potential to result in both capital cost reduction and improved operating cost relative to the standard ceramic candle filter system.

\subsection{THE OPTIMIZATION OF ADVANCED FILTER SYSTEMS PROGRAM}

The Optimization of Advanced Filter Systems program is being conducted to evaluate the two advanced designs and to ultimately demonstrate one of the concepts at pilot scale. In the Base Contract program, the subject of this report, Westinghouse has devel oped conceptual designs of the two advanced ceramic barrier filter systems to assess their performance, availability and cost potential, and to identify technical issues that may hinder the commercialization of the technologies. A plan for the Option I, bench-scale test program has also been developed based on the identified issues.

Two advanced coal-fired power generation applications have been considered in the evaluation: integrated gasification combined cycle (IGCC) and pressurized fluidized-bed combustion (PFBC). The design basis is described in Section 5 of the report. The specific IGCC and PFBC applications selected for the evaluation have been those most challenging to the ceramic barrier filter system. A $314 \mathrm{MWe}$, firstgeneration PFBC power plant, with ceramic barrier filter temperature of $1600^{\circ} \mathrm{F}$ $\left(871^{\circ} \mathrm{C}\right)$ was selected because of its high volumetric gas flow and high operating temperature. A $406 \mathrm{MWe}$, air-blown, fluid bed gasification IGCC power plant having a ceramic barrier filter temperature of $1007^{\circ} \mathrm{F}\left(542^{\circ} \mathrm{C}\right)$ was selected because of its high volumetric fuel gas flow and high filter operating temperature compared to alternative IGCC fuel gas filtration conditions.

A well-defined design basis was established for the ceramic barrier filter systems (Section 6). Ceramic barrier filter system operating conditions, design conditions, performance requirements, and design constraints were defined based on the advanced power plant needs and standard engineering practice. Cost premises were also selected. The scope of the ceramic barrier filter system equipment supply includes the filter vessels, the filter elements, all of the filter vessel internals, the pulse gas control skids, and the pulse gas compressor skids. Costs were also estimated for the connecting hot gas piping, and the filter ash handling equipment (water-cooled screw conveyors and lock hoppers) to properly account for the overall cost and reliability impacts of multiple filter vessel systems. 
Several assumptions were also developed and designated for the conceptual design activities, the key assumptions being:

- the PFBC and IGCC filter cake properties and behavior were selected from pilot test experience;

- the costs of the advanced ceramic filter el ements were assumed to be identical to those of conventional ceramic candle elements on the basis of dollars per unit of dirty-side filter area;

- the advanced ceramic barrier filter systems were assumed to function as configured: the inverted candles being non-plugging; free from filter cake bridging, and self-sealing in the event of a failure; the sheet filters being free from ash bridging and being mechanically/thermally stable and unable to drop from their positions. This last set of assumptions, of course, must be confirmed experimentally.

-

A procedure was devised for estimating relative filter system reliability, and the reliability estimates were performed for conditions that were conducive to ash bridging and ceramic filter element failures in the standard ceramic candle systems.

\subsection{PFBC CERAMIC BARRIER FILTER CONCLUSIONS}

The two advanced ceramic barrier filter systems evaluated for the PFBC application show the potential to provide hot gas particulate removal with comparable operating performance (pressure drop, pulse cleaning frequency, pulse gas consumption) and slightly lower-to-comparable capital cost to the standard candle cluster filter systems. With difficult ashes that are prone to bridging, sintering, and poor vessel hopper flow, the advanced ceramic barrier filter systems have the potential for significantly improved filter system reliability and availability, with easier maintenance and lower operating costs.

The major parameters considered were the advanced ceramic filter element dimensions, alternative support arrangements for the filter elements, number of filter vessels and number of filter clusters in each vessel. The details of the advanced ceramic filter configurations are described in Section 6 of the report. In the PFBC application, inverted ceramic candles having wall-thickness of 5-mm, outer diameter of $60-\mathrm{mm}$, and lengths of 1.5 and $2.0-\mathrm{m}$ were used. Three inverted candle cluster configurations were defined: 1) each inverted candle enclosed in a container, the "individual-enclosure cluster", 2) all of the inverted candles in a plenum enclosed in a single large container, the "complete-enclosure cluster", and 3) complete-enclosure clusters with "external support pipes" rather than the normal axially-located central support pipe. A single geometry for the sheet filter element was used, with a 1-ft by 1-ft $(0.3-\mathrm{m} \times 0.3-\mathrm{m})$ sheet dimension and about 1-inch (25$\mathrm{mm}$ ) thickness. Larger sheet filter elements were found to have little cost benefit 
and are expected to be more difficult to manufacture. Also, a single sheet filter cluster design was defined.

For each configuration, the minimum number of filter vessels, with the maximum acceptable number of filter clusters in each shop-fabricated vessel was selected, also resulting in a filter face velocity that would meet the pressure drop and pulse gas system constraints. All of the designs required that the filter clusters be arranged in the vessels so that inspection and maintenance could be performed within the filter vessel with manway access to the vessel interior.

The standard ceramic candle filter system cost is about $10 \%$ of the total PFBC power plant cost, a significant cost component of the PFBC power plant. The costs of the three inverted candle cluster configurations evaluated (individualencl osure clusters, complete-encl osure clusters, and complete-encl osure clusters with external support pipes) range from $6 \%$ higher in capital cost to $10 \%$ lower in capital cost than the standard candle cluster filter system. The inverted candle configurations using 2.0-m long inverted candles have the greatest cost potential . The sheet filter system evaluated has about a 5\% capital cost advantage over the standard candle cluster filter system. The advanced ceramic filter elements represent a cost of about $10-12 \%$ of the total capital cost of the advanced ceramic barrier filter systems.

The ease of maintenance of the inverted candle filter systems ranges from comparable to the standard candle cluster filter system for the individual-encl osure clusters configuration, to much easier for the complete-encl osure clusters configuration. The ease of maintenance of the sheet filter system is comparable to the standard candle cluster filter system.

The reliability and availability of the inverted candle filter configurations are potentially much higher than that of the standard candle cluster filter system if difficult ashes that are prone to bridging, sintering, and poor vessel hopper flow are characteristic of the PF BC application. Under the assumptions set, the standard candle cluster filter system would have about 3.2 forced shut downs every year (on average), and would be forced to shut down about every 2,700 hours and be out of service about $7.2 \%$ of the time. This outage rate only reduces the PFBC power plant availability if the filter outages cannot be accommodated by maintenance during scheduled power plant outages or during periods of forced outage due to other PF BC power plant systems. The current state of PFBC is such that forced outages, or planned maintenance periods occur more frequently than every 2,500 hours.

The inverted candle filter system is estimated to be shut down about 1.9 times every year, having about a $4.1 \%$ outage rate and a mean time between outages of about 4,500 hours. The sheet filter system availability is not quite as high as the inverted candle filter system, with shut downs about 2.5 times per year, about $5.4 \%$ outage rate, and mean time between outages about 3,500 hours. The 
potential improvements in the ceramic barrier filter system availability with the advanced ceramic barrier filter systems could have a great impact on the PFBC power plant performance and cost depending on the availability performance of the other major components in the plant. If the PFBC environment is such that the availability of the standard candle cluster filter system is high, the advanced ceramic barrier filter configurations still have the potential for significant cost and maintenance advantages.

\subsection{IGCC CERAMIC BARRIER FILTER CONCLUSIONS}

The two advanced ceramic barrier filter systems evaluated for IGCC application show the potential to provide hot gas particulate removal with comparable performance, but comparable to slightly higher capital cost compared to the standard candle cluster filter systems. With difficult ashes that are prone to bridging, and poor vessel hopper flow, the advanced ceramic barrier filter systems have the potential for significantly improved filter system availability and easier maintenance. In IGCC, the total capital cost of the standard ceramic candle filter system is a small fraction of the total power plant cost --about 3\% or less for the airblown gasification case considered in this evaluation, and even lower for oxygenblown gasification cases. The hot gas filter design emphasis should be placed on improved availability and ease of maintenance rather than of cost reduction.

The major parameters considered were again the advanced ceramic filter element dimensions, alternative support arrangements for the filter elements, number of filter vessels and number of filter clusters in each vessel. In the IGCC application, inverted ceramic candles having wall-thickness of 5-mm, outer diameter of $60-\mathrm{mm}$ and $110-\mathrm{mm}$, and lengths of 1.5 and $2.0-\mathrm{m}$ were used. A larger-diameter inverted candle was considered for the IGCC application because of the significantly lower permeability of the IGCC filter cake and the large impact of this on the maximum acceptable face velocity in the inverted candles. The same three inverted candle cluster configurations were used as those in the PFBC evaluation: individualencl osure clusters, compl ete-encl osure clusters, and complete-encl osure clusters with external support pipes. A single geometry for the sheet filter element was used, with a 1-ft by 1 -ft $(0.3-\mathrm{m} \times 0.3-\mathrm{m})$ sheet dimension and about 1-inch $(25-\mathrm{mm})$ thickness, and a single sheet filter cluster design was defined.

The three inverted candle cluster configurations evaluated (individualencl osure clusters, complete-encl osure clusters, and complete-encl osure clusters with external support pipes) are comparable-to-higher in capital cost (0 to 23\%) than the standard candle cluster filter system. The inverted candle configurations using 2.0$\mathrm{m}$ long inverted candles, $110-\mathrm{mm}$ in OD, have the greatest cost potential, being comparable in cost to the standard candle cluster system. The sheet filter system evaluated has almost identical capital cost to the standard candle cluster filter system. 
The ease of maintenance of the inverted candle filter systems ranges from comparable to the standard candle cluster filter system for the individual-encl osure clusters configuration, to much easier for the complete-encl osure clusters configuration. The ease of maintenance of the sheet filter system is comparable to the standard candle cluster filter system.

The reliability and availability of the inverted candle filter configurations are potentially much higher than that of the standard candle cluster filter system if difficult ashes that are prone to bridging, and poor vessel hopper flow are characteristic of the IGCC application. If the IGCC environment is such that the availability of the standard candle cluster filter system is high, the advanced ceramic barrier filter configurations still have the potential for significant maintenance advantages.

Under the assumptions set for IGCC, the standard candle cluster filter system would have about 3.5 forced shut downs every year (on average), and would be forced to shut down about every 2,500 hours and be out of service about $6.8 \%$ of the time. This availability is only a concern for the IGCC power plant if these outages cannot be accommodated by maintenance during scheduled plant outages or during periods of forced outage due to other IGCC power plant systems. The current state of IGCC is such that forced outages, or planned maintenance periods occur more frequently than every 2,500 hours.

The inverted candle filter system is estimated to be shut down about 2.1 times every year in IGCC, having about 3.9\% outage rate and a mean time between outages of greater than 4,100 hours. The sheet filter availability is not quite as high as the inverted candle system, with shut downs about 3.0 times per year, about $5.7 \%$ outage rate, and mean time between outages about 2,900 hours. The potential improvements in the hot gas filter system availability with the advanced ceramic barrier filter systems could have a great impact on the IGCC power plant performance and cost depending on the availability performance of the other major components in the IGCC plant.

\subsection{TECHNICAL ISSUES AND OPTION I PROGRAM PLAN}

In the Option I program, Bench-Scale Testing for the Resolution of Technical Issues, basic testing will be conducted, focusing on the key issues of the two advanced ceramic barrier filter concepts that have been identified in the Base Program. Option I will consist of 1 ) engineering activities related to inverted candle and sheet filter design, such as manufacturing, seals and element fixing, and failsafe/regenerator adaptation to the advanced configurations; and 2) testing focused on the advanced ceramic barrier filter systems key issues.

The testing will be conducted under simulated PFBC conditions and will utilize existing test facilities. For the inverted candle, ash plugging and cleanability 
over a range of PFBC conditions, and its potential to act as a self-sealing fail-safe will be demonstrated at small scale. Inverted candle filter engineered features for operability/durability will also be tested, including seals, element fixing, and shortterm ceramic filter element durability. For the sheet filter, the ability of the configuration to avoid ash bridging and provide free released ash path will be demonstrated. Sheet filter engineered features for operability/durability will also be tested, including seals, el ement fixing, fail-safe/regenerator, and short-term ceramic filter element durability.

Specific engineering tasks and test matrices have been developed for the Option I bench-scale test program. The Option I schedule has also been updated based on these plans. 


\section{PROGRAM INCE NTIVES AND GOALS}

Integrated gasification combined-cycle power generation (IGCC) and pressurized fluidized bed combustion (PFBC) are two recently-commercial coal-fired technologies that offer the potential for improved power generation efficiencies and reduced environmental emissions over conventional steam boilers. Coal is projected to be a primary fuel world-wide for the foreseeable future, with IGCC and PF BC potentially playing a significant role in new and repowered generation. The U.S. Clean Coal Demonstration program is geared to commercialize these technol ogies and to position them for world-wide application. The hot gas particulate filter is a key developing technology that will enable advanced forms of IGCC and PFBC power generation to operate with improved power generation economics and reliability. The hot gas particulate filter must itself be economical and reliable to fulfill this potential.

PFBC has been commercially demonstrated in its first-generation form using cyclone-based particulate removal and ruggedized turbines that can tolerate high dust loadings. The relatively poor PFBC plant efficiency, and high maintenance requirement of the ruggedized turbine are seen to limit the potential of PFBC to cost levels comparable to conventional coal-fired steam plants. The use of hot gas particulate filters to allow highly efficient and lower-cost turbines to be used, with the elimination of stack gas particulate cleaning, is seen as an approach for improving PFBC efficiency, economics and reliability. An advanced form of PFBC, Topping-PFBC, that has the potential for greatly improved power generation efficiency and economics is being developed with integrated hot gas particulate filters and is approaching a status for initial demonstration.

IGCC power plants that have been under demonstration using low temperature fuel gas cleaning have high capital investment and generation efficiencies that do not live up to the potential promise of IGCC. Again, hot gas particulate filters, in some cases combined with advanced high-temperature fuel gas desulfurization systems, are seen as a route to improved IGCC economics, efficiencies and reliability.

The type of hot gas particulate filter that has been subjected to the most extensive pilot testing and design evolution is the ceramic barrier filter. In pilot plant testing, the operating reliability of several types of ceramic barrier filters have been compromised by both process and design issues. This test experience has focused the issues and has hel ped to define advanced ceramic barrier filter design 
concepts that offer higher reliability. These design concepts must however be demonstrated in principle through pilot plant testing before commercial demonstration can proceed.

The development experience of hot gas, ceramic barrier filters reported by many vendors in the literature clearly shows that additional reliability and availability improvement is necessary for this technology to achieve the benefits that it offers to the advanced power generation techniques. The ceramic candle filter element is the current filter element having the most advanced state of development. The Westinghouse ceramic candle filter system, with over 12,000 hours of test experience in IGCC, PFBC, and Topping-PFBC test units, has directly experienced the issues that challenge the technical and economic viability of ceramic barrier filter systems. This experience has been recently reviewed (Newby et al., 1998).

Short-term degradation of the ceramic candle filter elements due to thermal fatigue and pilot plant process upsets was experienced in previous PFBC test programs. This experience resulted in the development and implementation of the Westinghouse fail-safe/regenerator device that shuts off damaged ceramic filter elements and preheats the cold pulse gas. New filter materials with improved toughness have also been identified, prototyped, and implemented under various Westinghouse/DOE programs.

Operating experience ( $6000 \mathrm{hrs})$ at the Tidd PFBC demonstration plant showed that the reliability of the ceramic candle filter system can be adversely impacted if component redundancy (pulse skid air compressor, pulse valves), inspectability, and maintainability are neglected. Ash bridging was a key technical concern in this testing. In-situ vessel access to the filter elements is a commercial requirement to achieve availability objectives.

Poor cleaning, excessive pulse gas consumption, and loss of pressure drop control are process and design issues that have been experienced. Hard filter cake deposits (PFBC) and ash re-entrainment (IGCC) are key factors influenced by the particle size distribution entering the filter unit, the gas chemistry, the process operating temperature, the coal and sorbent characteristics, and the design of the pulse cleaning system. Ash bridging and deposit formations are ranked as the most critical phenomena contributing to potentially unacceptable performance, and degrading of the reliability and availability of ceramic barrier filter systems. Test experience shows that the current cantilevered candle filter designs are susceptible to damage should ash bridging occur, particularly in PF BC applications.

Westinghouse, working with DOE, has identified potential solutions to these issues, and has implemented and demonstrated such solutions. The ash bridging problem initially encountered at the Tidd PFBC ceramic barrier filter slipstream was resolved by eliminating the upstream cycl one to produce a significantly coarser 
ash entering the filter unit. Although this solution proved effective for this application and this particular mechanism (ash sintering), laboratory studies and analyses show that with other operating conditions or different feed-stocks, other ash bridging mechanisms (formation of melts, for example) can occur, and the control of ash bridging through process modifications alone could adversely impact the commercial viability of advanced power generation systems, particularly PFBC and Topping-PFBC. Such controls might require reducing process operating temperatures or limiting the use of certain coal/sorbent combinations. The need therefore exists to devel op and demonstrate a cost-effective, ceramic barrier filter design that would provide higher inherent tolerance (i.e., robust design) to ash bridging events, particularly under high-temperature PFBC operating conditions.

The overall objective of this phased-program is to develop an advanced ceramic barrier filter system having superior economics, performance and reliability even under the most adverse process and feed stock conditions. This ceramic barrier filter system is to be applicable to both IGCC and PF BC power generation. The filter system development is aimed at several desirable performance goals:

- Achieve particle collection efficiencies that satisfy erosion tolerance requirements for gas turbine,

- Achieve operating reliabilities and availabilities commensurate with modern, high-performance gas turbine engines (i.e., >95\%),

- Be maintainable within current annual outage periods, so that filter vessels can be accessed to perform major inspections, make repairs and replace filter elements,

- Have a capital cost $10 \%$ less than current standard ceramic barrier filter system offerings,

- Be applicable to a wide range of process gas effluents resulting from differing gasifier/PFBC designs, differing process conditions, and fuels/sorbents,

- Be capable of retrofitting any future developments in ceramic filter element materials.

The focus of this evaluation is on ceramic barrier filter devices that operate in the high-temperature, high-pressure, corrosive environments of advanced power 
generation gas cleaning applications, and under the stringent particulate removal performance requirements relating to combustion turbines and environmental emissions. Thus, ceramic filter elements are a necessity in such environments, and conventional technologies such as fabric filter baghouse, el ectrostatic precipitators, and cyclones can either not function in these environments, or cannot meet the performance requirements. Alternative hot gas filtering approaches, such as moving granular bed filters are not considered in this evaluation, being further from commercial readiness than the ceramic barrier filter systems.

The objectives of this Base Contract phase of the program are to evaluate the potential benefits of two proposed advanced ceramic barrier filter concepts for both IGCC and PFBC power systems, to identify and rank technical issues that could hinder their commercialization, and to define a plan for bench-scale testing that will resolve the key technical issues during the following, Option I phase of the program. If successful, this program could proceed through three additional follow-on phases for advanced ceramic barrier filter system pilot scale design, construction and installation of the advanced ceramic barrier filter system, and pilot scale testing. 


\section{CERAMIC CANDLE FILTER SYSTEM TECHNICAL ISSUES}

The current, state-of-the-art ceramic candle filter system is subject to several technical issues relating to its use in PFBC and IGCC. This section describes the Westinghouse standard candle cluster filter system features and identifies the major technical issues and recommended directions of development and design to resolve these issues. The issues that are identified, and the avenues of improvement are analogous to those for other ceramic barrier filter configurations that are being devel oped by industry today.

\subsection{WESTINGHOUSE COMMERCIAL CANDLE FILTER DESCRIPTION}

The Westinghouse ceramic candle cluster filter design, schematically shown in Figure 3.1, consists of stacked arrays of filter elements supported from a common tube sheet structure. In this design, the arrays are formed by attaching individual candle el ements (I tem 1 ) to a common plenum section (I tem 2 ). All the dirty gas filtered through the candles comprising this single array is collected in the common plenum section and discharged through a pipe to the clean side of the tube sheet structure. Each array of filter elements is cleaned from a single pulse nozzle source. The individual plenum assemblies (or arrays) are stacked vertically from a common support structure (pipe), forming a filter cluster (Item 3). The individual clusters are supported from a common, high alloy, uncooled tube sheet structure and expansion assembly (I tem 4) that spans the pressure vessel and divides the vessel into its "clean" and "dirty" gas sides. Each cluster attaches to the tube sheet structure by a specially designed split ring assembly. The cluster is free to expand downward at operating temperatures. The plenum discharge pipes ducting the filtered gas to the clean gas side of the tube sheet structure are contained within the cluster support pipe and terminate at the tube sheet. Each discharge pipe contains an eductor section. Separate pulse nozzles are positioned over each eductor section. The eductors assist pulse cleaning. During cleaning, the pulse gas is contained within and ducted down the discharge pipe and pressurizes the respective plenum section.

The plenum assembly and cluster (stacked plenums) form the basic modules needed for constructing large filter systems indicative of utility power generation requirements. The scale-up approach is:

- Increasing plenum diameter (more filter elements per array),

- Increasing the number of plenums per cluster, 


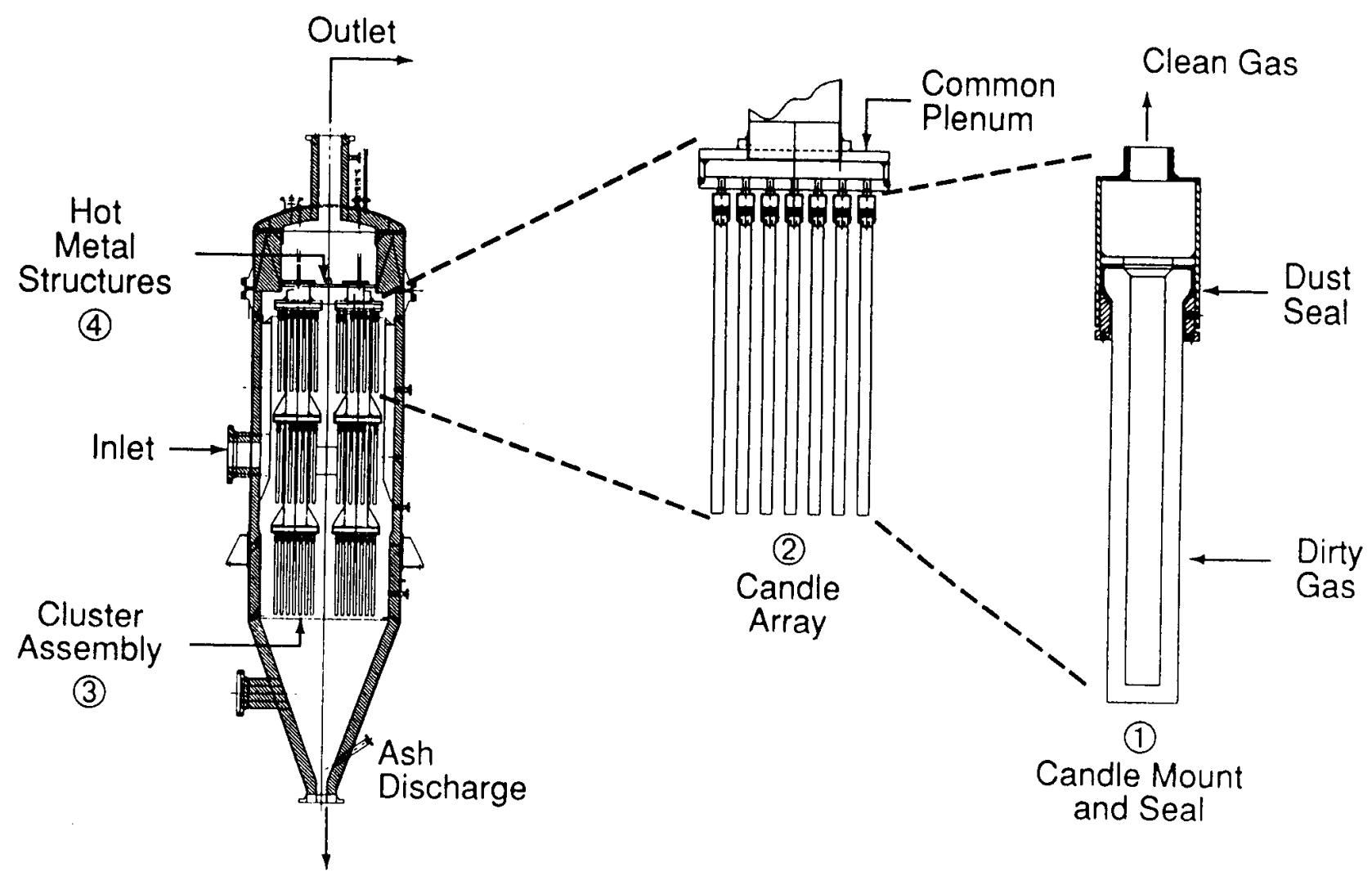

Filter System

Figure 3.1 - Westinghouse Standard Candle Filter Cluster Configuration 
- Increasing the vessel diameter to hold more clusters.

In general, vessel diameter will be limited by the uncooled tube sheet structure and the desire to shop fabricate the pressure vessel.

Standard ceramic candle dimensions are used, 1.5-m length, 60-mm outer diameter, and wall thickness of 10 to $15-\mathrm{mm}$. A variety of ceramic candle materials are available or are under development. Clay bonded silicon carbide (SiC) candle filters are commercially available. The structure of these candle elements is mainly a coarse-grained SiC bonded by a clay-based binder. Each element is provided with a fine grained $\mathrm{SiC}$ or aluminosilicate fiber outer skin that serves as the filtration surface.

Alternate, oxide-based ceramic materials are al so being devel oped for ceramic barrier filter application. Candle filter elements have been constructed using a homogeneous structure that is an alumina/mullite $(A / M)$ matrix containing a small percentage of amorphous (glass) phase.

Over the past several years, Westinghouse working with DOE and various suppliers, have hel ped to devel op and qualify alternative, advanced ceramic filter materials and candle elements. This devel opment has included both dense and lightweight monolithic, vapor infiltrated and Sol-Gel fiber reinforced and filament wound constructions. Laboratory and field evaluation of these and other materials are being conducted to identify, characterize and compare their respective chemical and thermal stability for IGCC and PFBC applications. The status of testing of commercial and advanced ceramic candle filters has been recently reviewed (Alvin et al., 1997).

\subsection{TECHNICAL ISSUES}

Technical and cost issues associated with the current generation of ceramic barrier filter systems exist in the areas of:

- Performance

- pulse cleaning effectiveness

- pulse gas consumption

- pressure drop control

- outlet dust penetration

- Operating procedures

- $\quad$ startup: heatup rate; residual carbon combustion; condensation; filter element deposits and damage

- $\quad$ shutdown: cooling rate; gas purge; filter element damage 
- Reliability

- filter element long-term properties degradation

- filter element short-time failure (e.g., mechanical failure from ash bridging or from falling objects)

- high-temperature gasket degradation

- degradation of uncooled metal structures

- ash hopper drainage failure (ash bridging or failed filter element plugs)

- ash handling system failure (normal mechanisms or failed filter element jamming)

- subsystem component failure (e.g., pulse valves; pulse gas compressor)

- Availability

- fail-safe features for minimum unscheduled shutdowns

- redundant critical component features

- Maintenance

- easy access to filter elements

- on-line access to critical subsystem components

- Cost Effectiveness

- filter elements (new and replacement)

- element support structure high alloy material requirements

- pressure vessel shop fabricated; shop insulated

- minimum number of shop fabricated vessels

- associated, connecting hot gas piping and ash handling systems

- impact of filter system availability on power plant availability

Ash bridging and deposit formation are ranked as the most critical, shortterm issue contributing to potentially unacceptable performance that impacts the reliability and availability of the barrier filter system, and represents a key focus of the proposed program. However, other issues must also be addressed.

In advanced coal-based power generation, the porous ceramic filter elements are exposed to steam and alkali vapor at process conditions that can react with the matrix, changing crystalline structure and therefore its mechanical/thermal properties. Choosing the appropriate ceramic filter material and its final configuration are important factors in achieving long-term material stability and lowest life cycle cost. The ceramic filter el ements undergo significant startup/shutdown thermal cycling and thermal cycling from pulse cleaning events. Westinghouse has targeted a 1 to 3 year filter element life for initial technology demonstration and believes a 5-year life may be needed for eventual commercial operation. 
Clay bonded silicon carbide ( $\mathrm{SiC}$ ) candle elements are available for operation below $1200^{\circ} \mathrm{F}\left(650^{\circ} \mathrm{C}\right)$ and testing is currently in progress to qualify this matrix for higher temperature operation up to $1600^{\circ} \mathrm{F}\left(870^{\circ} \mathrm{C}\right)$ where material creep issues had previously limited their application. The SiC (nonoxides) matrices are, however, susceptible to active/passive oxidation, possibly leading to longer term degradation issues.

Oxide systems (Coors alumina/mullite, DuPont PRD 66 and others) are favored for long-term stability, but will generally exhibit higher coefficients of thermal expansion and therefore may be more susceptible to thermal stressing than the nonoxide materials. Management of the thermal stresses in these matrices is achieved by eliminating sharp corners and edges in the filter element configuration. Westinghouse has also devel oped a device to regeneratively heat the cold pulse gas prior to passing through the ceramic matrix. Analysis and pilot testing has demonstrated the effectiveness of this approach.

Capital cost is not currently a major issue for ceramic barrier filter systems, but as the economics of the advanced power generation systems improve, the ceramic barrier filter system cost must be reduced to an acceptable level. Cost effectiveness, though, is an issue, and is related to the barrier filter system reliability, maintainability, and filter element life cycle cost.

Many design improvements and features have al ready been (or are being) developed through ongoing ceramic barrier filter test programs and have been implemented into current barrier filter commercial offerings, and are retained in the advanced ceramic barrier filter designs, particularly those features related to improving component operating reliability.

From the field and laboratory test experience the following recommendations were developed:

- Ceramic barrier filter systems can be better integrated into PFBC and IGCC to reduce the likelihood of ash bridging by the following:

- Controlling inlet particle size distribution (coarser fraction) with a resulting increased solids loading

- Better understanding of the selection of coal/sorbent combinations

- Understanding of the barrier filter process operating temperatures in relation to coal feedstock, selected sorbent(s) and gas chemistry.

- Improving the design of the barrier filter unit by:

- Minimizing or eliminating stagnant flow zones or incorporating flow turbulators 
- Applying appropriate criteria for sizing ash discharge hoppers and dust shed (i.e., developing ash properties and flow characteristics)

- Providing "soot" blowing capability to dislodge deposited ash

- Minimize or eliminate obstructions to the dislodging and fall of the dust cake into the ash hopper

- Eliminate long, cantilevered filter elements unless they can be contained or appropriately spaced.

The results and experience gained from laboratory studies and ceramic barrier filter field testing form the basis for the proposed program approach and the selected ceramic barrier filter system concepts. Two advanced ceramic barrier filter concepts are evaluated that should significantly mitigate the occurrence of ash bridging events. In conceiving these advanced filter configurations, other important technical and cost issues were also addressed:

- Designing the barrier filter unit for high dust loadings

- Providing a filter configuration that minimizes pulse gas consumption, and is readily deanable

- Providing acceptable pressure drop control

- Selecting a ceramic filter element material and design that is stable under process operating conditions

- Selecting design features that improve maintainability, reliability and availability

- Selecting cost-effective design features. 


\section{ADVANCED CERAMIC BARRIER FILTER CONCEPTS}

Ceramic barrier filter concepts are described here with respect to the geometric properties of the basic ceramic filter elements and the configuration of the support structure for the filter elements. The desirable features for a ceramic barrier filter system and the advanced filter system concepts selected for evaluation are described in this section.

\subsection{CERAMIC FILTER ELEMENT TYPES} the following:

Ceramic barrier filter elements that have previously been considered include

- Conventional ceramic candles

- Ceramic bags

- Ceramic channel filter elements (e.g., crossflow, CeraMem)

- Ceramic tubes

Currently, commercial ceramic candle filter elements of 1.5-m length, $60-\mathrm{mm}$ $\mathrm{OD}$, and 10 to 15-mm thickness are the dominant filter element type being demonstrated for IGCC and PFBC. Advanced ceramic materials and manufacturing methods for candles are also under development. The only alternative, ceramic filter elements that have been considered and tested in significant programs, having reasonable test scale, are crossflow elements (Alvin and Lippert, 1995), ceramic bags (Weber and Schelkoph, 1990) and ceramic tubes (Brown and Leitch, 1993). Of these, only the ceramic tubes are currently being demonstrated at large scale (Higashi et al., 1997).

In general, ceramic bag filter dust penetration performance has been poor and the current materials used in their construction may embrittle at process conditions typical of IGCC and PFBC. They have received little recent attention.

The limitations of the current generation of crossflow channel filter elements, relating to manufacturing and flange/holder design, have been determined, and development work in still progressing to improve the element. The CeraMem channel element is a compact, high internal surface area filter element adapted from a basic structure used in catalyst applications. It is similar in many aspects to the crossflow filter element. It has been tested by several organizations with limited 
success, showing a tendency for plugging. It is not considered practical for high solids loading applications since the potential for channel plugging is high and cleaning frequencies become impractical.

Two advanced ceramic filter element designs have been conceived:

- "inverted" candle -- thin-walled, ceramic candle-like element with inside filtering

- ceramic sheet filter element

I nverted candle, thin-walled, candle-like elements with inside membrane surface filtering, and sheet filter elements are applied in this evaluation of advanced barrier filter systems. The general features of these advanced ceramic filter elements are illustrated in Figure 4.1. The possible range of element dimensions are shown in the figure, and these dimensions are treated as parameters in the evaluation.

Advanced sheet filter elements are relatively simple structures, being parallel flat plate filtering surfaces that are closed on the edges except for one flanged face. The element is designed to be rugged with respect to IGCC and PF BC environments. As shown in Figure 4.1, the sheet filter element dimensions result in a surface area slightly smaller than a conventional candle filter, but the sheet design is very amiable to achieving very high surface area packaging. The use of lightweight ceramics and/or ceramic composites offers the potential for developing light-weight sheet elements that enhance economics and maintainability. The details of the sheet filter construction (materials, thicknesses, need for internal ribs, flange and holder design, fixture to permanently capture the element) have not been determined and are the subject of the Option I program.

The projected pressure drop behavior of conventional ceramic candles, inverted candles, sheet filters, and channel filter elements is shown in Figure 4.2. These projections have resulted from a Westinghouse model that has been established through laboratory and field data. The curves are for a typical, highdust-loading condition and filter cake permeability representative of I GCC barrier filter systems, with all of the filter elements operating with the same face velocity of $4.8 \mathrm{ft} / \mathrm{min}(2.4 \mathrm{~cm} / \mathrm{sec})$. The face velocity is based on the filter element surface area in contact with the dirty gas. At these conditions, both channel filter designs show an asymptotic pressure drop behavior that would be unacceptable in practice. Acceptable pressure drop behavior can be achieved with both the inverted candle and the sheet filter concepts. This program further explores and optimizes the filter surface geometry for cleaning and pressure drop control. 


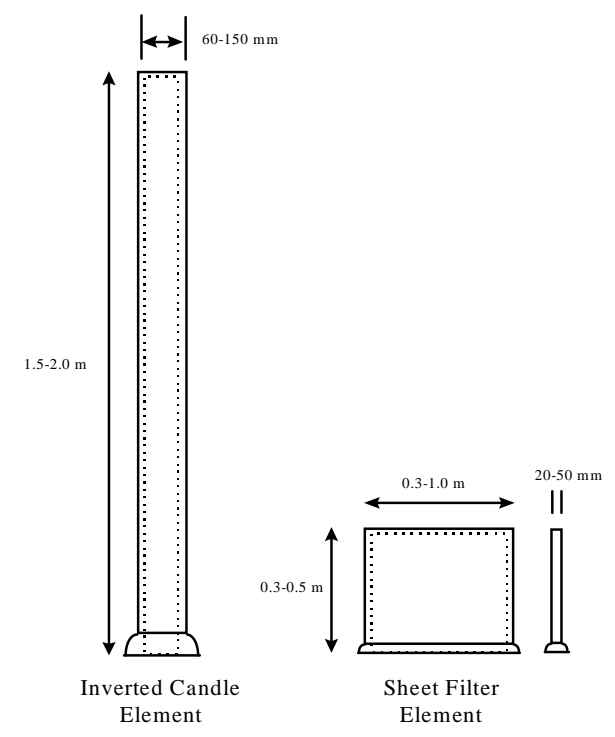

Figure 4.1 - I nverted candle and sheet filter geometry

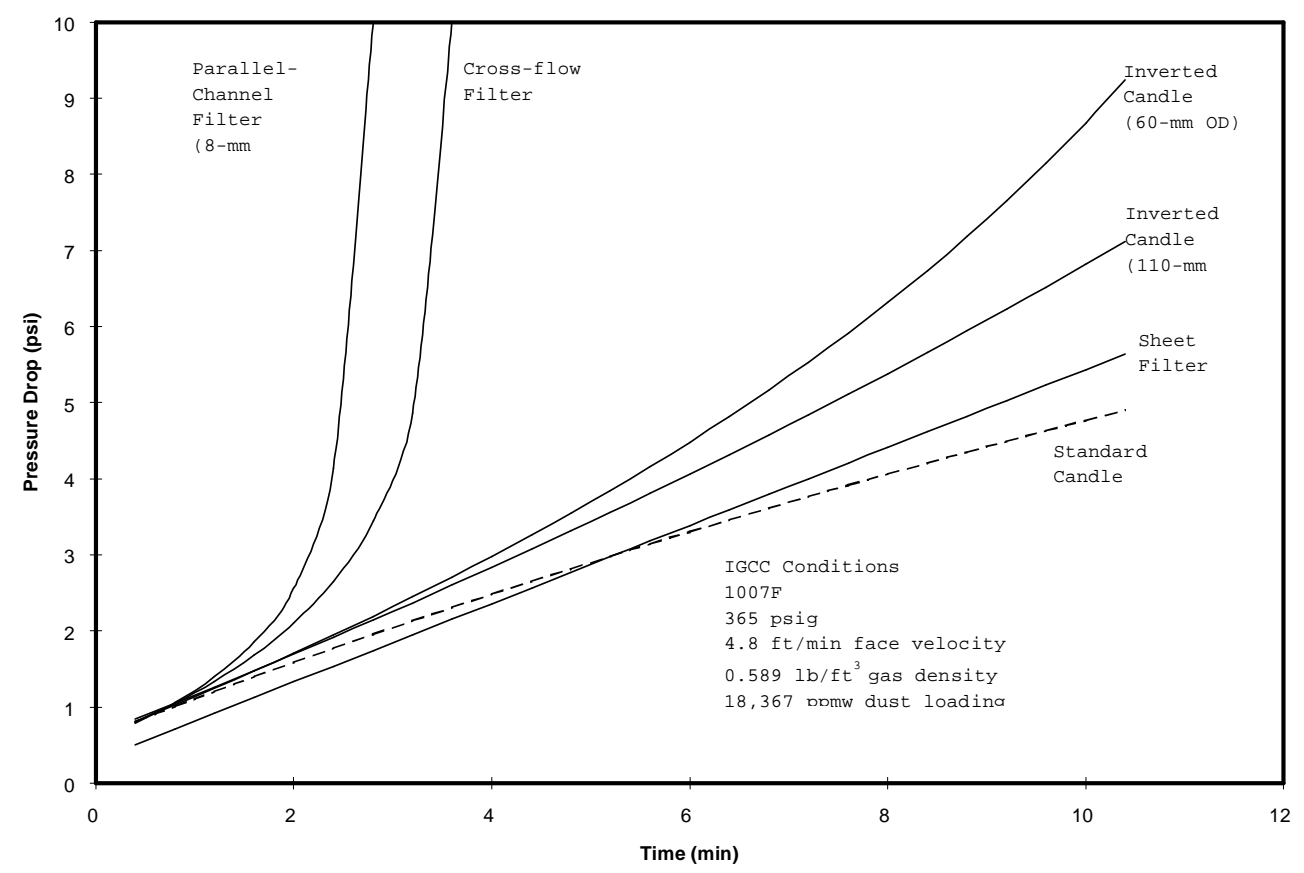

Figure 4.2 - Ceramic filter el ement pressure drop characteristics 
The channel filter elements, having channel dimensions that are comparable to typical filter cake thicknesses, show a dramatic pressure drop rise as the available gas flow channel decreases in size, and they also exhibit unrecoverable channel plugging in laboratory and field testing. The channel elements have a minimum pulse cleaning frequency for any given set of conditions (face vel ocity and dust loading) based on their filling rate, and they must be pulse-cleaned at a higher rate than this minimum to maintain acceptable pressure drop. While channel filter elements offer a large surface area-to-volume ratio that suggests compact barrier filter systems, the reality of these elements is that: (1) the channels result in nonlinear increase in pressure drop as they accumulate filter cake, resulting in very high pressure drops and high pulse cleaning rates that require operating at low face vel ocity, and (2) the channels can not operate reliably with fly ashes that are prone to deposits or bridging.

Test and operating experience shows the distinct advantage of having a course particle size distribution entering the barrier filter unit. Ash is less likely to sinter, will have lower flow resistance (enables low DP, higher face velocity) and be easier to remove from the filter vessel. Significant savings in capital cost are also achieved by eliminating the upstream cyclones and associated ash handling equipment. However, with the courser inlet loading, the filter unit must accommodate significantly higher inlet dust loadings (factor of 10 to 20 times higher expected). Under these conditions, channel filter designs with small flow channels will plug. It is concluded that channel-type filter elements would need to have channel dimensions (height and width) of at least 1-inch to operate reliably. Such channel dimensions make the channel elements unattractive with respect to filter vessel size and system cost.

The sheet filter concept eliminates the small flow channels but maintains a relatively high surface packaging potential. In the inverted candle concept, filtering occurs on the ID surface. In this concept, the ID is large compared to the channeled designs and can be further optimized for cleaning with little impact on filter surface packaging.

Filter el ement manufacturing is a key consideration in the development of advanced ceramic barrier filter concepts. Suppliers are identified and chosen based on both the particular ceramic matrix(s) they can process and on the actual process used. The manufacturing process must produce a product that meets the specified configuration and is inspectable, reproducible and cost effective. Both the inverted candle with ID membrane and the sheet filter concepts require processing that is different than the standard candle element. Suppliers capable of manufacturing the configurations and meeting specified requirements have been identified for the Option 1 test program. 


\subsection{CERAMIC FILTER ELEMENT SUPPORT ARRANGEMENT CONCEPTS}

There are a variety of ceramic barrier filter support arrangements that have been conceived, and these have been previously classified and described (Newby, and Lippert, 1995):

- single-plenum clusters supported from a common tube sheet

- multi-plenum clusters supported from a common tube sheet

- elements on pipe-headers with support from a common tube sheet or pipe header

The single-plenum clusters place the arrays of ceramic filter elements at a single plane located directly under the vessel tube sheet, and is representative of many of the smaller ceramic barrier filter units in sub-scale testing and in some larger IGCC pilot testing. The ceramic filter element may be removable from either the clean-side, above the tube sheet, or from the dirty-side, below the tube sheet, depending on the design details.

The multi-plenum clusters, for example the Westinghouse candle cluster configuration, place the filter element arrays at several discrete elevations. The pipe-header configuration has a variety of forms, but generally distributes the filter elements relatively uniformly throughout the filter vessel volume.

With respect to reliability and economics, the filter element support structure should have the following desirable features:

- eliminates the possibility for ash bridging and/or avoids the damaging effects of ash bridging

- provides a free path for dislodged ash to fall

- avoids the possibility of fractured filter elements falling and damaging other elements and/or plugging the ash drain nozzle, and/or damaging/jamming the ash conveyor system

- provides for ease of maintenance internal to the pressure vessel

The filter system must also meet a host of other performance and cost requirements.

Filter element support configuration concepts have been identified for each of the advanced ceramic filter el ements that potentially provide greater filter system reliability at competitive cost:

- The inverted candle filter el ements are supported on a multi-plenum cluster structure shown in Figure 4.3

- The sheet filter elements are supported on a pipe-header structure shown in Figure 4.4. 
In the inverted candle filter concept, dirty gas is filtered on the inside of each candle-type filter element. Each individual candle (Figure 4.3a) or each array of candles (Figure 4.3b) is contained in a metal housing that protects the element from cantilevered ash bridging. Each filter element is fixed at the bottom end and guides are used to maintain the candle in fixed positions within the housing. The holders are designed to al low removal of the candle element from beneath the plenum, into the dirty-side of the vessel. Major advantages of this configuration is that all of the filter elements are directly accessible without removal of any equipment or neighboring filter elements, and they are free from the possibility of ash bridging and the potential damage caused by bridging. Because of this, the candles may be as closely packed as is mechanically feasible. Furthermore, with the inverted candle concept, should an element crack or fail, it is al most certain to stay contained in its housing, possibly still providing effective filtering. The ceramic filter elements cannot drop out of their position if they are fractured, so cannot damage other filter elements, or plug the ash drain nozzle, or jam the ash removal system.

The key issues with this concept are to size the filter element ID to ensure cake discharge (effective cleaning) without plugging, to show the potential for selfplugging, fail-safe behavior, and to develop appropriate, thin-walled ceramic elements with inside membranes. The capital cost of the filter support structure may be higher than that of the conventional ceramic candle filter support structure, but the life cycle cost of the inverted candle system should be superior.

The sheet filter configuration concept is shown in Figure 4.4. The sheet elements are placed on parallel, vertical, clean-gas pipe manifolds, arranging the sheet elements to have uniform face-to-face spacing and providing clear pathways for released ash to drop to the vessel hopper. The configuration is potentially compact, increasing the filtration surface area within a given filter vessel substantially above that of a conventional candle filter configuration. The opportunity for ash bridge formation is minimized by the unobstructed path for ash cake discharge. The key issues include the devel opment of a durable sheet filter element and holder, its fixing to the plenum pipes so that it will not drop off if damaged, and packaging the configuration for ease of maintenance. Both capital cost reduction and improved operating cost should result.

Proven features of the standard Westinghouse candle cluster filter design are retained and implemented into the packaging of the advanced ceramic barrier filter concepts:

- Pulse skid design that incorporates redundant valving automatically activated in the event of a malfunction in any one of the primary valves, 


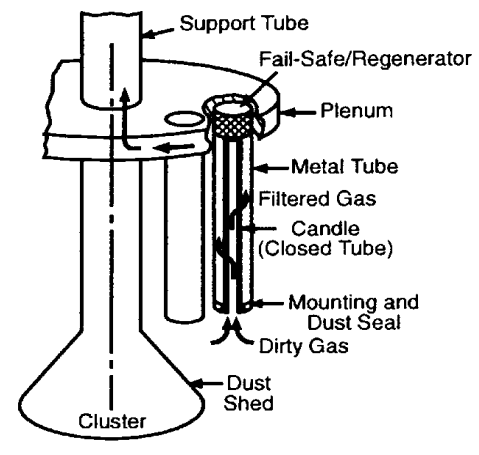

a. Individual Tubes

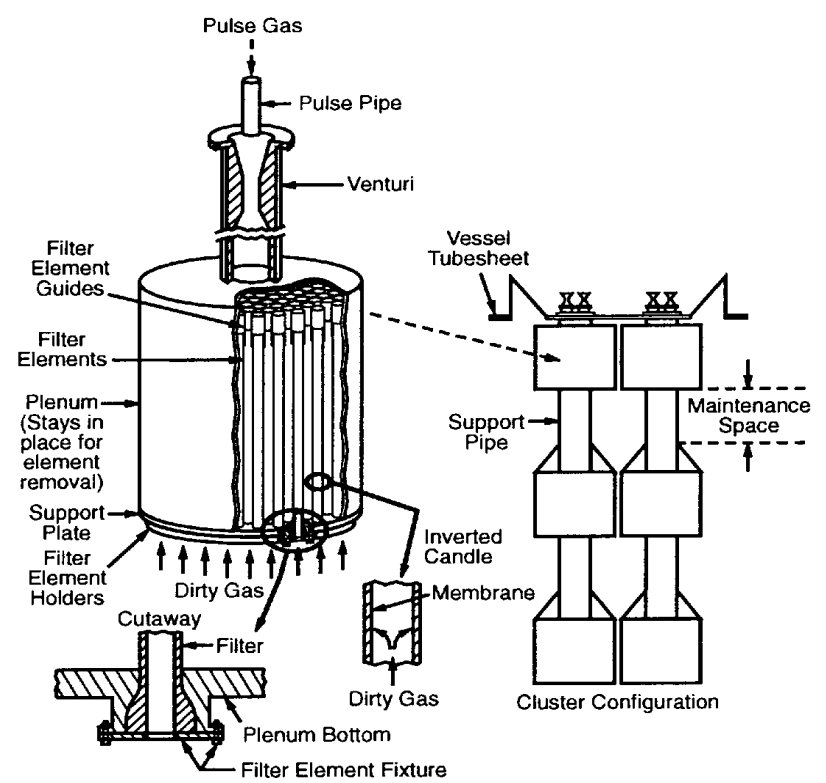

b. Array of Tubes

Figure 4.3 - Inverted candle configuration concept
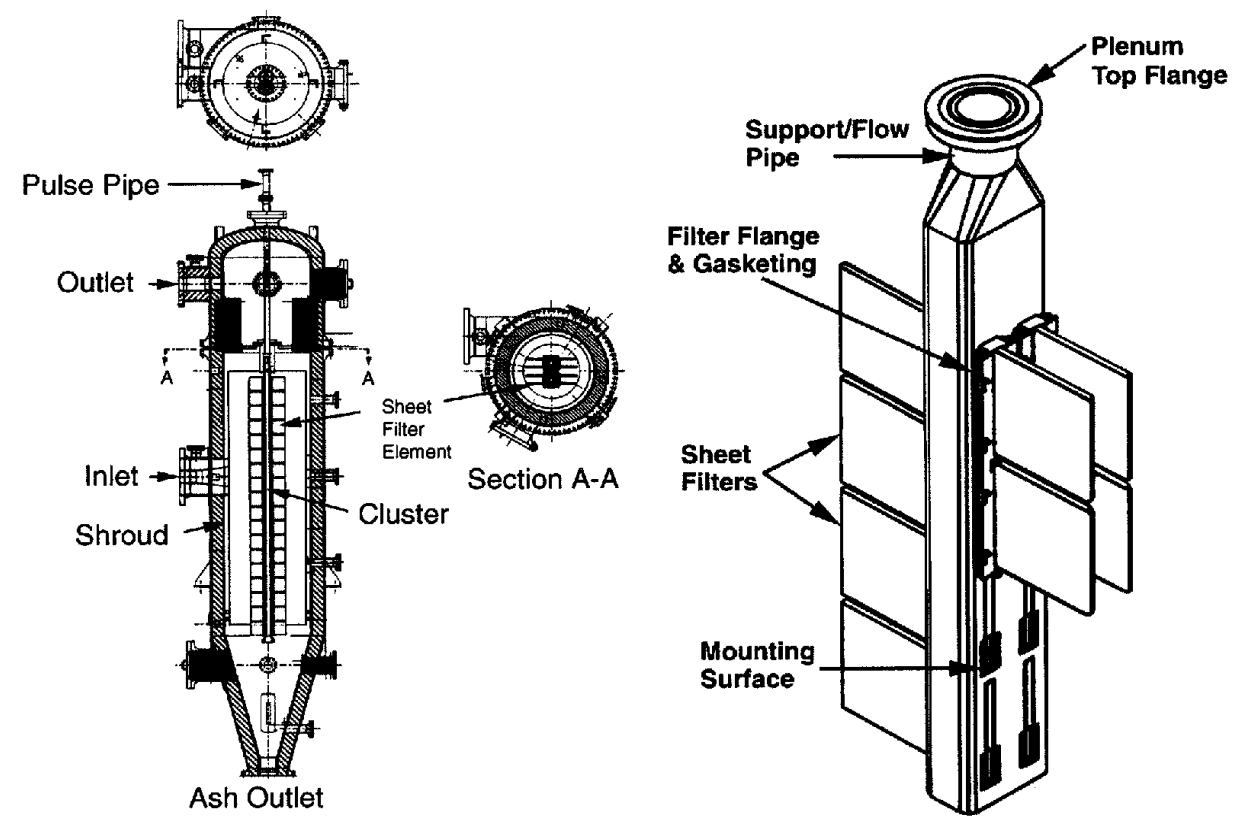

Figure 4.4 - Sheet filter configuration concept 
- Pulse pipe design that includes a thermal liner to accommodate pulse gas thermal fatigue,

- Integral fail-safe/regenerator device that is designed to reduce thermal fatigue of the ceramic during pulsing and protect downstream equipment should a candle element fail,

- Pulse component design features permitting the back-pulse cleaning of a large number of filter elements with a single pulse nozzle,

- A practical means to enter the filter vessel to perform inspection and maintenance,

- Special design features for Seismic Zone 4. 


\section{BASIS FOR ADVANCED CERAMIC BARRIER FILTER}

This section describes the basis applied for the evaluation of the advanced ceramic barrier filter concepts. Two specific advanced power plant environments were selected for the advanced ceramic barrier filters, one representative of firstgeneration PFBC and the other of air-blown IGCC. These advanced power plants were selected because they are the greatest performance, reliability, and cost challenges to the ceramic barrier filter system. The procedures used to generate conceptual designs and cost estimates are described here al ong with the major process assumptions and cost premises.

\subsection{ADVANCED POWER PLANT SELECTION}

The evaluation considers both PFBC and IGCC power plant applications, the most prominent advanced, coal-fired technologies being devel oped today. These are both considered because of the significant differences in the operating conditions, performance constraints, economic characteristics and fuel gas/entrained particulate properties existing in these two advanced power plant technologies.

\subsubsection{IGCC Power Plants}

A variety of coal gasification techniques and fuel gas cleanup techniques have been developed and several have been demonstrated. Generally, entrained gasifiers and fluid bed gasifiers are the most prevalent types under demonstration today, with the entrained gasifiers being primarily oxygen-blown and the fluid bed gasifiers being primarily air-blown. Three approaches to fuel gas cleaning are under development and demonstration: 1) conventional cold gas cleaning utilizing raw fuel gas temperature reduction followed by wet particulate and sulfur removal; 2) hot fuel gas particulate removal using a ceramic barrier filter followed by fuel gas temperature reduction and cold fuel gas desulfurization; 3) hot gas filtration in a ceramic barrier filter integrated with hot gas desulfurization. Approaches 1 and 2 have been commercially demonstrated while approach 3 is in startup for demonstration in 1998. IGCC plants, even those based on mature technologies that have operated for several years, have plant availability of about $75-80 \%$ with longest continuous run times of about 1000 hours. Quarterly maintenance outages are common, and some of the high-temperature, entrained gasifiers have major maintenance outages every 2 years related to gasifier refractory liner maintenance. 
It has been found advantageous in terms of IGCC power plant economics and performance, compared to the use of conventional cold fuel gas cleaning, to perform hot gas filtration prior to cold fuel gas desulfurization, and in these systems the ceramic barrier filter has been generally operated at about $500-600^{\circ} \mathrm{F}\left(260-315^{\circ} \mathrm{C}\right)$. $\mathrm{H}$ ot gas filtration integrated with hot gas desulfurization generally places the ceramic barrier filter after the hot gas desulfurizer, with the filter operated at the hot gas desulfurizer temperature of $800-1000^{\circ} \mathrm{F}\left(427-538^{\circ} \mathrm{C}\right)$.

The ceramic barrier filter conditions for these gasifier and gas cleaning variations are:

\section{Oxygen-blown, entrained gasifier hot gas filter conditions}

1) Ceramic barrier filter followed by cold gas desulfurization:

- $500-600^{\circ} \mathrm{F}\left(260-315^{\circ} \mathrm{C}\right)$

- medium-heating value fuel gas

- high reduced-sulfur content in fuel gas $\left(\mathrm{H}_{2} \mathrm{~S}, \mathrm{COS}\right)$

- low fuel gas tar content

- some carbon deposition potential

- high inlet dust loading

- particulate is slagged coal ash and flux agents with varying carbon content

2) Ceramic barrier filter integrated with hot gas desulfurization (filter located after desulfurizer)

- $800-1000^{\circ} \mathrm{F}\left(427-538^{\circ} \mathrm{C}\right)$

- medium heating-value fuel gas

- low reduced-sulfur content in fuel gas $\left(\mathrm{H}_{2} \mathrm{~S}, \mathrm{COS}\right)$

- low fuel gas tar content

- some carbon deposition potential

- low-to-high inlet dust loading depending process design

- particulate is slagged coal ash, flux agents, and zinc-based sorbent with varying carbon content

\section{Air-blown, fluid bed gasifier filter conditions}

1) Ceramic barrier filter followed by cold gas desulfurization:

- $500-600^{\circ} \mathrm{F}\left(260-315^{\circ} \mathrm{C}\right)$

- low heating-value fuel gas

- medium-to-high reduced-sulfur content in fuel gas $\left(\mathrm{H}_{2} \mathrm{~S}, \mathrm{COS}\right)$

- potential for some fuel gas tar content

- low carbon deposition potential

- high inlet dust loading

- particulate is coal ash/char, carbon, limestone-based sorbent 
2) Ceramic barrier filter integrated with hot gas desulfurization (filter located after desulfurizer)

- $800-1000^{\circ} \mathrm{F}\left(427-538^{\circ} \mathrm{C}\right)$

- low heating-value fuel gas

- low reduced-sulfur content in fuel gas $\left(\mathrm{H}_{2} \mathrm{~S}, \mathrm{COS}\right)$

- potential for fuel gas tar content

- some carbon deposition potential

- low-to-high inlet dust loading depending on process design

- particulate is coal ash/char, carbon, limestone-based sorbent, and zincbased sorbent.

The fuel gas volumetric flow rate is roughly twice as great for the air-blown fluid bed gasifier compared to the oxygen-blown entrained gasifier. This factor, combined with the significantly higher ceramic barrier filter temperature in the fuel gas cleanup approach that utilized hot fuel gas desulfurization, makes this the most challenging case for the ceramic barrier filter.

\subsubsection{PFBC Power Plants}

Two generations of PFBC technol ogies are under devel opment, with the firstgeneration PFBC technology currently commercially offered with cyclone gas cleaning and ruggedized turbines. The ceramic barrier filter conditions relating to these PFBC technol ogy variations are:

\section{First-generation, bubbling- or circulating-PFBC hot gas filter conditions}

- $1550-1600^{\circ} \mathrm{F}\left(843-871^{\circ} \mathrm{C}\right)$

- medium sulfur content in gas $\left(\mathrm{SO}_{2}\right)$

- high excess $\mathrm{O}_{2}$ content in gas

- high inlet dust loading, relatively coarse particles

- particulate is coal ash, some carbon content, sulfated-limestone-based sorbent

\section{Topping-PF BC (carbonizer and PFBC) filter conditions}

1) PFBC filter

- $1300-1600^{\circ} \mathrm{F}\left(704-871^{\circ} \mathrm{C}\right)$

- medium sulfur content in gas $\left(\mathrm{SO}_{2}\right)$

- high excess $\mathrm{O}_{2}$ content in gas

- high inlet dust loading, relatively coarse particles

- particulate is coal ash, carbon, sulfated-limestone-based sorbent

2) Carbonizer filter

- $1200-1600^{\circ} \mathrm{F}\left(649-871^{\circ} \mathrm{C}\right)$ 
- low heating-value fuel gas

- medium reduced-sulfur content in fuel gas $\left(\mathrm{H}_{2} \mathrm{~S}, \mathrm{COS}\right)$

- low potential for tar content

- some carbon deposition potential

- high inlet dust loading, relatively coarse particles

- particulate is coal char, sulfided-limestone-based sorbent

The evaluation is based on the selection of the most challenging power plant gas cleaning conditions for the advanced ceramic barrier filters. First-generation PFBC is comparable to Topping-PFBC with respect to the ceramic barrier filter challenge, but has generally higher filter temperature, higher volumetric gas flow, and potentially worst fly ash filter cake properties.

\subsection{REFERENCE IGCC AND PFBC OPERATING AND DESIGN CONDITIONS}

Table 5.1 lists the Reference IGCC and PFBC ceramic barrier filter operating conditions, design conditions, and performance/design constraints. The specific PFBC and IGCC power plant conditions have been selected from a recent DOE advanced power plant conceptual design and economic evaluation (DeLallo et al., 1997). The filter cake properties listed are typical of these two applications based on Westinghouse past experience, indicating a lower filter cake bulk density and permeability for the IGCC filter than for the PFBC filter. The maximum pressure drop and temperature drop constraints listed are also typical of such applications. The maximum vessel diameter constraints are based on maintaining shop fabrication and truck/rail transport of the pressure vessels, and the smaller PFBC filter vessel maximum diameter is based on expected technological limits on practical uncooled tubesheet designs. Limits have been set on the maximum pulse frequency to control pulse system reliability and maintenance, and on the maximum pulse gas power consumption to keep the filter system auxiliary power at a negligible level of impact on the power plant. The ability to perform maintenance and inspection within the filter pressure vessel is required in this evaluation.

\subsection{DESIGN AND PERFORMANCE ESTIMATION PROCEDURES}

Two standard ceramic barrier filter system configurations are considered in the evaluation, both using conventional ceramic candles (1.5-m long, 60-mm OD): the Westinghouse standard candle cluster configuration and the single-plenum cluster design using standard Westinghouse plenums. The scope of equipment supply included is:

- filter pressure vessels

- filter internals

- pulse gas control skids 
Table 5.1 - Ceramic Barrier Filter Design and Operating Conditions

\begin{tabular}{|c|c|c|}
\hline & PFBC & IGCC \\
\hline Power Plant Technology & $\begin{array}{c}\text { First-Generation } \\
\text { PFBC } \\
\text { (314 MWe) }\end{array}$ & $\begin{array}{l}\text { Air-Blown Fluid } \\
\text { Bed Gasifier } \\
\text { (406 MWe) }\end{array}$ \\
\hline \multicolumn{3}{|l|}{ Operating Conditions } \\
\hline Inlet gas rate, Ib/s $(\mathrm{kg} / \mathrm{s})$ & $843.6(383.0)$ & $298.3(135.4)$ \\
\hline Inlet gas rate, acfm (m³/s) & $203,539(96.1)$ & $30,414(14.4)$ \\
\hline Inlet dust rate, $\mathrm{Ib} / \mathrm{hr}(\mathrm{kg} / \mathrm{s})$ & $19,816(8,996)$ & $19,727(8,956)$ \\
\hline Inlet dust load, ppmw & 6,525 & 18,367 \\
\hline Inlet temperature, ${ }^{\circ} \mathrm{F}\left({ }^{\circ} \mathrm{C}\right)$ & $1600(871)$ & $1007(542)$ \\
\hline Inlet pressure, psig (bara) & $173.3(13.0)$ & $365(26.2)$ \\
\hline Inlet gas density, $\mathrm{Ib} / \mathrm{ft}^{3}\left(\mathrm{~kg} / \mathrm{m}^{3}\right)$ & $0.249(3.99)$ & $0.589(9.44)$ \\
\hline Inlet gas viscosity, Ib/ft-s (Pa s) & $\begin{array}{l}3 \times 10^{-5}(4.46 \times 10- \\
5)\end{array}$ & $\begin{array}{c}2.35 \times 10-5(3.5 \times 10 \\
5)\end{array}$ \\
\hline \multicolumn{3}{|l|}{ Design Conditions } \\
\hline Barometric pressure, psia (bara) & $14.5(1)$ & $14.3(0.99)$ \\
\hline Vessel design pressure, psig (bara) & $250(18.2)$ & $475(33.7)$ \\
\hline $\begin{array}{l}\text { Maximum vessel wall temperature, }{ }^{\circ} \mathrm{F} \\
\left({ }^{\circ} \mathrm{C}\right)\end{array}$ & $650(343)$ & $650(343)$ \\
\hline $\begin{array}{l}\text { Refractory, gas design temperature, }{ }^{\circ} \mathrm{F} \\
\left({ }^{\circ} \mathrm{C}\right)\end{array}$ & $1630(888)$ & $1010(543)$ \\
\hline I nlet gas nozzle velocity, ft/s (m/s) & $80(24.4)$ & $120(36.6)$ \\
\hline Filter cake bulk density, $\mathrm{lb} / \mathrm{ft}^{3}\left(\mathrm{~kg} / \mathrm{m}^{3}\right)$ & $30(481)$ & $20(321)$ \\
\hline Ash angle internal friction (degrees) & 65 & 68 \\
\hline \multicolumn{3}{|l|}{ Design Constraints } \\
\hline Maximum pressure drop, psi (mbar) & $4(276)$ & $8(552)$ \\
\hline Maximum temperature drop, ${ }^{\circ} \mathrm{F}\left({ }^{\circ} \mathrm{C}\right)$ & $10(5.6)$ & $10(5.6)$ \\
\hline Maximum vessel OD, ft $(\mathrm{m})$ & $12(3.7)$ & $16(4.9)$ \\
\hline Maximum pulse frequency, $1 / \mathrm{hr}$ & 5 & 6 \\
\hline Maximum pulse power, $\mathrm{kWe}$ & 200 & 200 \\
\hline Maintenance & In-vessel & In-vessel \\
\hline
\end{tabular}


- pulse gas compressor skids

- filter ash handling equipment

- connecting hot gas piping and manifolding

The filter pressure vessels are shipped with refractory lining and metal liners installed and are equipped with probes for temperature, pressure drop, and ash level sensing. Manways are also provided in the vessel for access to the internals and head at strategic points. The filter internals include the ceramic filter elements, gaskets, fail-safe/regenerator devices, shroud, tube sheet, and maintenance items. Pulse gas control skids include all instrumentation, control system and data recording to operate the filter system. Generally, one pulse gas control skid for each filter vessel is used. The pulse gas compressor skid is a single compressor system and accumulators to provide the required pulse gas pressure source, receiving its pulse gas supply from the power plant. Redundant features are built into the filter system for key components needed to maintain system reliability (pulse control valves and pulse gas compressors). Spare equipment needed for long-term plant operation is not included in this evaluation. The filter ash handling equipment (water-cooled screw conveyors, ash lock hopper systems) is included because it represent a key interface between the filter and the power plant and its requirements change for each type of application and filter system type. Likewise, connecting hot gas piping and manifolding required to mesh with the main gas inlet piping and the main turbine gas piping is included in the design evaluation.

The two standard ceramic barrier filter systems have been characterized conceptually using Westinghouse design techniques that provide design characteristics and performance (equipment dimensions, materials selection and thicknesses, weights, performance) consistent with actual filter systems supplied commercially by Westinghouse. Performance estimates are based on component modeling and correlation of field data that together produce performance representative of that observed/measured in pilot testing.

The objective of the Base Contract evaluation is to determine if the advanced filter systems that have been conceptualized show overall performance, availability and cost advantages over the conventional filter systems to merit their continued feasibility testing and development. The advanced filter system designs are conceptual in nature and apply the same type of design tools as those used for the standard Westinghouse filter conceptual designs, but are adapted to the special geometry and features of the advanced ceramic barrier filter systems. The scope of supply is identical to that listed for the standard Westinghouse filter systems. 


\subsection{ECONOMIC PREMISES AND COST ESTIMATION PROCEDURES}

Costs of the filter systems are developed that represent total capital requirement for delivered equipment, but do not include the installation cost into the power plant structure. The costing is based on the use of algorithms developed by Westinghouse that are incorporated into the design routines to produce approximate costs on a major component basis (materials and labor to fabricate) that are consistent with the costs of ceramic barrier filter systems previously supplied by Westinghouse.

The costs are reported as dollars per kWe of net plant generation on the basis of end-1997 dollars. The reported costs include engineering costs and fees as extrapolated for a mature ceramic barrier filter design basis. An important factor is that the cost of the advanced ceramic filter elements are not established, and for this evaluation the advanced ceramic filter elements are assumed to have costs the same as those for standard ceramic candles on a dollars per unit of dirty-side filtering area. The Option I program will develop more information on the costs of advanced filter elements from interactions with ceramic filter element suppliers and developers. 


\section{CERAMIC BARRIER FILTER CHARACTERISTICS AND FEATURES}

The design philosophy applied to the ceramic barrier filter design is to establish standard cluster designs for each of the ceramic filter element types that would be fixed for all applications apart from changes in materials of construction specific to the application conditions. Multiples of these established clusters are then arranged in filter vessels to satisfy the application performance requirements and design constraints. This section defines the details of the filter elements and standard clusters that are used in the evaluation. The special features provided with each configuration are also described.

\subsection{STANDARD CERAMIC CANDLE FILTER CONFIGURATIONS}

Two standard ceramic candle filter system designs are considered in this evaluation: a standard Westinghouse candle cluster design, and a single-plenum cluster design using standard Westinghouse candle plenums. The standard designs are used as the basis for comparison of design, performance, availability and cost with the advanced ceramic barrier filter concepts.

Table 6.1 lists the dimensions, weights, selected cost information and features applied for the conventional $1.5-\mathrm{m}$ ceramic candles in standard candle clusters and standard single- plenum clusters. Note that the units in this table, and all the tables to follow in Sections 6, 7 and 8 are English Engineering units, the units of actual equipment design and fabrication, and conversion to SI-units has not been made. The items listed represent some of the inputs to the conceptual design algorithms. The filter element characteristic listed as the "conditioned DP" is the pressure drop across a filter element, measured at a face velocity of $10 \mathrm{ft} / \mathrm{min}$, at a temperature of $1600^{\circ} \mathrm{F}$, after the filter element has been exposed to the gas environment for a long period of time. The value listed is assumed to be identical for all of the filter el ement-types considered. Both of these standard design cases utilize maintenance from the dirty-side of the filter, that is, the vessel is entered through manways located below the level of the tube sheet to inspect and perform maintenance.

The concept of clean-side maintenance for the single-plenum cluster configuration is probably not feasible at the temperatures considered in this evaluation due to the structural requirements for uncooled tube sheets. None-theless, a hypothetical case with clean-side maintenance has also been considered, assuming that an uncooled tube sheet with all of the penetrations required could be 
Table 6.1 - Standard Candle Cluster and Single-PIenum Cluster Dimensions and Features

\begin{tabular}{|c|c|c|c|}
\hline & $\begin{array}{l}\text { Standard } \\
\text { Candle } \\
\text { Cluster }\end{array}$ & $\begin{array}{l}\text { Single-Plenum } \\
\text { Cluster }\end{array}$ & $\begin{array}{l}\text { Single-Plenum } \\
\text { Cluster }\end{array}$ \\
\hline Filter Element & & $\begin{array}{c}\text { Clean-Side } \\
\text { Maintenance }\end{array}$ & $\begin{array}{c}\text { Dirty-Side } \\
\text { Maintenance }\end{array}$ \\
\hline $\begin{array}{l}\text { length (in): } \\
\text { OD (in): } \\
\text { ID (in) } \\
\text { thickness (in): } \\
\text { surface area (ft²): } \\
\text { weight (Ib): } \\
\text { conditioned DP (psi): } \\
\text { element cost (\$): }\end{array}$ & $\begin{array}{c}59 \\
2.36 \\
1.18 \\
0.59 \\
2.85 \\
14 \\
1.2 \\
460 \\
\end{array}$ & $\begin{array}{c}59 \\
2.36 \\
1.18 \\
0.59 \\
2.85 \\
14 \\
1.2 \\
460 \\
\end{array}$ & $\begin{array}{c}59 \\
2.36 \\
1.18 \\
0.59 \\
2.85 \\
14 \\
1.2 \\
460 \\
\end{array}$ \\
\hline \multicolumn{4}{|l|}{ Cluster } \\
\hline $\begin{array}{l}\text { number elements: } \\
\text { element distribution: } \\
\text { number plenums in cluster: }\end{array}$ & $\begin{array}{c}187 \\
61,42,42 \\
42 \\
4\end{array}$ & $\begin{array}{l}61 \\
61 \\
1\end{array}$ & $\begin{array}{l}61 \\
61 \\
1\end{array}$ \\
\hline \multicolumn{4}{|l|}{ Features } \\
\hline $\begin{array}{l}\text { include soot blower equipment?: } \\
\text { include shroud?: } \\
\text { include fail-safe?: } \\
\text { internal maintenance items? }\end{array}$ & $\begin{array}{l}\text { yes } \\
\text { yes }(1) \\
\text { yes } \\
\text { yes }\end{array}$ & $\begin{array}{l}\text { yes } \\
\text { yes ( } 2) \\
\text { yes } \\
\text { no }\end{array}$ & $\begin{array}{l}\text { yes } \\
\text { yes (1) } \\
\text { yes } \\
\text { no }\end{array}$ \\
\hline
\end{tabular}

1: top shroud design

2: full shroud design

built at a cost comparable to a normal, candle cluster tube sheet. With the cleanside design, sufficient maintenance space and separation between the plenums is required in the head of the vessel so that personnel can work in the head and remove the plenum covers and pulse pipes before withdrawal of individual filter elements through the tube sheet holes.

Note that the two dirty-side maintenance cases use the same type of shroud, a top shroud that distributes the inlet gas to the top of the clusters in a zone having extended top support pipes. This permits access to all of the ceramic candles for maintenance from platform locations al ong the inner wall of the vessel.

Figure 6.1 illustrates the standard candle cluster arrangement in a vessel, showing the top shroud and extended support pipe with the gas inlet nozzle located near the bottom of the tube sheet. A two-plenum cluster is shown for illustration purposes, and the configuration would be comparable for the single-plenum cluster with dirty-side maintenance. Sufficient space is required at the inner vessel wall for maintenance platforms. Only limited vertical space is needed between the neighboring stacked plenum, and close spacing between the adjacent clusters is 
possible and desirable. The vessel cone section starts exactly at the base of the clusters, with no excess ash storage capacity included.

\subsection{INVERTED CANDLE FILTER}

I nverted candle clusters are constructed similarly to the standard candle clusters, with large support pipes providing the mechanical support for the plenums ( 3 or 4 in number), hanging from the tube sheet for free thermal growth, and carrying several flow pipes (one for each plenum). The inverted candle filter elements may each be contained in a pipe section ("individual-enclosure" cluster), or the entire array of ceramic elements in the plenum may be contained in a single, large enclosure ("complete-enclosure" cluster).

Figure 6.2 illustrates the individual-enclosure cluster arrangement in a vessel, showing only two plenum levels. In this evaluation, the individual enclosure pipes are assumed to be removable from the top interface with the plenum, much as a single candle filter element is removed from a standard candle plenum. Thus, there is no need to provide maintenance space bel ow the contained elements to any greater extent than is provided in the standard candle cluster. Ample space must be provided in the vessel for maintenance from platform locations at the inner vessel wall. No shroud or extended support pipe is needed, although a gas inlet baffle is shown to prevent direct impingement of the inlet gas stream on the clusters. The gas inlet nozzle does not need to be located near the base of the tube sheet, but can be placed at a location selected for simpler fabrication. Only limited vertical space is needed between the neighboring stacked plenum, and close spacing between the adjacent clusters is possible and desirable. The vessel cone section starts exactly at the base of the clusters.

Figure 6.3 illustrates the complete-enclosure cluster arrangement in a vessel, showing only two plenum levels. The inverted arrangement with completeenclosure clusters requires a maintenance space under each plenum with sufficient height for the removal of the inverted candle - a height slightly greater than the length of the ceramic filter element. This configuration does not require space for platform locations at the vessel wall and the inverted candle clusters do not need to be rotated for element removal, except possibly for removal of some of the bottom plenum inverted candle elements. No shroud or extended support pipe is needed, and the gas inlet nozzle may be located at any desired location that directs the gas between the support pipes. Close spacing between the adjacent clusters is possible and desi rable. The vessel cone section starts exactly at the base of the clusters.

An alternative arrangement for the complete-enclosure cluster is illustrated in Figure 6.4 and has some advantages. In this configuration the flow pipes, and their containment pipes, are located external to the inverted candle plenums so that each plenum can contain the same number of inverted filter elements. Three plenum levels are shown to illustrate the differing support configuration for the top, central and bottom plenums. The flow pipe containment pipe supports the cantilevered plenums, again by hanging from the tube sheet. For additional support 
and stiffness, the neighboring clusters are bolted together. This is possible because the complete-enclosure clusters do not need to be rotated for element maintenance. 


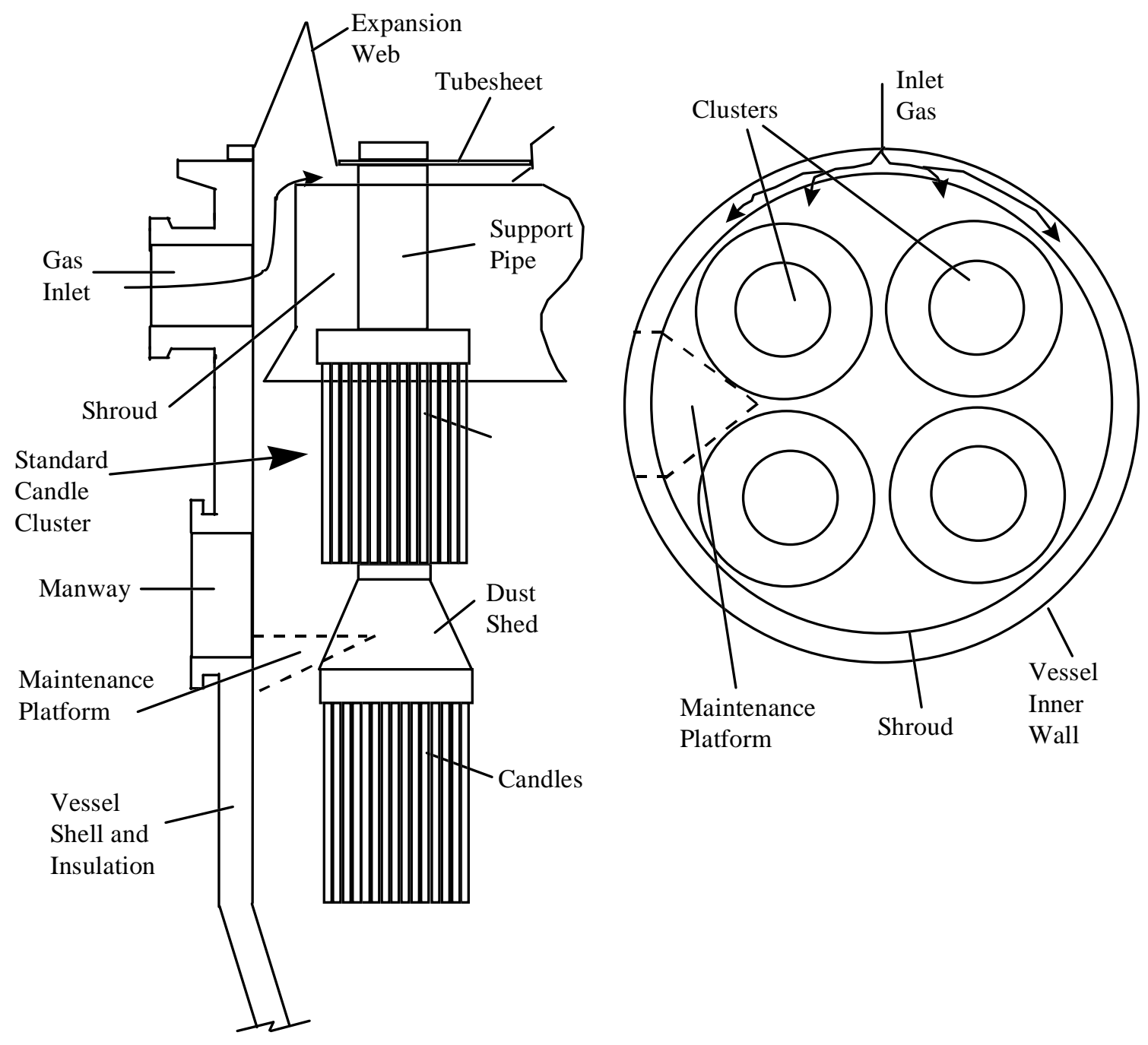

Figure 6.1 - Standard candle cluster arrangement 
Close spacing of the clusters cannot be achieved because space must be available to accommodate the external support pipes. The vessel cone section starts exactly at the base of the clusters, and the lowest plenums are aligned toward the center of the vessel so that all of the inverted filter elements can be withdrawn without interference from the vessel wall.

Table 6.2 lists the filter element characteristics, the cluster characteristics, and special features for the individual-enclosure clusters. Two filter element parameters included in the table are the inverted candle length (1.5-m and 2.0-m) and the inverted candle outer diameter (60-mm and $110-\mathrm{mm}$ ). In columns of the table where values are not shown, the missing values are identical to the values listed in the column to the left. All of the inverted candles are of thin-walled construction (5-mm thickness) to maximize the dirty-side surface areas in an element. All of the cluster arrangements listed have nearly equivalent dirty-side filtering area. Fail-safes, soot-blowers, and shroud are not required, although any of these features can be incorporated into the design if desired. Maintenance features are included for platform fixtures and ladders in the vessel.

Table 6.3 lists the filter element characteristics, the cluster characteristics, and special features for the inverted candle complete-encl osure dusters. Two filter element parameters included in the table are the inverted candl e length $(1.5-\mathrm{m}$ and 2.0-m) and the inverted candle outer diameter (60- $\mathrm{mm}$ and $110-\mathrm{mm})$. All of the inverted candles are of thin-walled construction (5-mm thickness). All of the cluster arrangements listed have the same dirty-side filtering areas as their counter-parts in Table 6.2. This complete-encl osure cluster arrangement requires no fail-safes, no soot-blowers, and no shroud, and no special maintenance features in the vessel.

\subsection{SHEET FILTER}

Table 6.5 lists the characteristics of the sheet filter element, cluster, and special features. A single filter element geometry is considered having dimensions that are likely to be easily manufactured. A sketch of the sheet filter arrangement with four clusters in a vessel is shown in Figure 6.5. The sheet filter clusters are similar to the standard candle clusters in that they utilize a top shroud, an extended support pipe length, fail-safes, and internal maintenance items to inspect and repair the clusters. A soot blower is not incorporated into the design because the design should inherently avoid ash accumulation and bridging. The vertical manifold pipes are square in cross-section with divider plates welded in place to form four independent gas flow channels. Each face of the manifold pipe holds three sheet filter elements. The spacing of the four clusters is sufficient to allow rotation of the individual clusters.

The mechanical feasibility of the ceramic sheet filter element has been evaluated using typical ceramic material properties (Poisson's ratio, Modulus of Elasticity) in a finite-element stress model. The sheet filter porous-wall thickness, length and width were varied to estimate the maximum element stress as a function 


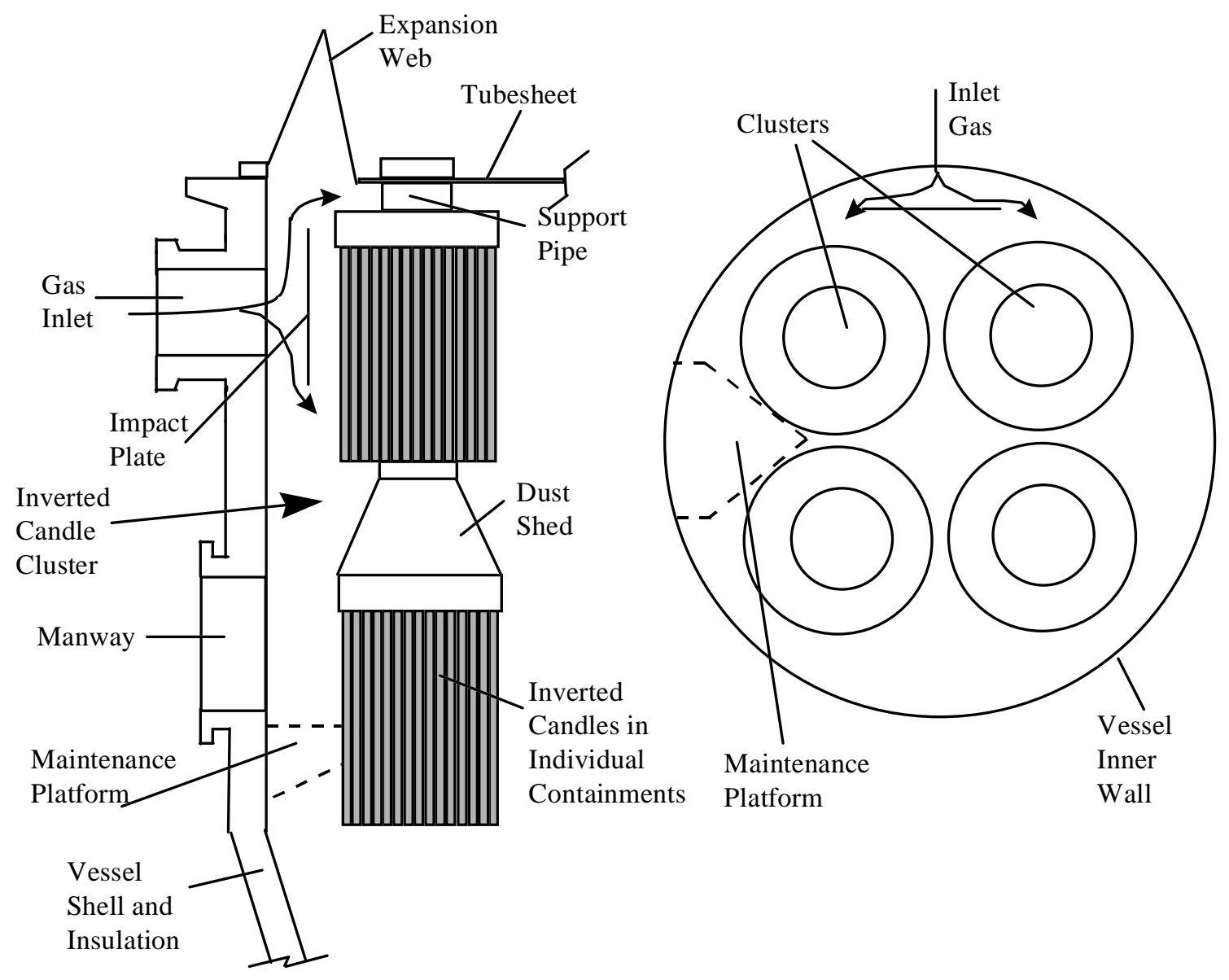

Figure 6.2 - Inverted candle individual-enclosure cluster arrangement 


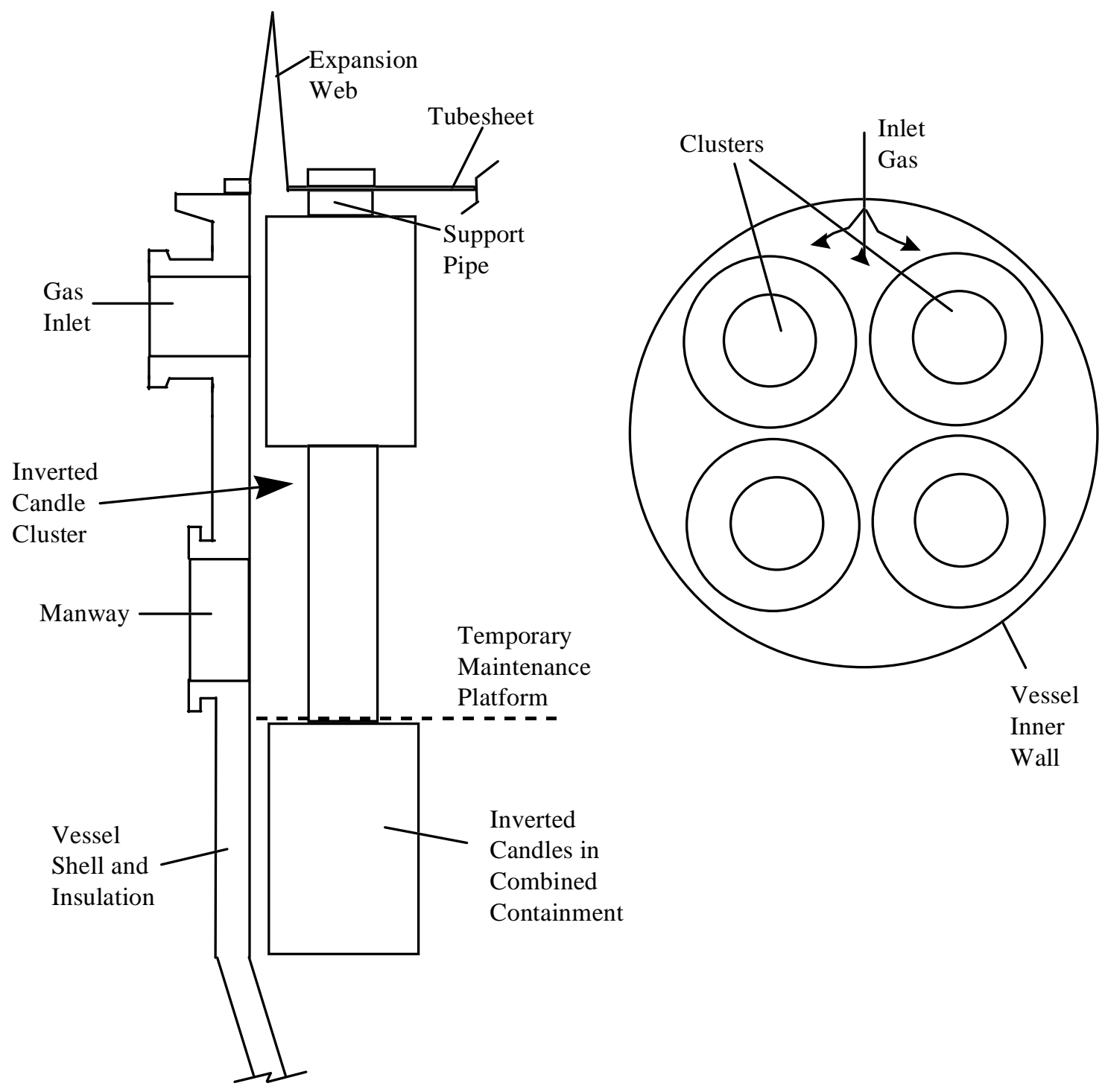

Figure 6.3 - I nverted candle complete-enclosure cluster arrangement 


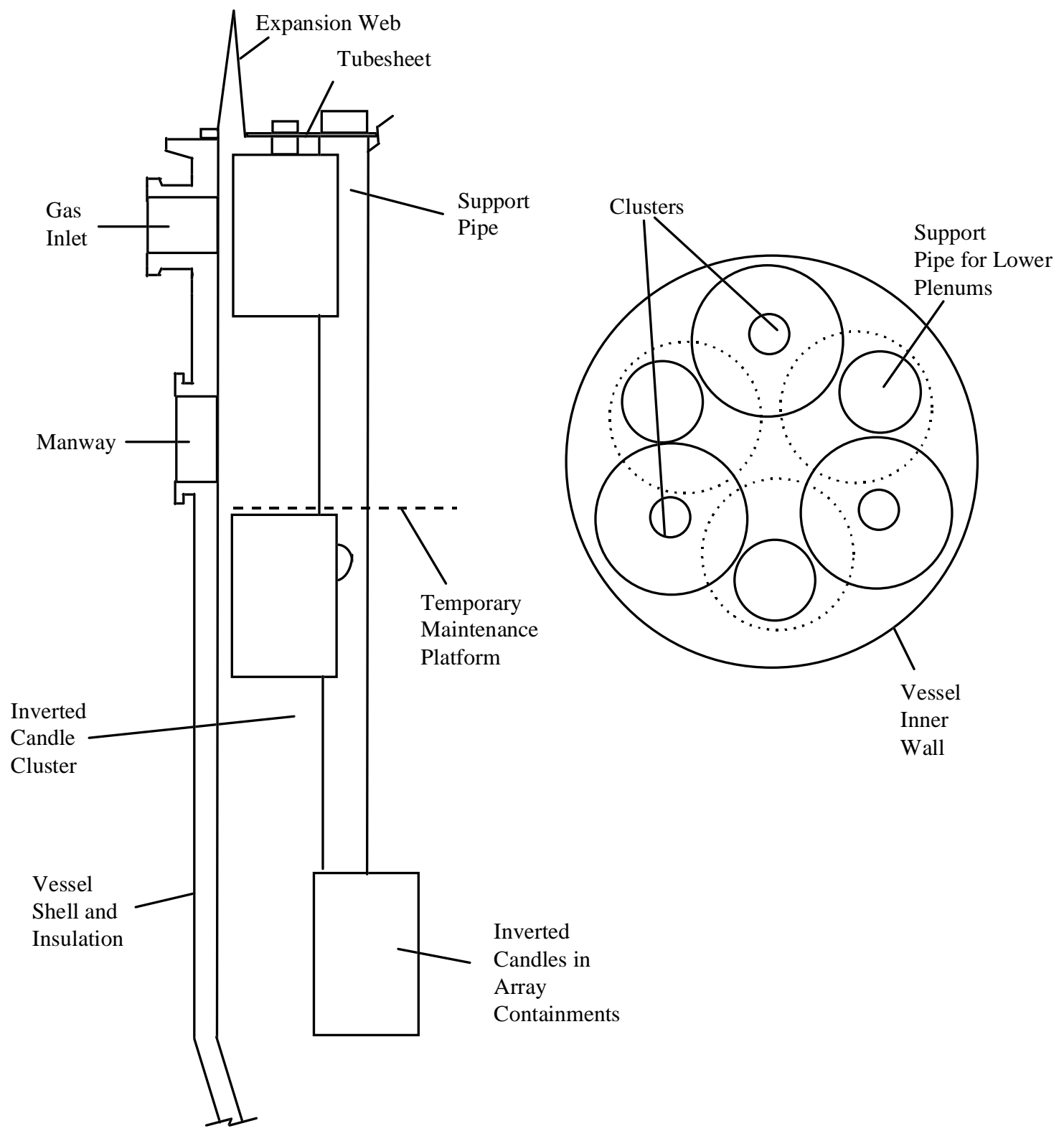

Figure 6.4 - I nverted candle complete-encl osure cluster with external support pipe arrangement 
of the pulse cleaning intensity. It is concluded that ceramic sheet filter elements having nominal 1-ft $\times 1$ - $\mathrm{ft}(0.3-\mathrm{m} \times 0.3-\mathrm{m})$ dimensions should be mechanically tolerant of pulse cleaning if the wall thickness is about 0.4-inch (10- $\mathrm{mm})$ and three internal ribs are added. The sheet filter structural evaluation is presented in Appendix A. A flange and holder design that is mechanically/thermally reliable and a fixture that will prevent the sheet filter from dropping off if the element fractures must also be devel oped, and this development is a subject of the Option I program.

Table 6.4 lists the filter element characteristics, the cluster characteristics, and special features for the inverted candle complete-enclosure clusters with the support pipe located externally. Two filter element parameters included in the table are the inverted candle length (1.5-m and 2.0-m) and the inverted candle outer diameter (60-mm and 110-mm). All of the inverted candles are of thin-walled construction (5-mm thickness). All of the cluster arrangements listed have considerably more dirty-side filtering area than their counter-parts in Tables 6.2 and 6.3. Again, this arrangement requires no fail-safes, no soot-blowers, no shroud, and no special maintenance features in the vessel. 
Table 6.2 - Inverted Candle with Individual-Enclosures - Cluster Dimensions and Features

\begin{tabular}{|c|c|c|c|c|}
\hline \multirow{2}{*}{ Filter Element } & \multicolumn{2}{|c|}{ 1.5-m candles } & \multicolumn{2}{|c|}{ 2-m candles } \\
\hline & 60-mm OD & 110-mm OD & 60-mm OD & 110-mm OD \\
\hline Iength (in): & 59 & & 79 & \\
\hline OD (in): & 2.36 & 4.33 & 2.36 & 4.33 \\
\hline ID (in) & 1.97 & 3.94 & 1.97 & 3.94 \\
\hline thickness (in): & 0.2 & & 0.2 & \\
\hline surface area $\left(\mathrm{ft}^{2}\right)$ : & 2.38 & 4.76 & 3.17 & 6.34 \\
\hline weight (lb): & 5 & 10 & 6.3 & 12.6 \\
\hline conditioned DP (psi): & 1.2 & & 1.2 & \\
\hline element cost (\$): & 460 & 920 & 615 & 1230 \\
\hline \multicolumn{5}{|l|}{ Cluster } \\
\hline number elements: & 235 & 123 & 181 & 95 \\
\hline $\begin{array}{l}\text { element distribution: } \\
\text { number plenums in cluster: }\end{array}$ & $\begin{array}{c}73,54,54,54 \\
4\end{array}$ & $39,28,28,28$ & $\begin{array}{c}73,54,54 \\
3\end{array}$ & $39,28,28$ \\
\hline \multicolumn{5}{|l|}{ Features } \\
\hline include soot blower equipment?: & no & & no & \\
\hline include shroud?: & no & & no & \\
\hline include fail-safe?: & no & & no & \\
\hline internal maintenance items? & yes & & yes & \\
\hline
\end{tabular}

Table 6.3 - Inverted Candle with Complete-Enclosure - Cluster Dimensions and Features

\begin{tabular}{|c|c|c|c|c|}
\hline \multirow{2}{*}{ Filter Element } & \multicolumn{2}{|c|}{ 1.5-m candles } & \multicolumn{2}{|c|}{ 2-m candles } \\
\hline & 60-mm OD & 110-mm OD & 60-mm OD & 110-mm OD \\
\hline length (in): & 59 & & 79 & \\
\hline OD (in): & 2.36 & 4.33 & 2.36 & 4.33 \\
\hline ID (in) & 1.97 & 3.94 & 1.97 & 3.94 \\
\hline thickness (in): & 0.2 & & 0.2 & \\
\hline surface area $\left(\mathrm{ft}^{2}\right)$ : & 2.38 & 4.76 & 3.17 & 6.34 \\
\hline weight (lb): & 5 & 10 & 6.3 & 12.6 \\
\hline conditioned DP (psi): & 1.2 & & 1.2 & \\
\hline element cost (\$): & 460 & 920 & 615 & 1230 \\
\hline \multicolumn{5}{|l|}{ Cluster } \\
\hline number elements: & 235 & 123 & 181 & 95 \\
\hline $\begin{array}{l}\text { element distribution: } \\
\text { number plenums in cluster: }\end{array}$ & $\begin{array}{c}73,54,54,54 \\
4\end{array}$ & $39,28,28,28$ & $\begin{array}{c}73,54,54 \\
3\end{array}$ & $39,28,28$ \\
\hline \multicolumn{5}{|l|}{ Features } \\
\hline include soot blower equipment?: & no & & no & \\
\hline include shroud?: & no & & no & \\
\hline include fail-safe?: & no & & no & \\
\hline internal maintenance items? & no & & no & \\
\hline
\end{tabular}


Table 6.4 - Inverted Candle with Complete-Enclosure and External Support Pipe Cluster Dimensions and Features

\begin{tabular}{|c|c|c|c|c|}
\hline \multirow[t]{2}{*}{ Filter Element } & \multicolumn{2}{|c|}{$1.5-\mathrm{m}$ candles } & \multicolumn{2}{|c|}{ 2-m candles } \\
\hline & 60-mm OD & $110-\mathrm{mm}$ OD & 60-mm OD & 110-mm OD \\
\hline length (in): & 59 & & 79 & \\
\hline OD (in): & 2.36 & 4.33 & 2.36 & 4.33 \\
\hline ID (in) & 1.97 & 3.94 & 1.97 & 3.94 \\
\hline thickness (in): & 0.2 & & 0.2 & \\
\hline surface area $\left(\mathrm{ft}^{2}\right)$ : & 2.38 & 4.76 & 3.17 & 6.34 \\
\hline weight (lb): & 5 & 10 & 6.3 & 12.6 \\
\hline conditioned DP (psi): & 1.2 & & 1.2 & \\
\hline element cost (\$): & 460 & 920 & 615 & 1230 \\
\hline \multicolumn{5}{|l|}{ Cluster } \\
\hline number elements: & 292 & 156 & 219 & 117 \\
\hline $\begin{array}{l}\text { element distribution: } \\
\text { number plenums in cluster: }\end{array}$ & $\begin{array}{c}73,73,73,73 \\
4\end{array}$ & $39,39,39,39$ & $\begin{array}{c}73,73,73 \\
3\end{array}$ & 39, 39, 39 \\
\hline \multicolumn{5}{|l|}{ Features } \\
\hline include soot blower equipment?: & no & & no & \\
\hline include shroud?: & no & & no & \\
\hline include fail-safe?: & no & & no & \\
\hline internal maintenance items? & no & & no & \\
\hline
\end{tabular}

Table 6.5 - Sheet Filter Internals Dimension and Features

\begin{tabular}{|l|c|}
\hline Filter Element & \\
\hline length and height (in): & 13 \\
width (in): & 1.2 \\
thickness (in): & 0.4 \\
surface area (ft2): & 2 \\
weight (lb): & 10 \\
conditioned DP (psi): & 1.2 \\
element cost (\$): & 325 \\
\hline Cluster & 336 \\
\hline number elements: & $84,84,84,84$ \\
element distribution: & 4 \\
number plenums in cluster: & no \\
\hline Features & yes (1) \\
\hline include soot blower & yes \\
equipment?: & yes \\
include shroud?: & \\
include fail-safe?: & \\
internal maintenance items? & \\
\hline
\end{tabular}



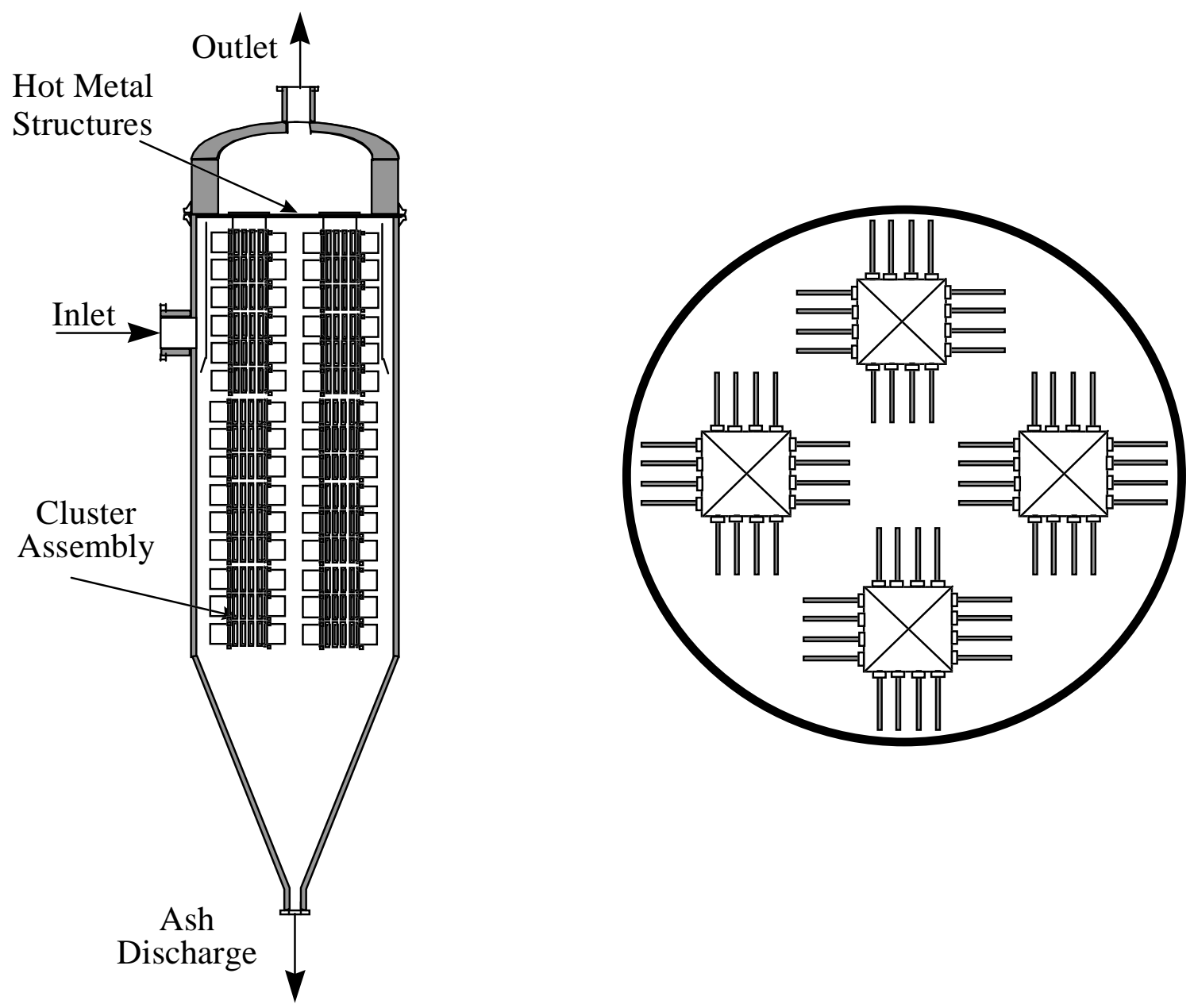

Figure 6.5 - Sheet filter configuration 


\section{PFBC CERAMIC BARRIER FILTER RESULTS}

This section presents the results of the evaluation of the inverted candle filter system and the sheet filter system in the PF BC environment. Design information (component sizes and weights, numbers of components), system performance, and system costs are presented for several forms of the two advanced ceramic barrier filter systems and are compared with the standard candle filter systems. Ceramic barrier filter system availability is also addressed. The PF BC environment, operating and design conditions, are outlined in Section 5.

\subsection{DESIGN, PERFORMANCE, AND COST}

The results for the PFBC application are tabulated in Tables 7.1 through 7.4. Each table lists results for three categories of information: design (component number, sizes and weights), performance, and costs. The design items are fairly clear without additional definition. The face velocity is al ways based on the dirty filtering surface of the filter elements at the actual volumetric gas flow through the vessel. The total vessel weight is that of a single refractory-lined vessel with metal liners and head installed. The internals weight is that of all of the internal components within a single filter vessel. In all cases for PFBC, the number of working pulse valves (for the entire multiple-vessel system) is al ways one-half of the total number of plenums in the plant, with each valve serving two plenums. One redundant pulse valve exists for each working pulse valve. It should be noted that there is no reliability advantage for more filter vessels since these vessels cannot be isolated in the operating plant, and if one vessel needs to be shut down, the entire power plant must be shut down. Further consideration of this will be made in Section 7.2 on availability. The design characteristics listed are closely related to ceramic barrier filter system cost, complexity and availability.

The performance factors reported are the actual trigger pressure drop for the filter, the maximum pressure drop across the filter vessel reached before the pulse cleaning sequence is initiated; the frequency of pulsing in number per hour; and the pulse gas compression power consumed. The estimated maximum percentage of the filter elements that can be lost, with their fail-safe devices plugged, before the filter system would violate its pressure drop and pulse cleaning limits is also listed in the tables. The ash storage capacity (the operating time required to fill the vessel to the point of reaching the lowest filter elements if the ash discharge is not functioning) is reported, and a small capacity would be expected to adversely impact reliability more than a larger capacity. The term "cake per pulse" in the tables is the bulk 
volume of ash discharged on the pulse cleaning of a single plenum. Larger values of this quantity would be expected to potentially lead to greater difficulties in the system.

The costs are reported as $\$ / \mathrm{kWe}$, and are broken down among the major components of the ceramic barrier filter system. The cost of hot gas piping and ash handling systems have been combined in the tables.

\subsubsection{Standard Candle Filter Systems}

Table 7.1 lists the characteristics of the three standard candle filter systems, the standard candle cluster and the two single-plenum cluster systems. The singleplenum cluster designs require about three times as many vessels as the standard candle cluster design, and have fewer pulse points and working pulse valves than the standard candle cluster case. The single-plenum cluster cases operate at slightly higher face vel ocity than the standard candle cluster design due simply to the need to use an integral number of pre-designed clusters. The three standard candle filter systems meet the pressure drop and pulse cleaning constraints imposed. The singleplenum cluster cases have much greater ash storage capacities than the standard candle cluster, but the standard candle cluster case ash storage capacity of more than 6 hours should be quite sufficient for reliable operation. The maximum fraction of the filter elements that can be lost is about 50\% greater for the standard candle cluster than for the single-plenum cluster cases, and this primarily results from the higher face velocity of the single-plenum cluster cases.

The most striking comparison in Table 7.1 is between the three sets of costs. The much higher cost for vessels, internals (primarily tube sheets), and hot gas piping and ash handling equipment makes the single-plenum cluster configurations much more expensive (30-45\%) than the standard candle cluster system for PFBC. The cost of ceramic filter elements represents only about $10 \%$ of the total filter system cost and is one of the smaller cost categories reported. The total standard candle cluster filter system cost for PFBC is on the order of $10 \%$ of the total projected future PFBC power plant investment.

\subsubsection{Inverted Candle (60-mm OD, 1.5-m long) Configurations and Sheet Filter}

Table 7.2 lists the PFBC results for the two inverted candle configurations using thin-wall candles, $60-\mathrm{mm}$ OD and 1.5-m long, as well as the results for the sheet filter clusters. Comparing the two inverted candle cases shows that the case with complete-enclosure clusters results in vessels having smaller diameter, but greater vessel height than those for the individual-enclosure clusters. The performance and costs of the two cases are comparable, with the inverted candle complete-enclosure clusters configuration being only $2 \%$ greater in capital cost than the individual-encl osure cluster configuration. The inverted candle configurations result in smaller vessel diameter than the standard candle cluster design (Table 
7.1), but have considerably greater internals weight and cost. The inverted candle configurations have a total cost about $5 \%$ greater than that of the standard candle cluster system cost, and this results mainly from the increased cost of the filter elements (more inverted candles are needed than standard candles) and the internals. This result will be sensitive to the actual cost of supply of the inverted candles that ultimately evolves.

The sheet filter elements can be accommodated on four clusters, in comparison to the five needed by the inverted candle configurations and the standard candle configuration, thus, the vessels are smaller in diameter for the sheet filter clusters, but are comparable in length. The number of pulse valves is reduced significantly. The sheet filter, having outside surface filtering in comparison to the inside filtering nature of the inverted candles, can operate at a slightly higher face velocity but maintain a lower trigger pressure drop. Other performance factors are comparable to the inverted candle configurations and the standard candle cluster configuration. The total capital cost is about $10 \%$ lower than the inverted candle configurations, and about 5\% lower than the standard candle cluster configuration. This cost advantage results from the reduced vessel cost, reduced internals cost, and reduced pulse control skid cost. Note that the results are sensitive to the assumption that all of the filter elements considered in this evaluation have the same cost per unit of filtering surface area, and thus, the sheet filter elements may increase or decrease in cost. The filter element costs will be more closely established during the Option I program.

\subsubsection{Inverted Candle (60-mm OD, 2.0-m long) Configurations}

Table 7.3 lists the PFBC results for the two inverted candle configurations using thin-wall candles, 60-mm OD and 2.0-m long. Comparing the two inverted candle cases shows that the case with complete-encl osure clusters results in vessels having smaller diameter, but greater vessel height than those for the individualencl osure clusters configuration. The vessels have the same diameters as those found for the 1.5-m long candles (Table 7.2), but have reduced height. Vessel and internals weights, and the number of pulse valves are also reduced by using the 2.0$\mathrm{m}$ long inverted candles.

The performance and costs of the two cases in Table 7.3 are comparable, with the inverted candle complete-end osure clusters having less than $2 \%$ greater capital cost than the individual-enclosure dusters configuration. The inverted candle configurations with 2.0-m long inverted candles result in a total cost about $5 \%$ lower than that of the standard candle cluster system cost (Table 7.1). This cost difference results mainly from the decreased vessel costs and pulse control and compressor skid costs. The overall inverted candle (2.0-m long) configuration system costs are comparable to those of the sheet filter configuration. 
Table 7.1 - Filter System Characteristics for PFBC (314 MWe)

Standard Candle Filter Configurations - 60-mm OD, 1.5-m Long Candles

\section{Constraints}

- Total pressure drop (pulse trigger): $<4.0 \mathrm{psi}$

- Inlet and outlet gas nozzle velocity: $80 \mathrm{ft} / \mathrm{s}$

- Pulse cleaning frequency: $<5 / \mathrm{hr}$

- Pulse gas system power: $<200 \mathrm{kWe}$

- Pulse gas consumption: $<0.2 \%$ of clean gas flow

- Vessel OD: <12 ft

- Ample space for in-vessel maintenance

\begin{tabular}{|c|c|c|c|}
\hline & $\begin{array}{l}\text { Westinghouse } \\
\text { Candle Clusters }\end{array}$ & $\begin{array}{c}\text { Single-Plenum } \\
\text { Clusters } \\
\text { Clean-Side } \\
\text { Maintenance }\end{array}$ & $\begin{array}{c}\text { Single-Plenum } \\
\text { Clusters } \\
\text { Dirty-Side } \\
\text { Maintenance }\end{array}$ \\
\hline Element type & $\begin{array}{l}\text { 60-mm OD } \\
1.5-\mathrm{m} \text { long }\end{array}$ & $\begin{array}{l}\text { 60-mm OD } \\
1.5-\mathrm{m} \text { long }\end{array}$ & $\begin{array}{c}\text { 60-mm OD } \\
1.5-\mathrm{m} \text { long }\end{array}$ \\
\hline \multicolumn{4}{|l|}{ Design } \\
\hline Number vessels & 8 & 28 & 22 \\
\hline Number clusters each vessel & 5 & 4 & 5 \\
\hline Number elements each vessel & 935 & 344 & 305 \\
\hline Face velocity (ft/min) & 9.5 & 10.5 & 10.6 \\
\hline Vessel OD (ft) & 12.0 & 11.5 & 11.5 \\
\hline Total vessel height (ft) & 62 & 32 & 37 \\
\hline $\begin{array}{l}\text { Total vessel weight (tons, } \\
\text { each) }\end{array}$ & 88.1 & 43.9 & 49.9 \\
\hline $\begin{array}{l}\text { Internals weight (tons, each } \\
\text { vessel) }\end{array}$ & 37.5 & 10.2 & 12.5 \\
\hline $\begin{array}{l}\text { Number working pulse } \\
\text { valves }\end{array}$ & 80 & 56 & 55 \\
\hline \multicolumn{4}{|l|}{ Performance } \\
\hline Trigger DP (psi) & 3.6 & 3.9 & 4.0 \\
\hline Pulse frequency $(1 / \mathrm{hr})$ & 1.7 & 1.8 & 1.9 \\
\hline Pulse power (kWe) & 196 & 196 & 206 \\
\hline Max. Elements Lost (\%) & 24.1 & 16.4 & 16.4 \\
\hline Ash storage (hr) & 6.3 & 20.2 & 15.6 \\
\hline Cake per pulse $\left(\mathrm{ft}^{3}\right)$ & 2.5 & 3.2 & 3.2 \\
\hline \multicolumn{4}{|l|}{ Costs $(\$ / \mathbf{k W})$} \\
\hline Total & 119.7 & 175.0 & 155.1 \\
\hline
\end{tabular}


Table 7.2 - Filter System Characteristics for PFBC (314 MWe)

Inverted Candle (60-mm OD, 1.5-m Long) and Sheet Filter Configurations

\section{Constraints}

- Total pressure drop (pulse trigger): $<4.0 \mathrm{psi}$

- Inlet and outlet gas nozzle velocity: $80 \mathrm{ft} / \mathrm{s}$

- Pulse cleaning frequency: $<5 / \mathrm{hr}$

- Pulse gas system power: $<200 \mathrm{kWe}$

- Pulse gas consumption: $<0.2 \%$ of clean gas flow

- Vessel OD: <12 ft

- Ample space for in-vessel maintenance

\begin{tabular}{|c|c|c|c|}
\hline & $\begin{array}{c}\text { Inverted } \\
\text { Candles } \\
\text { (Individual } \\
\text { Endosures) }\end{array}$ & $\begin{array}{c}\text { Inverted } \\
\text { Candles } \\
\text { (Complete } \\
\text { Enclosure) }\end{array}$ & $\begin{array}{l}\text { Sheet Filter } \\
\text { Clusters }\end{array}$ \\
\hline Element type & $\begin{array}{l}\text { 60-mm OD, } \\
5-\mathrm{mm} \text { thick, } \\
1.5-\mathrm{m} \text { long }\end{array}$ & $\begin{array}{l}\text { 60-mm OD, } \\
5-\mathrm{mm} \text { thick, } \\
1.5-\mathrm{m} \text { long }\end{array}$ & $\begin{array}{l}\text { 1-ft } \times 1 \text {-ft } \\
\text { sheets }\end{array}$ \\
\hline \multicolumn{4}{|l|}{ Design } \\
\hline Number vessels & 8 & 8 & 8 \\
\hline $\begin{array}{l}\text { Number clusters each } \\
\text { vessel }\end{array}$ & 5 & 5 & 4 \\
\hline $\begin{array}{l}\text { Number elements each } \\
\text { vessel }\end{array}$ & 1175 & 1175 & 1344 \\
\hline Face velocity (ft/min) & 9.1 & 9.1 & 9.5 \\
\hline Vessel OD (ft) & 11.6 & 10.9 & 10.6 \\
\hline Total vessel height (ft) & 59 & 67 & 65 \\
\hline $\begin{array}{l}\text { Total vessel weight (tons, } \\
\text { each)) }\end{array}$ & 79.5 & 82.0 & 77.6 \\
\hline $\begin{array}{l}\text { Internals weight (tons, } \\
\text { each vessel) }\end{array}$ & 43.9 & 54.3 & 35.6 \\
\hline $\begin{array}{l}\text { Number working pulse } \\
\text { valves }\end{array}$ & 80 & 80 & 60 \\
\hline \multicolumn{4}{|l|}{ Performance } \\
\hline Trigger DP (psi) & 3.8 & 3.8 & 3.5 \\
\hline Pulse frequency ( $1 / \mathrm{hr})$ & 1.9 & 2.0 & 1.8 \\
\hline Pulse power (kWe) & 159 & 163 & 175 \\
\hline Max. Elements Lost (\%) & 32.5 & 32.0 & 28.6 \\
\hline Ash storage (hr) & 5.6 & 4.6 & 5.1 \\
\hline Cake per pulse $\left(\mathrm{ft}^{3}\right)$ & 2.1 & 2.1 & 2.4 \\
\hline \multicolumn{4}{|l|}{ Costs $(\$ / k W)$} \\
\hline Total & 123.8 & 126.5 & 113.6 \\
\hline
\end{tabular}




\subsubsection{Inverted Candle (60-mm OD, 1.5-m and 2.0-m long) Configurations with External Support Pipes}

The final configuration considered for PFBC is the inverted candle (1.5-m and 2.0-m long) complete-enclosure clusters with external support pipes, and these results are reported in Table 7.4. In comparison to the analogous cases in Tables 7.2 and 7.3 , the use of the external support pipes allows the number of clusters in each vessel to be reduced from 5 to 4 . This does not result in a vessel diameter reduction as the cluster spacing must also allow for the external support pipe clearances. Performance is comparable to the analogous cases, but the cost of the filter systems are reduced by about $5 \%$. This configuration is as much as $10 \%$ lower in cost than the standard candle cluster configuration, with the 2.0-m long inverted candles resulting in the lowest capital cost.

\subsection{AVAILABILITY ESTIMATES}

The availability of the standard candle filter system cannot be estimated based on the type of statistical data generally applied in industry since an extensive reliability data base is not available for this technology. Instead, availability estimates are made based on qualitative reasoning and the application of standard availability al gorithms. The behavior of the filter cake and the interaction of the gas contaminants with the filter internals are key factors in availability, and it is assumed in this evaluation that the filter cake is prone to bridging and sintering behavior.

Ceramic barrier filter system availabilities have been estimated based on the qualitative arguments that follows. The ceramic barrier filter system might be forced to shut down for four reasons:

- the filter outlet dust loading exceeds the required outlet loading,

- the filter pressure drop exceeds the required maximum pressure drop,

- the pulse gas cleaning system fails to operate properly,

- ash cannot be removed from the filter vessels.

Each of these shut down incidents can be caused by several mechanisms:

1) filter outlet dust exceeds limit

- filter element leak

$\Rightarrow$ chemical-thermal degradation

$\Rightarrow$ process shock

$\Rightarrow$ ash bridging mechanical damage

$\Rightarrow$ mechanical shock from falling element(s) 
Table 7.3 - Filter System Characteristics for PFBC (314 MWe) Inverted Candle (60-mm OD, 2.0-m Long) Filter Configurations

\section{Constraints}

- Total pressure drop (pulse trigger): $<4.0 \mathrm{psi}$

- Inlet and outlet gas nozzle velocity: $80 \mathrm{ft} / \mathrm{s}$

- Pulse cleaning frequency: $<5 / \mathrm{hr}$

- Pulse gas system power: $<200 \mathrm{kWe}$

- Pulse gas consumption: $<0.2 \%$ of clean gas flow

- Vessel OD: <12 ft

- Ample space for in-vessel maintenance

\begin{tabular}{|c|c|c|}
\hline & $\begin{array}{c}\text { Inverted Candles } \\
\text { (Individual } \\
\text { Enclosures) }\end{array}$ & $\begin{array}{c}\text { Inverted Candles } \\
\text { (CompleteEnclosure) }\end{array}$ \\
\hline Element type & $\begin{array}{c}\text { 60-mm OD, } \\
\text { 5-mm thick, } \\
\text { 2.0-m long }\end{array}$ & $\begin{array}{l}\text { 60-mm OD, } \\
\text { 5-mm thick, } \\
\text { 2.0-m long }\end{array}$ \\
\hline \multicolumn{3}{|l|}{ Design } \\
\hline Number vessels & 8 & 8 \\
\hline $\begin{array}{l}\text { Number clusters each } \\
\text { vessel }\end{array}$ & 5 & 5 \\
\hline $\begin{array}{l}\text { Number elements each } \\
\text { vessel }\end{array}$ & 905 & 905 \\
\hline F ace velocity (ft/min) & 8.9 & 8.9 \\
\hline Vessel OD (ft) & 11.6 & 10.9 \\
\hline Total vessel height (ft) & 56 & 64 \\
\hline $\begin{array}{l}\text { Total vessel weight (tons, } \\
\text { each) }\end{array}$ & 76.1 & 79.3 \\
\hline $\begin{array}{l}\text { Internals weight (tons, } \\
\text { each vessel) }\end{array}$ & 39.5 & 48.5 \\
\hline $\begin{array}{l}\text { Number working pulse } \\
\text { valves }\end{array}$ & 60 & 60 \\
\hline \multicolumn{3}{|l|}{ Performance } \\
\hline Trigger DP (psi) & 3.7 & 3.7 \\
\hline Pulse frequency ( $1 / \mathrm{hr})$ & 2.0 & 2.0 \\
\hline Pulse power (kWe) & 172 & 177 \\
\hline Max. Elements Lost (\%) & 28.7 & 28.2 \\
\hline Ash storage (hr) & 5.6 & 4.6 \\
\hline Cake per pulse ( $\left.\mathrm{ft}^{3}\right)$ & 2.8 & 2.8 \\
\hline \multicolumn{3}{|l|}{ Costs (\$/kW) } \\
\hline Total & 111.9 & 113.9 \\
\hline
\end{tabular}


Table 7.4 - Filter System Characteristics for PFBC (314 MWe) Inverted Candle (60-mm OD, 1.5 and 2.0-m Long) Complete-E nclosure Clusters with External Support Pipe Filter Configurations

\section{Constraints}

- Total pressure drop (pulse trigger): $<4.0 \mathrm{psi}$

- Inlet and outlet gas nozzle velocity: $80 \mathrm{ft} / \mathrm{s}$

- Pulse cleaning frequency: $<5 / \mathrm{hr}$

- Pulse gas system power: $<200 \mathrm{kWe}$

- Pulse gas consumption: $<0.2 \%$ of clean gas flow

- Vessel OD: <12ft

- Ample space for in-vessel maintenance

\begin{tabular}{|c|c|c|}
\hline & $\begin{array}{c}\text { Inverted } \\
\text { Candles } \\
\text { (Complete } \\
\text { Enclosure) }\end{array}$ & $\begin{array}{c}\text { Inverted Candles } \\
\text { (Complete Enclosure) }\end{array}$ \\
\hline Element type & $\begin{array}{l}\text { 60-mm OD, } \\
5-\mathrm{mm} \text { thick, } \\
1.5-\mathrm{m} \text { long }\end{array}$ & $\begin{array}{l}\text { 60-mm OD, } \\
\text { 5-mm thick, } \\
\text { 2.0-m long }\end{array}$ \\
\hline \multicolumn{3}{|l|}{ Design } \\
\hline Number vessels & 8 & 8 \\
\hline $\begin{array}{l}\text { Number clusters each } \\
\text { vessel }\end{array}$ & 4 & 4 \\
\hline $\begin{array}{l}\text { Number elements each } \\
\text { vessel }\end{array}$ & 1168 & 876 \\
\hline Face vel ocity (ft/min) & 9.2 & 9.2 \\
\hline Vessel OD (ft) & 11.5 & 11.5 \\
\hline Total vessel height (ft) & 68 & 66 \\
\hline $\begin{array}{l}\text { Total vessel weight (tons, } \\
\text { each) }\end{array}$ & 89.2 & 86.2 \\
\hline $\begin{array}{l}\text { Internals weight (tons, } \\
\text { each vessel) }\end{array}$ & 47.7 & 42.3 \\
\hline $\begin{array}{l}\text { Number working pulse } \\
\text { valves }\end{array}$ & 64 & 48 \\
\hline \multicolumn{3}{|l|}{ Performance } \\
\hline Trigger DP (psi) & 3.7 & 3.8 \\
\hline Pulse frequency $(1 / h r)$ & 2.1 & 2.1 \\
\hline Pulse power (kWe) & 198 & 188 \\
\hline Max. Elements Lost (\%) & 30.0 & 26.0 \\
\hline Ash storage (hr) & 5.5 & 5.5 \\
\hline Cake per pulse $\left(\mathrm{ft}^{3}\right)$ & 2.4 & 3.3 \\
\hline \multicolumn{3}{|l|}{ Costs (\$/kW) } \\
\hline Total & 120.8 & 108.6 \\
\hline
\end{tabular}


$\Rightarrow$ ash over-fill mechanical damage
gasket leak

$\Rightarrow$ chemical-thermal degradation

$\Rightarrow$ mechanical, flow induced damage

$\Rightarrow$ process shock

- metal structure leak

$\Rightarrow$ corrosion, erosion

$\Rightarrow$ thermal fatigue

$\Rightarrow$ process shock

- fail-safe leaks

$\Rightarrow$ corrosion, erosion

$\Rightarrow$ thermal fatigue

$\Rightarrow$ process shock

2) filter pressure drop exceeds limit

- pulse cleaning ineffective

$\Rightarrow$ pulse nozzle misalignment

$\Rightarrow$ pulse pipe fails

$\Rightarrow$ can't deliver enough pulse gas or develop sufficient pulse intensity

- component flow resistances rise

$\Rightarrow$ filter elements blind (chemical deposition, internal ash backflow plugging)

$\Rightarrow$ ash bridging

$\Rightarrow$ plugging of too many fail-safes

$\Rightarrow$ plugging, deposition, corrosion on other components (e.g., venturi eductors)

3) pulse supply system fails

- pulse valve fails

- activated ball valve fails

- pulse gas compressor fails

- pulse gas source fails

- key instrumentation or controllers fail

4) can not remove ash from vessel

- failure of ash removal system

- bridging of ash hopper nozzle

- plugging of ash hopper nozzle by broken element(s)

To estimate the availability of the advanced filter system, the relative reliability of the filter systems need to be assessed, based on 1) rel ative frequency of failure, and 2) relative consequences of failure. Only the four generic ceramic barrier filter types are considered, with the variations in the availability due to configuration changes within the inverted candle configurations expected to be small. To make such estimates, a ranking method is first applied. It is based on the two ranking factors: 
1. Frequency of Failure: Assuming conditions are suitable for the event, what is the likelihood that the failure mechanism will occur (ranking of 5 is certain; $4-2$ is less certain; 1 is very unlikely; 0 is never).

2. Consequences of Failure: Assuming the failure mechanism results, what is the likelihood that the system will be shut down due to the performance requirement being violated (ranking of 5 is certain; 4-2 is less certain; 1 is very unlikely; 0 is never).

The failure categories and mechanisms listed above are ranked in Table 7.5 based on these two factors. Each of the four ceramic barrier filter systems is considered, and an average ranking value is determined for each of the four failure categories and for the total matrix. Two of the failure categories are identical for all of the barrier filter systems ("gasket leak" and "pulse cleaning ineffective"), while "metal structure leak" differs very little between the four filter arrangements. Note that this tabulation assumes that several failure incidents can never occur with the inverted candle configurations, and these assumptions are subject to proof-ofprinciple testing in the Option I program. Other assumptions made are:

- A failed pulse valve automatically switches to a redundant valve with no system shutdown. A failed pulse gas compressor automatically switches to a redundant compressor.

- If ash flow from a vessel stops, the plant must shut down to avoid overfill. Only a relatively short time is available to fix an ash removal system before shutdown is needed.

- In the single-plenum cluster configuration, a broken candle is not likely to damage another filter element if it falls. The large storage capacity of the single-plenum cluster vessel hopper makes overfill less likely, but the consequences of overfill are greater since all of the filter elements is the vessel will be damaged simultaneously. Due to the larger number of ash handling systems and ash hopper nozzles in the single-plenum cluster configurations, periodic blockage of a vessel hopper is more likely. Metal structure leaking is more likely in the single-plenum clusters configuration because of the large, highly-stressed tube sheet having many penetrations.

- The inverted candle configurations with a damaged candle or leaking gasket has higher consequences because there is no fail-safe. The possibility of ash bridging damage is zero, and it is 
Table 7.5 - Reliability Factor Ranking for Advanced Ceramic Filter Systems In PF BC

\begin{tabular}{|c|c|c|c|c|c|c|c|c|}
\hline & \multicolumn{2}{|c|}{$\begin{array}{l}\text { Stand. } \\
\text { Candle } \\
\text { Cluster }\end{array}$} & \multicolumn{2}{|c|}{$\begin{array}{l}\text { Single- } \\
\text { Plenum } \\
\text { Cluster }\end{array}$} & \multicolumn{2}{|c|}{$\begin{array}{c}\text { Inverted } \\
\text { Candle Cluster }\end{array}$} & \multicolumn{2}{|c|}{ Sheet F ilter Cluster } \\
\hline & $\mathrm{F}^{*}$ & $\mathrm{C}^{*}$ & $\mathrm{~F}$ & $\mathrm{C}$ & $\mathrm{F}$ & $\mathrm{C}$ & $\mathrm{F}$ & $\mathrm{C}$ \\
\hline \multicolumn{9}{|l|}{$\begin{array}{l}\text { 1) OUTLET DUST EXCEEDS } \\
\text { EMISSIONS }\end{array}$} \\
\hline ELEMENT PLUS FAIL-SAFE LEAK & & $(50) * *$ & & (40) & & (14) & & (26) \\
\hline chemical-thermal degradation & 2 & 2 & 2 & 2 & 2 & 3 & 2 & 2 \\
\hline process shock & 2 & 3 & 2 & 3 & 2 & 4 & 2 & 3 \\
\hline ash bridge mechanical damage & 4 & 4 & 4 & 4 & 0 & 0 & 1 & 4 \\
\hline ash over-fill mechanical damage & 4 & 3 & 2 & 5 & 0 & 0 & 4 & 2 \\
\hline mechanical damage from falling el ement & 3 & 4 & 1 & 4 & 0 & 0 & 1 & 4 \\
\hline GASKET LEAK & & (6) & & (6) & & (9) & & (6) \\
\hline chemical-thermal degradation & 1 & 2 & 1 & 2 & 1 & 3 & 1 & 2 \\
\hline mechanical flow induced damage & 1 & 2 & 1 & 2 & 1 & 3 & 1 & 2 \\
\hline process shock & 1 & 2 & 1 & 2 & 1 & 3 & 1 & 2 \\
\hline METAL STRUCTURE LEAK & & $(12)$ & & (18) & & $(12)$ & & $(12)$ \\
\hline corrosion, erosion & 1 & 3 & 1 & 3 & 1 & 3 & 1 & 3 \\
\hline thermal fatigue & 2 & 3 & 3 & 3 & 2 & 3 & 2 & 3 \\
\hline process shock & 1 & 3 & 2 & 3 & 1 & 3 & 1 & 3 \\
\hline $\begin{array}{ll}\text { Average } & \text { Category }\end{array}$ & 2.0 & 2.8 & 1.8 & 3.0 & 1.0 & 2.3 & 1.5 & 2.7 \\
\hline \multicolumn{9}{|l|}{ 2) PRESSURE DROP EXCEEDS LIMIT } \\
\hline PULSE CLEANING INEFFECTIVE & & (17) & & (17) & & (17) & & (17) \\
\hline pulse nozzle misalignment & 1 & 3 & 1 & 3 & 1 & 3 & 1 & 3 \\
\hline pulse pipe fails & 2 & 3 & 2 & 3 & 2 & 3 & 2 & 3 \\
\hline can't deliver enough gas or pulse intensity & 2 & 4 & 2 & 4 & 2 & 4 & 2 & 4 \\
\hline $\begin{array}{l}\text { COMPONENT FLOW RESISTANCE } \\
\text { RISE }\end{array}$ & & (33) & & (36) & & (11) & & (25) \\
\hline $\begin{array}{l}\text { filter element blinding (internal } \\
\text { resistance) }\end{array}$ & 2 & 4 & 2 & 4 & 2 & 4 & 2 & 4 \\
\hline ash bridging & 4 & 4 & 4 & 4 & 0 & 0 & 2 & 4 \\
\hline plugging too many fail-safes & 2 & 3 & 3 & 3 & 0 & 0 & 2 & 3 \\
\hline $\begin{array}{l}\text { plugging, deposition, corrosion of } \\
\text { components (e.g., eductors) }\end{array}$ & 1 & 3 & 1 & 3 & 1 & 3 & 1 & 3 \\
\hline $\begin{array}{ll}\text { Average } & \text { Category } \\
\end{array}$ & 2.0 & 3.4 & 2.1 & 3.4 & 1.1 & 2.4 & 1.7 & 3.4 \\
\hline 3) PULSE SYSTEM FAILS & & (11) & & (11) & & (11) & & (11) \\
\hline Pulse valve failure & 3 & 0 & 3 & 0 & 3 & 0 & 3 & 0 \\
\hline Activated ball valve failure & 1 & 3 & 1 & 3 & 1 & 3 & 1 & 3 \\
\hline Pulse gas compressor fails & 2 & 1 & 2 & 1 & 2 & 1 & 2 & 1 \\
\hline Instrumentation/ controller fails & 2 & 3 & 2 & 3 & 2 & 3 & 2 & 3 \\
\hline $\begin{array}{ll}\text { Average } & \text { Category }\end{array}$ & 2.0 & 1.8 & 2.0 & 1.8 & 2.0 & 1.8 & 2.0 & 1.8 \\
\hline $\begin{array}{l}\text { 4) CAN'T REMOVAL ASH FROM } \\
\text { VESSEL }\end{array}$ & & (33) & & (51) & & (23) & & (28) \\
\hline Ash Removal System Failure & 2 & 4 & 4 & 4 & 2 & 4 & 2 & 4 \\
\hline Ash Hopper Nozzle Bridging & 3 & 5 & 4 & 5 & 3 & 5 & 3 & 5 \\
\hline $\begin{array}{l}\text { Ash Hopper Nozzle Plug - Broken } \\
\text { Elements }\end{array}$ & 2 & 5 & 3 & 5 & 0 & 0 & 1 & 5 \\
\hline Category & 2.3 & 4.7 & 3.7 & 4.7 & 1.7 & 3.0 & 2.0 & 4.7 \\
\hline
\end{tabular}




\begin{tabular}{|c|c|c|c|c|c|c|c|}
\hline Average & & & & & & & \\
\hline
\end{tabular}

*: $\mathrm{F}$ is failure frequency ranking for each event; $\mathrm{C}$ is shutdown consequences ranking.

**: Numbers in parentheses are the sum of the product of $\mathrm{F}$ and $\mathrm{C}$ for each failure group. 
assumed that inverted candle plugging cannot occur in normal operation.

- In the sheet filter, ash bridging is unlikely even with no turbulator. Overfill will cause less damage due to the configuration of the internals and the continuous, pipe-header distribution of the filter elements. The possibility of falling sheet filter elements is minimized by having a fixture on each sheet filter element that ensures it cannot fall.

In this ranking table (Table 7.5), a combination of low frequency and low consequences is best, and the inverted candle filter has the lowest average rankings for both of these factors. The sheet filter also has average rankings lower than the standard candle configurations. The single-plenum clusters configuration reliability ranking suffers greatly due to its large number of vessels, large number of ash handling systems, and the need to shut down the entire power plant if any one ash drain nozzle plugs or if any single ash handling system does not function.

For the inverted candle filter to achieve this superior reliability behavior in practice, the following features must be demonstrated in testing:

- the inverted candle will not plug, or can recover from plugging by normal pulse cleaning,

- the inverted candle will operate in an inherently fail-safe mode, self-plugging cracks if they occur (although fail-safe/regenerators can be implemented with the inverted candles),

- the inverted candle is thermally and mechanically stable,

- the inverted candle with internal membrane skin will not blind,

Similarly, for the sheet filter the following reliability factors must be demonstrated in testing:

- the sheet filter configuration is free from ash bridging,

- the sheet filter is thermally and mechanically stable,

- the sheet filter, if damaged, will be retained in its normal position to avoid damage to lower elements or plugging of the vessel ash outlet,

A quantitative estimate of availability can be made if, for each failure category, estimates are made of the mean number of occurrences per year, and the mean number of hours required to recover from a shut down of the system. The estimates of the number of occurrences per year are generated by using the ranking table (Table 7.5) based on the following assumed conditions in the PFBC filter system: 
- the PFBC ash has a high filter cake bridging/sintering tendency and poor flow properties,

- soot blowers/turbulators are only moderately effective at bridging elimination,

- the fail-safe/regenerator is effective, with little ash leakage.

The estimates are made relative to the standard candle cluster system, and the number of filter system shut downs per year for the standard candle cluster system due to excessive dust resulting from candle filter element leaks and fail-safe leaks (primarily due to ash bridging) is set as 1.0. The other shut downs per year for the other six major failure categories, and for the three other filter systems, are estimated from the ranking table, as follows. The frequency ranking value is multiplied by the consequence ranking value for each item in the table and these are total ed for each of the seven major categories. These totals appear in Table $7.5 \mathrm{in}$ parentheses. The shut down outage frequency (number per year) for each major category is taken as the ratio of its sum to the summed value for the standard candle cluster - that is, each sum in Table 7.5 is divided by 50 to obtain the relative mean outage frequency.

The estimated mean recovery times for PFBC are based on past filter system experience, and include times for system depressurization and cool down; filter vessel internals inspection; installation of maintenance equipment; cleanup and disassembly; maintenance times for filter element replacement, gasket replacement, fail-safe replacement, metal structure repair; and reassembly of the system. The estimated mean recovery times are:

- Following shut down due to excessive outlet gas dust (element leaks, failsafe leaks, gasket leaks): 260 hours

- Following shut down due to excessive outlet gas dust (metal structure leaks): 500 hours

- Following shut down due to excessive pressure drop (pulse cleaning ineffective): 100 hours

- Following shut down due to excessive pressure drop (flow resistance rise): 260 hours

- Following shut down due to pulse system failure: 24 hours

- Following shut down due to loss of vessel ash removal: 70 hours

Basic availability relationships are then used to estimate the effective outage rate, the mean time between outages, and the overall filter system availability (Ireson and Coombs, 1966):

The mean time between outages due to $\mathrm{i}$-th category $\left(\mathrm{MTBO}_{\mathrm{i}}\right)$ is calculated by 


$$
\mathrm{MTBO}_{\mathrm{i}}=8760 / \mathrm{FO}_{\mathrm{i}}-\mathrm{MTTR}_{\mathrm{i}}
$$

where $M T T R_{i}$ is the mean time to recover after a failure shut down due to the $i$-th category, and $\mathrm{FO}_{i}$ is the mean frequency of shut downs (number per year) due to the i-th category.

The outage rate due to the $\mathrm{i}$-th category $\left(\mathrm{OR}_{\mathrm{i}}\right)$ is

$$
\mathrm{OR}_{\mathrm{i}}=\mathrm{MTTR}_{\mathrm{i}} /\left(\mathrm{MTBO}_{\mathrm{i}}+\mathrm{MTTR}_{\mathrm{i}}\right)
$$

The mean time between outages for filter system due to all failure categories (MTBO) is calculated from

$$
\mathrm{MTBO}=\mathrm{SUM}_{\mathrm{i}}\left(1 / \mathrm{MTBO}_{\mathrm{i}}\right)
$$

and the mean time to recovery due to all failure categories (MTTR) is

$$
\operatorname{MTTR}=\operatorname{SUM}_{i}\left(\mathrm{OR}_{\mathrm{i}}\right) / \mathrm{SUM}_{\mathrm{i}}\left(1 / \mathrm{MTBO}_{\mathrm{i}}\right)
$$

The Overall Outage Rate for the ceramic barrier filter system is found from the ratio MTTR / ( MTBO + MTTR) and the Availability is equal to 1 minus the Overall Outage Rate.

The availability results are listed in Tables 7.6 - 7.10 for each of the four ceramic barrier filter types. Under the assumptions set, the standard candle cluster filter system (Table 7.6) would have more than 3 forced shut downs every year (on average), and would be forced to shut down about every 2,700 hours and be out of service more than $7 \%$ of the time. This outage rate only reduces the PFBC power plant availability if the filter outages cannot be accommodated by maintenance during scheduled power plant outages or during periods of forced outage due to other PFBC power plant systems. The current state of PFBC is such that forced outages, or planned maintenance periods occur more frequently than every 2,500 hours.

In comparison, the single-plenum cluster filter system in PF BC (Table 7.7) would be forced to shut down more than 5 times per year with an average outage rate of about $9 \%$, and a mean time between outages of about 1,600 hours. The inverted candle filter system (Table 7.8) is estimated to be shut down less than twice every year, having about $4 \%$ outage rate and a mean time between outages of more than 4,000 hours. The sheet filter system availability (Table 7.9) is not quite as high as the inverted candle filter system, with shut downs less than 3 times 
Table 7.6 - Availability Estimates for Standard Candle Cluster Filter in PFBC

\begin{tabular}{|l|c|c|c|c|}
\hline \multicolumn{1}{|c|}{$\begin{array}{c}\text { Shut Down } \\
\text { Occurrence }\end{array}$} & $\begin{array}{c}\text { Number } \\
\text { per year }\end{array}$ & $\begin{array}{c}\text { Mean } \\
\text { recovery } \\
\text { time (hrs) }\end{array}$ & $\begin{array}{c}\text { Outage } \\
\text { rate (\%) }\end{array}$ & $\begin{array}{c}\text { Mean time between } \\
\text { outages (hrs) }\end{array}$ \\
\hline $\begin{array}{l}\text { Excess dust due to } \\
\text { element and fail-safe } \\
\text { leaks }\end{array}$ & 1.0 & 260 & 2.97 & 8,506 \\
\hline $\begin{array}{l}\text { Excess dust due to } \\
\text { gasket leaks }\end{array}$ & 0.12 & 260 & 0.36 & 72,790 \\
\hline $\begin{array}{l}\text { Excess dust due to } \\
\text { metal structure } \\
\text { leaks }\end{array}$ & 0.24 & 500 & 1.37 & 36,025 \\
\hline $\begin{array}{l}\text { Excess pressure drop } \\
\text { due to poor pulse } \\
\text { cleaning }\end{array}$ & 0.34 & 100 & 0.39 & 25,682 \\
\hline $\begin{array}{l}\text { Excess pressure drop } \\
\text { due to flow } \\
\text { resistance rise }\end{array}$ & 0.66 & 260 & 1.96 & 13,022 \\
\hline $\begin{array}{l}\text { Pulse cleaning } \\
\text { system failure }\end{array}$ & 0.22 & 24 & 0.06 & 39,821 \\
\hline $\begin{array}{l}\text { Ash removal system } \\
\text { failure }\end{array}$ & 0.66 & 70 & 0.53 & 13,212 \\
\hline $\begin{array}{l}\text { Total System } \\
\text { Results }\end{array}$ & 3.24 & 206 & 7.19 & 2,662 \\
\hline $\begin{array}{l}\text { Overall Filter } \\
\text { System Availability } \\
\text { (\%) }\end{array}$ & & 92.81 & \\
\hline
\end{tabular}


Table 7.7 - Availability Estimates for Single-Plenum Candle Cluster Filter in PFBC

\begin{tabular}{|l|c|c|c|c|}
\hline \multicolumn{1}{|c|}{$\begin{array}{l}\text { Shut Down } \\
\text { Occurrence }\end{array}$} & $\begin{array}{c}\text { Number } \\
\text { per year }\end{array}$ & $\begin{array}{c}\text { Mean } \\
\text { recovery } \\
\text { time (hrs) }\end{array}$ & $\begin{array}{c}\text { Outage } \\
\text { rate (\%) }\end{array}$ & $\begin{array}{c}\text { Mean time } \\
\text { between } \\
\text { outages } \\
\text { (hrs) }\end{array}$ \\
\hline $\begin{array}{l}\text { Excess dust due to } \\
\text { element and fail-safe } \\
\text { leaks }\end{array}$ & 0.8 & 260 & 2.37 & 10,698 \\
\hline $\begin{array}{l}\text { Excess dust due to } \\
\text { gasket leaks }\end{array}$ & 0.12 & 260 & 0.36 & 72,790 \\
\hline $\begin{array}{l}\text { Excess dust due to } \\
\text { metal structure } \\
\text { leaks }\end{array}$ & 0.36 & 500 & 2.05 & 23,850 \\
\hline $\begin{array}{l}\text { Excess pressure drop } \\
\text { due to poor pulse } \\
\text { cleaning }\end{array}$ & 0.34 & 100 & 0.39 & 25,682 \\
\hline $\begin{array}{l}\text { Excess pressure drop } \\
\text { due to flow } \\
\text { resistance rise }\end{array}$ & 0.72 & 260 & 2.14 & 11,915 \\
\hline $\begin{array}{l}\text { Pulse cleaning } \\
\text { system failure }\end{array}$ & 0.22 & 24 & 0.06 & 39,821 \\
\hline $\begin{array}{l}\text { Ash removal system } \\
\text { failure }\end{array}$ & 2.81 & 70 & 2.24 & 3,050 \\
\hline $\begin{array}{l}\text { Total System } \\
\text { Results }\end{array}$ & 5.37 & 157 & 8.93 & 1,600 \\
\hline $\begin{array}{l}\text { Overall Filter } \\
\text { System Availability } \\
\text { (\%) }\end{array}$ & & 91.07 & \\
\hline
\end{tabular}


Table 7.8 - Availability Estimates for Inverted Candle Cluster Filter in PFBC

\begin{tabular}{|l|c|c|c|c|}
\hline \multicolumn{1}{|c|}{$\begin{array}{l}\text { Shut Down } \\
\text { Occurrence }\end{array}$} & $\begin{array}{c}\text { Number } \\
\text { per year }\end{array}$ & $\begin{array}{c}\text { Mean } \\
\text { recovery } \\
\text { time (hrs) }\end{array}$ & $\begin{array}{c}\text { Outage } \\
\text { rate (\%) }\end{array}$ & $\begin{array}{c}\text { Mean time } \\
\text { between } \\
\text { outages } \\
\text { (hrs) }\end{array}$ \\
\hline $\begin{array}{l}\text { Excess dust due to } \\
\text { element and fail-safe } \\
\text { leaks }\end{array}$ & 0.28 & 260 & 0.83 & 31,047 \\
\hline $\begin{array}{l}\text { Excess dust due to } \\
\text { gasket leaks }\end{array}$ & 0.18 & 260 & 0.53 & 48,440 \\
\hline $\begin{array}{l}\text { Excess dust due to } \\
\text { metal structure } \\
\text { leaks }\end{array}$ & 0.24 & 500 & 1.37 & 36,025 \\
\hline $\begin{array}{l}\text { Excess pressure drop } \\
\text { due to poor pulse } \\
\text { cleaning }\end{array}$ & 0.34 & 100 & 0.39 & 25,682 \\
\hline $\begin{array}{l}\text { Excess pressure drop } \\
\text { due to flow } \\
\text { resistance rise }\end{array}$ & 0.22 & 260 & 0.65 & 39,585 \\
\hline $\begin{array}{l}\text { Pulse cleaning } \\
\text { system failure }\end{array}$ & 0.22 & 24 & 0.06 & 39,821 \\
\hline $\begin{array}{l}\text { Ash removal system } \\
\text { failure }\end{array}$ & 0.46 & 70 & 0.37 & 18,987 \\
\hline $\begin{array}{l}\text { Total System } \\
\text { Results }\end{array}$ & 1.94 & 190 & 4.05 & 4,493 \\
\hline $\begin{array}{l}\text { Overall Filter } \\
\text { System Availability } \\
\text { (\%) }\end{array}$ & & 95.95 & \\
\hline
\end{tabular}


per year, about $6 \%$ outage rate, and mean time between outages greater than 3,000 hours. The potential improvements in the ceramic barrier filter system availability with the advanced ceramic barrier filter systems could have a great impact on the PFBC power plant performance and cost depending on the availability performance of the other major components in the plant.

\subsection{PFBC CERAMIC BARRIER FILTER CONCLUSIONS}

The two advanced ceramic barrier filter systems evaluated for the PFBC application show the potential to provide hot gas particulate removal with comparable operating performance (pressure drop, pulse cleaning frequency, pulse gas consumption) and slightly lower-to-comparable capital cost to the standard candle cluster filter systems. With difficult ashes that are prone to bridging, sintering, and poor vessel hopper flow, the advanced ceramic barrier filter systems have the potential for significantly improved filter system reliability and availability, with easier maintenance and lower operating costs.

The three inverted candle cluster configurations evaluated (individualencl osure clusters, complete-encl osure clusters, and complete-enclosure clusters with external support pipes) range from $6 \%$ higher in capital cost to $10 \%$ lower in capital cost than the standard candle cluster filter system. The inverted candle configurations using 2.0-m long inverted candles have the greatest capital cost potential. The ease of maintenance of the inverted candle filter systems range from comparable to the standard candle cluster filter system for the individual-encl osure clusters configuration, to much easier for the complete-enclosure clusters configuration. The availability of the inverted candle filter configurations are potentially much higher than that of the standard candle cluster filter systems if difficult ashes that are prone to bridging, sintering, and poor vessel hopper flow are characteristic of the PFBC application. If the PFBC environment is such that the availability of the standard candle cluster filter system is high, the inverted candle filter configurations still have the potential for significant cost and maintenance advantages.

The sheet filter system evaluated has about a 5\% capital cost advantage over the standard candle cluster filter system. It also has availability advantages over the standard candle cluster filter system if difficult ashes that are prone to bridging, sintering, and poor vessel hopper flow are characteristic of the PF BC application. The ease of maintenance of the sheet filter system is comparable to the standard candle cluster filter system. If the PFBC environment is such that the availability of the standard candle cluster filter system is high, the sheet filter cluster filter system has the potential for significant cost advantage, and the maintenance and availability will be comparable to that of the standard candle cluster filter system. 
Table 7.9 - Availability Estimates for Sheet Filter in PFBC

\begin{tabular}{|l|c|c|c|c|}
\hline \multicolumn{1}{|c|}{$\begin{array}{c}\text { Shut Down } \\
\text { Occurrence }\end{array}$} & $\begin{array}{c}\text { Number } \\
\text { per year }\end{array}$ & $\begin{array}{c}\text { Mean } \\
\text { recovery } \\
\text { time (hrs) }\end{array}$ & $\begin{array}{c}\text { Outage } \\
\text { rate (\%) }\end{array}$ & $\begin{array}{c}\text { Mean time } \\
\text { between outages } \\
\text { (hrs) }\end{array}$ \\
\hline $\begin{array}{l}\text { Excess dust due to } \\
\text { element and fail-safe } \\
\text { leaks }\end{array}$ & 0.52 & 260 & 1.54 & 16,598 \\
\hline $\begin{array}{l}\text { Excess dust due to } \\
\text { gasket leaks }\end{array}$ & 0.12 & 260 & 0.36 & 72,790 \\
\hline $\begin{array}{l}\text { Excess dust due to } \\
\text { metal structure } \\
\text { leaks }\end{array}$ & 0.24 & 500 & 1.37 & 36,025 \\
\hline $\begin{array}{l}\text { Excess pressure drop } \\
\text { due to poor pulse } \\
\text { cleaning }\end{array}$ & 0.34 & 100 & 0.39 & 25,682 \\
\hline $\begin{array}{l}\text { Excess pressure drop } \\
\text { due to flow } \\
\text { resistance rise }\end{array}$ & 0.50 & 260 & 1.48 & 17,272 \\
\hline $\begin{array}{l}\text { Pulse cleaning } \\
\text { system failure }\end{array}$ & 0.22 & 24 & 0.06 & 39,821 \\
\hline $\begin{array}{l}\text { Ash removal system } \\
\text { failure }\end{array}$ & 0.56 & 70 & 0.45 & 15,584 \\
\hline $\begin{array}{l}\text { Total System } \\
\text { Results }\end{array}$ & 2.50 & 198 & 5.39 & 3,474 \\
\hline $\begin{array}{l}\text { Overall Filter } \\
\text { System Availability } \\
\text { (\%) }\end{array}$ & & 94.61 & \\
\hline
\end{tabular}




\section{IGCC CERAMIC BARRIER FILTER RESULTS}

This section presents the results of the evaluation of the inverted candle filter system and the sheet filter system in the IGCC environment. Design information (component sizes and weights, numbers of components), system performance, and system costs are presented for several forms of the two advanced ceramic barrier filter systems and are compared with the standard candle filter systems. Ceramic barrier filter system availability is also addressed. The IGCC environment operating and design conditions are outlined in Section 5.

\subsection{DESIGN, PERFORMANCE, AND COST}

The results for the IGCC application are tabulated in Tables 8.1 through 8.5. Each table lists results for three categories of information: design (component number, sizes and weights), performance, and costs. The design items and performance factors reported are the same as those reported for PFBC in Section 7, and have been defined in Section 7.1. In all cases for IGCC, the number of working pulse valves (for the entire multiple-vessel system) is always one-quarter of the total number of plenums in the plant. The IGCC application has significantly lower volumetric gas flow and fewer number of filter vessels than the PFBC application, but the IGCC ceramic barrier filters operate at significantly lower face velocities than the PGBC filters due to the lower filter cake permeability in IGCC.

The performance of the IGCC ceramic barrier filter differs from the PFBC ceramic barrier filter in several ways:

- IGCC has a higher filter trigger pressure drop than PFBC, the power plant performance being less sensitive to this pressure drop in IGCC,

- IGCC has higher pulse cleaning frequency, but lower pulse power consumption than PFBC,

- A smaller fraction of ceramic filter elements can be taken out of service before exceeding the maximum system pressure drop in IGCC,

- Ash storage capacity is smaller in IGCC ceramic barrier filters, and the volume of filter cake released on each back pulse is higher.

- The ceramic barrier filter system capital costs are significantly lower in IGCC than in PFBC. 


\subsubsection{Standard Candle Filter Systems}

Table 8.1 lists the characteristics of the three standard candle filter systems, the standard candle cluster and the two single-plenum cluster systems. The singleplenum cluster designs require twice as many vessels as the standard candle cluster design, and has fewer pulse points and working pulse valves than the standard candle cluster case. The single-plenum cluster cases happen to operate at a slightly higher face velocity than the standard candle cluster design due simply to the need to use an integral number of pre-designed clusters. The single-plenum cluster cases have much greater ash storage capacities than the standard candle cluster, with the standard candle cluster case ash storage capacity being only 1.3 hours. The maximum percentage of the filter el ements that can be lost is about $75 \%$ greater for the standard candle cluster than for the single-plenum cluster case, this difference resulting from the higher face velocity of the single-plenum cluster case.

In Table 8.1, the higher cost for vessels, and hot gas piping and ash handling equipment make the single-plenum cluster configurations about $13 \%$ more expensive than the standard candle cluster system for IGCC, a smaller cost differential than was found in the PFBC application. The cost of ceramic candle elements represents less than $8 \%$ of the total filter system cost and is one of the smaller cost categories reported. The total standard candle cluster filter system cost for IGCC is on the order of only $3 \%$ of the total projected future IGCC power plant investment.

\subsubsection{Inverted Candle (60-mm OD, 1.5-m long) Configurations and Sheet Filter}

Table 8.2 lists the IGCC results for the two inverted candle cluster configurations using thin-wall candles, 60-mm OD and 1.5-m long, as well as the results for the sheet filter clusters. Comparing the two inverted candle duster cases shows that the case with complete-enclosure clusters results in vessels having smaller diameter, but greater vessel height than those for the individual-enclosure clusters. The performance and costs of the two cases are comparable, with the inverted candle complete-encl osure clusters configuration being only $3 \%$ greater in capital cost than the individual-enclosure cluster configuration. The inverted candle configurations using thin-wall candles, 60-mm OD and 1.5-m long, require more clusters in the vessel than the standard candle cluster design (7 compared to 6) because of the less favorable pressure drop characteristics of the inverted candles. The inverted candle configurations also result in considerably greater internals weight and cost than the standard candle cluster design. The inverted candle configurations using thin-wall candles, 60-mm OD and 1.5-m long, have a total cost as much as $20 \%$ greater than that of the standard candle cluster system cost, and this results mainly from the increased cost of the vessels, filter elements and internals. This result will be sensitive to the actual cost of supply of the inverted candles that ultimately evolves. 
Table 8.1 - Filter System Characteristics for IGCC (406 MWe) Standard Candle Filter Configurations - 60-mm OD, 1.5-m Long Candles

\section{Constraints}

- Total pressure drop (pulse trigger): <8.0 psi

- Inlet and outlet gas nozzle velocity: $120 \mathrm{ft} / \mathrm{s}$

- Pulse cleaning frequency: $<6 / \mathrm{hr}$

- Pulse gas system power: $<200 \mathrm{kWe}$

- Pulse gas consumption: $<0.2 \%$ of clean gas flow

- Vessel OD: <16 ft

- Ample space for in-vessel maintenance

\begin{tabular}{|c|c|c|c|}
\hline & $\begin{array}{l}\text { Westinghouse } \\
\text { Candle Clusters }\end{array}$ & $\begin{array}{c}\text { Single-Plenum } \\
\text { Clusters } \\
\text { Clean-Side }\end{array}$ & $\begin{array}{c}\text { Single-Plenum } \\
\text { Clusters } \\
\text { Dirty-Side }\end{array}$ \\
\hline Element type & $\begin{array}{l}\text { 60-mm OD, 1.5- } \\
\text { m long }\end{array}$ & $\begin{array}{l}\text { 60-mm OD, 1.5- } \\
\text { m long }\end{array}$ & $\begin{array}{l}\text { 60-mm OD, 1.5- } \\
\text { m long }\end{array}$ \\
\hline \multicolumn{4}{|l|}{ Design } \\
\hline Number vessels & 2 & 4 & 4 \\
\hline $\begin{array}{l}\text { Number clusters each } \\
\text { vessel }\end{array}$ & 6 & 8 & 8 \\
\hline $\begin{array}{l}\text { Number elements each } \\
\text { vessel }\end{array}$ & 1122 & 488 & 488 \\
\hline Face vel ocity (ft/min) & 4.8 & 5.5 & 5.5 \\
\hline Vessel OD (ft) & 12.2 & 14.4 & 14.1 \\
\hline Total vessel height (ft) & 58 & 37 & 41 \\
\hline $\begin{array}{l}\text { Total vessel weight (tons, } \\
\text { each) }\end{array}$ & 152.2 & 120.6 & 130.0 \\
\hline $\begin{array}{l}\text { Internals weight (tons, } \\
\text { each vessel) }\end{array}$ & 43.2 & 17.3 & 18.4 \\
\hline $\begin{array}{l}\text { Number working pulse } \\
\text { valves }\end{array}$ & 12 & 8 & 8 \\
\hline \multicolumn{4}{|l|}{ Performance } \\
\hline Trigger DP (psi) & 6.9 & 7.3 & 7.7 \\
\hline Pulse frequency $(1 / h r)$ & 5.0 & 5.9 & 5.9 \\
\hline Pulse power (kWe) & 52 & 56 & 56 \\
\hline Max. Elements Lost (\%) & 17.1 & 9.8 & 9.8 \\
\hline Ash storage (hr) & 1.3 & 4.7 & 4.4 \\
\hline Cake per pulse (ft ${ }^{3}$ ) & 4.1 & 5.2 & 5.2 \\
\hline \multicolumn{4}{|l|}{ Costs $(\$ / \mathbf{k W})$} \\
\hline Total & 36.0 & 40.4 & 41.1 \\
\hline
\end{tabular}


Table 8.2 - Filter System Characteristics for IGCC (406 MWe)

Inverted Candle (60-mm OD, 1.5-m Long) and Sheet Filter Configurations

\section{Constraints}

- Total pressure drop (pulse trigger): $<8.0 \mathrm{psi}$

- Inlet and outlet gas nozzle velocity: $120 \mathrm{ft} / \mathrm{s}$

- Pulse cleaning frequency: $<6 / \mathrm{hr}$

- Pulse gas system power: $<200 \mathrm{kWe}$

- Pulse gas consumption: $<0.2 \%$ of clean gas flow

- Vessel OD: <16 ft

- Ample space for in-vessel maintenance

\begin{tabular}{|c|c|c|c|}
\hline & $\begin{array}{c}\text { Inverted } \\
\text { Candles } \\
\text { (individual } \\
\text { Enclosures) }\end{array}$ & $\begin{array}{c}\text { Inverted } \\
\text { Candles } \\
\text { (Complete } \\
\text { Enclosure) }\end{array}$ & $\begin{array}{c}\text { Sheet Filter } \\
\text { Clusters }\end{array}$ \\
\hline Element type & $\begin{array}{l}\text { 60-mm OD, } \\
5-\mathrm{mm} \text { thick, } \\
1.5-\mathrm{m} \text { long }\end{array}$ & $\begin{array}{l}\text { 60-mm OD, } \\
5-\mathrm{mm} \text { thick, } \\
1.5-\mathrm{m} \text { long }\end{array}$ & $\begin{array}{l}1 \text {-ft } \times 1 \text {-ft } \\
\text { sheets }\end{array}$ \\
\hline \multicolumn{4}{|l|}{ Design } \\
\hline Number vessels & 2 & 2 & 2 \\
\hline Number clusters each vessel & 7 & 7 & 5 \\
\hline $\begin{array}{l}\text { Number el ements each } \\
\text { vessel }\end{array}$ & 1645 & 1645 & 1680 \\
\hline Face vel ocity (ft/min) & 3.9 & 3.9 & 4.5 \\
\hline Vessel OD (ft) & 13.3 & 11.6 & 11.7 \\
\hline Total vessel height (ft) & 58 & 64 & 64 \\
\hline $\begin{array}{l}\text { Total vessel weight (tons, } \\
\text { each) }\end{array}$ & 170.8 & 152.3 & 156.2 \\
\hline $\begin{array}{l}\text { Internals weight (tons, each } \\
\text { vessel) }\end{array}$ & 59.8 & 73.5 & 43.9 \\
\hline $\begin{array}{l}\text { Number working pulse } \\
\text { valves }\end{array}$ & 14 & 14 & 10 \\
\hline \multicolumn{4}{|l|}{ Performance } \\
\hline Trigger DP (psi) & 7.2 & 7.1 & 6.9 \\
\hline Pulse frequency (1/hr) & 6.0 & 6.0 & 6.0 \\
\hline Pulse power (kWe) & 51 & 53 & 60 \\
\hline Max. Elements Lost (\%) & 6.0 & 5.1 & 9.8 \\
\hline Ash storage (hr) & 1.7 & 1.1 & 1.1 \\
\hline Cake per pulse $\left(\mathrm{ft}^{3}\right)$ & 3.0 & 2.9 & 4.1 \\
\hline \multicolumn{4}{|l|}{ Costs $(\$ / \mathbf{k W})$} \\
\hline Total & 41.8 & 43.2 & 36.1 \\
\hline
\end{tabular}


The sheet filter elements can be accommodated on five clusters, in comparison to the seven needed by the inverted candle configurations using thinwall candles, 60-mm OD and 1.5-m long, and the six clusters used in the standard candle configuration. Thus, the vessels are smaller in diameter for the sheet filter clusters, but are comparable in length, and the number of pulse valves is reduced significantly. The sheet filter, having outside surface filtering in comparison to the nature of the inverted candle filtering, can operate at a higher face velocity but maintain a lower trigger pressure drop. Other performance factors are comparable to the inverted candle configurations and the standard candle cluster configuration. The total capital cost is about $15-20 \%$ lower than the inverted candle configurations using thin-wall candles, 60-mm OD and 1.5-m long, and is about the same as that for the standard candle cluster configuration. This cost advantage results from the reduced vessel cost, reduced filter elements and internals cost, and reduced pulse control skid cost. Note that the reduction in the cost of the filter el ements is dependent on the assumption that all of the filter elements considered in this evaluation have the same cost per unit of filtering surface area, and thus, the sheet filter elements may increase or decrease in cost.

\subsubsection{Inverted Candle (60-mm OD, 2.0-m long) Configurations}

Table 8.3 lists the IGCC results for the two inverted candle configurations using thin-wall candles, 60-mm OD and 2.0-m long. Comparing the two inverted candle cases shows that the case with complete-encl osure clusters results in vessels having smaller diameter, but greater vessel height than those for the individualencl osure clusters configuration. The vessels have the same diameters as those found for the 1.5-m long candles (Table 8.2), but have reduced height. Vessel and internals weights, and the number of pulse valves are also reduced by using the 2.0$\mathrm{m}$ long inverted candles.

The performance and costs of the two cases in Table 8.3 are comparable, with the inverted candle complete-end osure clusters having less than $3 \%$ greater capital cost than the individual-encl osure dusters configuration. The inverted candle configurations with $2.0-\mathrm{m}$ long inverted candles result in a total cost about $7-10 \%$ greater than that of the standard candle cluster system cost (Table 8.1). This cost difference results mainly from the relative costs of vessels, filter elements, and internals. The overall inverted candle (2.0-m long) configuration costs are also 7$10 \%$ greater than those of the sheet filter configuration (Table 8.2).

\subsubsection{Inverted Candle (110-mm OD, 1.5-m and 2.0-m long) Configurations}

Larger diameter inverted candles have been considered to see if the improved pressure drop performance resulting from a larger inverted filter inside 
Table 8.3 - Filter System Features for IGCC (406 MWe) Inverted Candle (60-mm OD, 2.0-m Long) Filter Configurations

\section{Constraints}

- Total pressure drop (pulse trigger): $<8.0 \mathrm{psi}$

- Inlet and outlet gas nozzle velocity: $120 \mathrm{ft} / \mathrm{s}$

- Pulse cleaning frequency: $<6 / \mathrm{hr}$

- Pulse gas system power: $<200 \mathrm{kWe}$

- Pulse gas consumption: $<0.2 \%$ of clean gas flow

- Vessel OD: <16 ft

- Ample space for in-vessel maintenance

\begin{tabular}{|l|c|c|}
\hline & $\begin{array}{c}\text { Inverted Candles } \\
\text { (Individual } \\
\text { Enclosures) }\end{array}$ & $\begin{array}{c}\text { Inverted Candles } \\
\text { (Complete Enclosure) }\end{array}$ \\
\hline Element type & $\begin{array}{c}\text { 60-mm OD, } \\
\text { 5-mm thick, } \\
2.0-m \text { long }\end{array}$ & $\begin{array}{c}\text { 60-mm OD, } \\
\text { 5-mm thick, } \\
\text { 2.0-m long }\end{array}$ \\
\hline Design & 2 \\
\hline Number vessels & 2 & 7 \\
\hline $\begin{array}{l}\text { Number clusters each } \\
\text { vessel }\end{array}$ & 7 & 1267 \\
\hline $\begin{array}{l}\text { Number elements each } \\
\text { vessel }\end{array}$ & 1267 & 3.8 \\
\hline Face velocity (ft/min) & 3.8 & 11.6 \\
\hline Vessel OD (ft) & 13.3 & 61 \\
\hline Total vessel height (ft) & 55 & 146.4 \\
\hline $\begin{array}{l}\text { Total vessel weight (tons, } \\
\text { each) }\end{array}$ & 162.1 & 65.4 \\
\hline $\begin{array}{l}\text { Internals weight (tons, } \\
\text { each vessel) }\end{array}$ & 53.7 & 10 \\
\hline $\begin{array}{l}\text { Number working pulse } \\
\text { valves }\end{array}$ & 10 & 6.9 \\
\hline Performance & \multicolumn{2}{|l|}{} \\
\hline Trigger DP (psi) & 6.9 & 5.9 \\
\hline Pulse frequency (1/hr) & 5.9 & 54 \\
\hline Pulse power (kWe) & 54 & 1.7 \\
\hline Max. Elements Lost (\%) & 7.7 & 4.0 \\
\hline Ash storage (hr) & 1.7 & 39.7 \\
\hline Cake per pulse (ft3) & 4.0 & \\
\hline Costs (\$/kW) & 38.6 & \\
\hline Total & \\
\hline
\end{tabular}


diameter would result in improved overall costs. Table 8.4 lists the IGCC results for the two inverted candle configurations using thin-wall candles, 1100-mm OD, and 1.5 and 2.0-m long. Only six clusters are needed in each vessel, but the vessels are of larger diameter than those needed when using the 60-mm OD inverted candles (Tables 8.2 and 8.3). The larger diameter, 110-mm inverted candles do allow operation at higher face velocities than the 60-mm OD inverted candles, and this results in an overall cost reduction of about $6-9 \%$, but the costs are still higher than those of the standard candle cluster system (Table 8.1).

\subsubsection{Inverted Candle (60-mm and 110-mm OD, 1.5-m and 2.0-m long) Configurations with External Support Pipes}

The final configuration considered for IGCC is the inverted candle (1.5-m and 2.0-m long; 60 and 110-mm OD) complete-encl osure clusters with external support pipes, and these results are reported in Table 8.5. In comparison to the analogous cases in Tables 8.2, 8.3, and 8.4, the use of the external support pipes allows the number of clusters in each vessel to be reduced by one. This does not result in a vessel diameter reduction as the cluster spacing must also allow for the external support pipe clearances. Performance is comparable to the analogous cases, and the cost of the systems are reduced by a small amount at most This lowest cost configuration, using the 110-mm OD inverted candles with 2.0-m length, has total capital cost comparable to the standard candle cluster configuration.

\subsection{AVAILABILITY ESTIMATES}

Ceramic barrier filter system availabilities in IGCC have been estimated using the same qualitative arguments, reasoning, assumptions, and procedures used for the PFBC application (Section 7.2). The failure categories and mechanisms are ranked in Table 8.6. Each of the four ceramic barrier filter systems is considered, and an average value is determined for each of the four failure categories and for the total matrix. Two of the failure categories are identical for all of the barrier filter systems ("gasket leak", "pulse cleaning ineffective"), while "metal structure leak" differs very little between the four filter arrangements.

In this ranking table (Table 8.6), a combination of low frequency and low consequences is best, and the results are similar to those for the PFBC application. The inverted candle filter has the lowest average rankings for both of these. The sheet filter also has rankings lower than the standard candle configurations. The single-plenum cluster design reliability ranking suffers due to its large number of vessels, large number of ash handling systems, and the need to shut down the entire power plant if any one ash drain nozzle plugs or if any single ash handling system does not function. 
Table 8.4 - Filter System Features for IGCC (406 MWe)

Inverted Candle (110-mm OD, $1.5 \&$ 2.0-m Long) Filter Configurations

\section{Constraints}

- Total pressure drop (pulse trigger): $<8.0 \mathrm{psi}$

- Inlet and outlet gas nozzle velocity: $120 \mathrm{ft} / \mathrm{s}$

- Pulse cleaning frequency: $<6 / \mathrm{hr}$

- Pulse gas system power: $<200 \mathrm{kWe}$

- Pulse gas consumption: $<0.2 \%$ of clean gas flow

- Vessel OD: <16 ft

- Ample space for in-vessel maintenance

\begin{tabular}{|c|c|c|c|c|}
\hline & $\begin{array}{l}\text { Inverted } \\
\text { Candles } \\
\text { (Individual } \\
\text { Enclosures) }\end{array}$ & $\begin{array}{l}\text { Inverted } \\
\text { Candles } \\
\text { (Individual } \\
\text { Enclosures) }\end{array}$ & $\begin{array}{c}\text { Inverted } \\
\text { Candles } \\
\text { (Complete } \\
\text { Enclosure) }\end{array}$ & $\begin{array}{l}\text { Inverted } \\
\text { Candles } \\
\text { (Complete } \\
\text { Enclosure) }\end{array}$ \\
\hline Element type & $\begin{array}{c}\text { 110-mm OD, } \\
5-\mathrm{mm} \text { thick, } \\
1.5-\mathrm{m} \text { long }\end{array}$ & $\begin{array}{c}\text { 110-mm OD, } \\
5-\mathrm{mm} \text { thick, } \\
2.0-\mathrm{m} \text { long }\end{array}$ & $\begin{array}{l}\text { 110-mm OD, } \\
\text { 5-mm thick, } \\
1.5-\mathrm{m} \text { long }\end{array}$ & $\begin{array}{l}\text { 110-mm OD, } \\
5-\mathrm{mm} \text { thick, } \\
2.0-\mathrm{m} \text { long }\end{array}$ \\
\hline \multicolumn{5}{|l|}{ Design } \\
\hline Number vessels & 2 & 2 & 2 & 2 \\
\hline $\begin{array}{l}\text { Number clusters each } \\
\text { vessel }\end{array}$ & 6 & 6 & 6 & 6 \\
\hline $\begin{array}{l}\text { Number el ements each } \\
\text { vessel }\end{array}$ & 738 & 570 & 738 & 570 \\
\hline Face velocity (ft/min) & 4.3 & 4.2 & 4.3 & 4.2 \\
\hline Vessel OD (ft) & 14.5 & 14.5 & 13.9 & 13.9 \\
\hline Total vessel height (ft) & 60 & 57 & 69 & 66 \\
\hline $\begin{array}{l}\text { Total vessel weight (tons, } \\
\text { each) }\end{array}$ & 202.4 & 192.4 & 212.9 & 204.8 \\
\hline $\begin{array}{l}\text { Internals weight (tons, } \\
\text { each vessel) }\end{array}$ & 57.6 & 51.8 & 72.9 & 65.0 \\
\hline $\begin{array}{l}\text { Number working pulse } \\
\text { valves }\end{array}$ & 12 & 9 & 12 & 9 \\
\hline \multicolumn{5}{|l|}{ Performance } \\
\hline Trigger DP (psi) & 7.2 & 7.0 & 7.5 & 7.2 \\
\hline Pulse frequency $(1 / \mathrm{hr})$ & 6.0 & 5.9 & 6.0 & 5.9 \\
\hline Pulse power (kWe) & 52 & 53 & 51 & 53 \\
\hline Max. Elements Lost (\%) & 5.7 & 8.4 & 4.1 & 6.3 \\
\hline Ash storage (hr) & 2.3 & 2.3 & 2.0 & 2.0 \\
\hline Cake per pulse $\left(\mathrm{ft}^{3}\right)$ & 3.4 & 4.6 & 3.4 & 4.6 \\
\hline \multicolumn{5}{|l|}{ Costs $(\$ / k W)$} \\
\hline Total & 38.1 & 35.8 & 40.3 & 37.2 \\
\hline
\end{tabular}


Table 8.5 - Filter System F eatures for IGCC (406 MWe) Inverted Candle (60 \& 110-mm OD, 1.5 \& 2.0-m Long) In Complete-Enclosures with External Support Pipe Filter Configurations

\section{Constraints}

- Total pressure drop (pulse trigger): $<8.0 \mathrm{psi}$

- Inlet and outlet gas nozzle velocity: $120 \mathrm{ft} / \mathrm{s}$

- Pulse cleaning frequency: $<6 / \mathrm{hr}$

- Pulse gas system power: $<200 \mathrm{kWe}$

- Pulse gas consumption: $<0.2 \%$ of clean gas flow

- Vessel OD: $<16 \mathrm{ft}$

- Ample space for in-vessel maintenance

\begin{tabular}{|c|c|c|c|c|}
\hline & $\begin{array}{c}\text { Inverted } \\
\text { Candles } \\
\text { (Complete } \\
\text { Enclosures) }\end{array}$ & $\begin{array}{c}\text { Inverted } \\
\text { Candles } \\
\text { (Complete } \\
\text { Enclosures) }\end{array}$ & $\begin{array}{l}\text { Inverted } \\
\text { Candles } \\
\text { (Complete } \\
\text { Enclosure) }\end{array}$ & $\begin{array}{c}\text { Inverted } \\
\text { Candles } \\
\text { (Complete } \\
\text { Enclosure) }\end{array}$ \\
\hline Element type & $\begin{array}{l}\text { 60-mm OD, } \\
\text { 5-mm thick, } \\
\text { 1.5-m long }\end{array}$ & $\begin{array}{l}\text { 60-mm OD, } \\
\text { 5-mm thick, } \\
\text { 2.0-m long }\end{array}$ & $\begin{array}{l}\text { 110-mm OD, } \\
5-\mathrm{mm} \text { thick, } \\
1.5-\mathrm{m} \text { long }\end{array}$ & $\begin{array}{l}\text { 110-mm OD, } \\
\text { 5-mm thick, } \\
\text { 2.0-m long }\end{array}$ \\
\hline \multicolumn{5}{|l|}{ Design } \\
\hline Number vessels & 2 & 2 & 2 & 2 \\
\hline $\begin{array}{l}\text { Number clusters each } \\
\text { vessel }\end{array}$ & 6 & 6 & 5 & 5 \\
\hline $\begin{array}{l}\text { Number elements each } \\
\text { vessel }\end{array}$ & 1752 & 1314 & 780 & 585 \\
\hline Face velocity (ft/min) & 3.6 & 3.7 & 4.1 & 4.1 \\
\hline Vessel OD (ft) & 13.8 & 13.8 & 14.5 & 14.5 \\
\hline Total vessel height (ft) & 68 & 66 & 70 & 67 \\
\hline $\begin{array}{l}\text { Total vessel weight (tons, } \\
\text { each) }\end{array}$ & 211.8 & 203.8 & 232.0 & 223.3 \\
\hline $\begin{array}{l}\text { Internals weight (tons, } \\
\text { each vessel) }\end{array}$ & 69.7 & 61.7 & 65.3 & 58.0 \\
\hline $\begin{array}{l}\text { Number working pulse } \\
\text { valves }\end{array}$ & 24 & 18 & 20 & 15 \\
\hline \multicolumn{5}{|l|}{ Performance } \\
\hline Trigger DP (psi) & 6.3 & 6.4 & 6.8 & 6.8 \\
\hline Pulse frequency $(1 / h r)$ & 6.0 & 6.0 & 6.0 & 6.0 \\
\hline Pulse power (kWe) & 61 & 60 & 58 & 59 \\
\hline \multicolumn{5}{|l|}{ Max. Elements Lost (\%) } \\
\hline Ash storage (hr) & 2.0 & 2.0 & 2.3 & 2.3 \\
\hline Cake per pulse $\left(\mathrm{ft}^{3}\right)$ & 3.4 & 4.6 & 4.1 & 5.4 \\
\hline \multicolumn{5}{|l|}{ Costs $(\$ / k W)$} \\
\hline Total & 44.1 & 40.3 & 39.4 & 36.4 \\
\hline
\end{tabular}


For the inverted candle filter to achieve this superior reliable behavior in practice, the foll owing features must be demonstrated in IGCC testing:

- the inverted candle will not plug, or can recover from plugging by normal pulse cleaning,

- the inverted candle will operate in an inherently fail-safe mode, selfplugging cracks if they occur (although fail-safe/regenerators can be implemented with the inverted candles),

- the inverted candle is thermally, mechanically stable,

- the inverted candle with internal membrane skin will not blind.

Similarly, for the sheet filter the following reliability factors must be demonstrated in IGCC testing:

- the sheet filter configuration is free from ash bridging,

- the sheet filter is thermally, mechanically stable,

the sheet filter, if damaged, will be retained in its normal position to avoid damage to lower elements or plugging of the vessel ash outlet.

These test demonstrations would be expected to be less challenging in the IGCC environment than in the PFBC environment.

Quantitative estimates of availability made by using the ranking table based on the following assumed conditions in the IGCC filter system:

- the IGCC ash has a high filter cake bridging tendency and poor flow properties,

- soot blower/turbulators are only moderately effective at bridging elimination,

- the fail-safe/regenerator is effective, with little dust leakage.

The estimates are made relative to the standard candle cluster system, and the number of filter system shut downs per year due to excessive dust resulting from candle filter element leaks and fail-safe leaks (primarily due to ash bridging) is set as 1.0. The other shut downs per year for the other six major failure categories, and for the three other filter systems, are estimated from the ranking table as follows. The frequency value is multiplied by the consequence ranking value for each item and these are totaled for the seven major categories. These totals appear in parentheses in the table. The shut down frequency (number per year) is the taken as the ratio of the sum to the summed value to the number for the standard candle cluster - that is, each sum is divided by 46. 
Table 8.6 - Reliability Ranking for Advanced Ceramic Filter Systems In IGCC

\begin{tabular}{|c|c|c|c|c|c|c|c|c|}
\hline & \multicolumn{2}{|c|}{$\begin{array}{l}\text { Stand. } \\
\text { Candle } \\
\text { Cluster }\end{array}$} & \multicolumn{2}{|c|}{$\begin{array}{l}\text { Single- } \\
\text { Plenum } \\
\text { Cluster }\end{array}$} & \multicolumn{2}{|c|}{$\begin{array}{c}\text { Inverted } \\
\text { Candle } \\
\text { Cluster }\end{array}$} & \multicolumn{2}{|c|}{$\begin{array}{l}\text { Sheet Filter } \\
\text { Cluster }\end{array}$} \\
\hline & $\mathrm{F}^{*}$ & $C^{*}$ & $\mathrm{~F}$ & $\mathrm{C}$ & $\mathrm{F}$ & $\mathrm{C}$ & $\mathrm{F}$ & $\mathrm{C}$ \\
\hline \multicolumn{9}{|l|}{$\begin{array}{l}\text { 1) OUTLET DUST EXCEEDS } \\
\text { EMISSIONS }\end{array}$} \\
\hline ELEMENT PLUS FAIL-SAFE LEAK & & $(46)$ & & (36) & & (14) & & $(30)$ \\
\hline chemical-thermal degradation & 2 & 2 & 2 & 2 & 2 & 3 & 2 & 2 \\
\hline process shock & 2 & 3 & 2 & 3 & 2 & 4 & 2 & 3 \\
\hline ash bridge mechanical damage & 3 & 4 & 3 & 4 & 0 & 0 & 1 & 4 \\
\hline ash over-fill mechanical damage & 4 & 3 & 2 & 5 & 0 & 0 & 4 & 2 \\
\hline mechanical damage from falling element & 3 & 4 & 1 & 4 & 0 & 0 & 2 & 4 \\
\hline GASKET LEAK & & $(6)$ & & (6) & & (9) & & $(6)$ \\
\hline chemical-thermal degradation & 1 & 2 & 1 & 2 & 1 & 3 & 1 & 2 \\
\hline mechanical flow induced damage & 1 & 2 & 1 & 2 & 1 & 3 & 1 & 2 \\
\hline process shock & 1 & 2 & 1 & 2 & 1 & 3 & 1 & 2 \\
\hline METAL STRUCTURE LEAK & & (12) & & (18) & & (12) & & $(12)$ \\
\hline corrosion, erosion & 1 & 3 & 1 & 3 & 1 & 3 & 1 & 3 \\
\hline thermal fatigue & 2 & 3 & 3 & 3 & 2 & 3 & 2 & 3 \\
\hline process shock & 1 & 3 & 2 & 3 & 1 & 3 & 1 & 3 \\
\hline Category Average & 2.0 & 2.8 & 1.7 & 3.0 & 1.0 & 2.3 & 1.6 & 2.7 \\
\hline \multicolumn{9}{|l|}{ 2) DP EXCEEDS LIMIT } \\
\hline PULSE CLEANING INEFFECTIVE & & $(17)$ & & $(17)$ & & $(17)$ & & $(17)$ \\
\hline pulse nozzle misalignment & 1 & 3 & 1 & 3 & 1 & 3 & 1 & 3 \\
\hline pulse pipe fails & 2 & 3 & 2 & 3 & 2 & 3 & 2 & 3 \\
\hline $\begin{array}{l}\text { can't deliver enough gas or pulse } \\
\text { intensity }\end{array}$ & 2 & 4 & 2 & 4 & 2 & 4 & 2 & 4 \\
\hline $\begin{array}{l}\text { COMPONENT FLOW RESISTANCE } \\
\text { RISE }\end{array}$ & & (33) & & (36) & & (11) & & $(28)$ \\
\hline $\begin{array}{l}\text { filter element blinding (internal } \\
\text { resistance) }\end{array}$ & 2 & 4 & 2 & 4 & 2 & 4 & 2 & 4 \\
\hline ash bridging & 4 & 4 & 4 & 4 & 0 & 0 & 2 & 4 \\
\hline plugging too many fail-safes & 2 & 3 & 3 & 3 & 0 & 0 & 3 & 3 \\
\hline $\begin{array}{l}\text { plugging, deposition, corrosion of } \\
\text { components (e.g., eductors) }\end{array}$ & 1 & 3 & 1 & 3 & 1 & 3 & 1 & 3 \\
\hline Category Average & 2.0 & 3.4 & 2.1 & 3.4 & 1.1 & 2.4 & 1.9 & 3.4 \\
\hline 3) PULSE SYSTEM FAILS & & (11) & & (11) & & (11) & & $(11)$ \\
\hline Pulse valve failure & 3 & 0 & 3 & 0 & 3 & 0 & 3 & 0 \\
\hline Activated ball valve failure & 1 & 3 & 1 & 3 & 1 & 3 & 1 & 3 \\
\hline Pulse gas compressor fails & 2 & 1 & 2 & 1 & 2 & 1 & 2 & 1 \\
\hline Instrumentation/ controller fails & 2 & 3 & 2 & 3 & 2 & 3 & 2 & 3 \\
\hline $\begin{array}{ll}\text { Category Average } \\
\end{array}$ & 2.0 & 1.8 & 2.0 & 1.8 & 2.0 & 1.8 & 2.0 & 1.8 \\
\hline 4) CAN'T RE MOVAL ASH - VESSE L & & (33) & & $(46)$ & & $(23)$ & & $(33)$ \\
\hline Ash Removal System Failure & 2 & 4 & 4 & 4 & 2 & 4 & 2 & 4 \\
\hline Ash Hopper Nozzle Bridging & 3 & 5 & 4 & 5 & 3 & 5 & 3 & 5 \\
\hline $\begin{array}{l}\text { Ash Hopper Nozzle Plug - Broken } \\
\text { Elements }\end{array}$ & 2 & 5 & 2 & 5 & 0 & 0 & 2 & 5 \\
\hline Category Average & 2.3 & 4.7 & 3.3 & 4.7 & 1.7 & 3.0 & 2.3 & 4.7 \\
\hline AVERAGE & & 158 & & 170 & & 97 & & 137 \\
\hline
\end{tabular}

*: $\mathrm{F}$ is failure frequency ranking for each event; $\mathrm{C}$ is shutdown consequences ranking.

**: Numbers in parentheses are the sum of the product of $\mathrm{F}$ and $\mathrm{C}$ for each failure group. 
The estimated mean recovery times for IGCC are based on past filter system experience, and include times for system depressurization and cool down; filter vessel inspection; installation of maintenance equipment; cleanup and disassembly; maintenance times for filter el ement replacement, gasket replacement, fail-safe replacement, metal structure repair; and reassembly of the system. The estimated, mean recovery times are:

- Following shut down due to excessive outlet gas dust (element leaks, failsafe leaks, gasket leaks): 240 hours

- Following shut down due to excessive outlet gas dust (metal structure leaks): 400 hours

- Following shut down due to excessive pressure drop (pulse cleaning ineffective): 100 hours

- Following shut down due to excessive pressure drop (flow resistance rise): 240 hours

- Following shut down due to pulse system failure: 24 hours

- Following shut down due to ash removal system failure: 60 hours

The results are shown in Tables 8.7 - 8.11. Under the assumptions set, the standard candle cluster filter system would have more than 3 forced shut downs every year (on average), and would be forced to shut down about every 2,500 hours and be out of service about $7 \%$ of the time. This availability is only a concern for the IGCC power plant if these outages cannot be accommodated by maintenance during scheduled plant outages or during periods of forced outage due to other IGCC power plant systems. The current state of IGCC is such that forced outages, or planned maintenance periods occur more frequently than every 2,500 hours.

In comparison, the single-plenum cluster filter system in IGCC would be forced to shut down almost 5 times per year with an average outage rate of about $8 \%$, and a mean time between outages of about 1,800 hours. The inverted candle filter system is estimated to be shut down about twice every year, having about $4 \%$ outage rate and a mean time between outages of greater than 4,000 hours. The sheet filter availability is not quite as high as the inverted candle system, with shut downs about 3 times per year, about $6 \%$ outage rate, and mean time between outages greater than 3,000 hours. The potential improvements in the hot gas filter system availability with the advanced ceramic barrier filter systems could have a great impact on the IGCC power plant performance and cost depending on the availability performance of the other major components in the IGCC plant.

\subsection{IGCC CERAMIC BARRIER FILTER CONCLUSIONS}

The two advanced ceramic barrier filter systems evaluated for the IGCC application show the potential to provide hot gas particulate removal with 
comparable operating performance (pressure drop, pulse cleaning frequency, pulse gas consumption) and slightly higher-to-comparable capital cost to the standard candle cluster filter systems. With difficult ashes that are prone to bridging, sintering, and poor vessel hopper flow, the advanced 
Table 8.7 - Availability Estimates for Standard Candle Cluster Filter in IGCC

\begin{tabular}{|l|c|c|c|c|}
\hline \multicolumn{1}{|c|}{$\begin{array}{c}\text { Shut Down } \\
\text { Occurrence }\end{array}$} & $\begin{array}{c}\text { Number } \\
\text { per year }\end{array}$ & $\begin{array}{c}\text { Mean } \\
\text { recovery } \\
\text { time (hrs) }\end{array}$ & $\begin{array}{c}\text { Outage } \\
\text { rate (\%) }\end{array}$ & $\begin{array}{c}\text { Mean time between } \\
\text { outages (hrs) }\end{array}$ \\
\hline $\begin{array}{l}\text { Excess dust due to } \\
\text { element and fail-safe } \\
\text { leaks }\end{array}$ & 1.0 & 240 & 2.74 & 8,526 \\
\hline $\begin{array}{l}\text { Excess dust due to } \\
\text { gasket leaks }\end{array}$ & 0.13 & 240 & 0.36 & 67,191 \\
\hline $\begin{array}{l}\text { Excess dust due to } \\
\text { metal structure } \\
\text { leaks }\end{array}$ & 0.26 & 400 & 1.19 & 33,315 \\
\hline $\begin{array}{l}\text { Excess pressure drop } \\
\text { due to poor pulse } \\
\text { cleaning }\end{array}$ & 0.37 & 100 & 0.42 & 25,592 \\
\hline $\begin{array}{l}\text { Excess pressure drop } \\
\text { due to flow } \\
\text { resistance rise }\end{array}$ & 0.72 & 240 & 1.97 & 11,935 \\
\hline $\begin{array}{l}\text { Pulse cleaning } \\
\text { system failure }\end{array}$ & 0.24 & 24 & 0.07 & 36,501 \\
\hline $\begin{array}{l}\text { Ash removal system } \\
\text { failure }\end{array}$ & 0.72 & 60 & 0.49 & 12,115 \\
\hline $\begin{array}{l}\text { Total System } \\
\text { Results }\end{array}$ & 3.43 & 184 & 6.84 & 2,511 \\
\hline $\begin{array}{l}\text { Overall Filter } \\
\text { System Availability } \\
\text { (\%) }\end{array}$ & & 93.16 & \\
\hline
\end{tabular}


Table 8.8 - Availability Estimates for Single-PIenum Candle Cluster Filter in IGCC

\begin{tabular}{|l|c|c|c|c|}
\hline \multicolumn{1}{|c|}{$\begin{array}{c}\text { Shut Down } \\
\text { Occurrence }\end{array}$} & $\begin{array}{c}\text { Number } \\
\text { per year }\end{array}$ & $\begin{array}{c}\text { Mean } \\
\text { recovery } \\
\text { time (hrs) }\end{array}$ & $\begin{array}{c}\text { Outage } \\
\text { rate (\%) }\end{array}$ & $\begin{array}{c}\text { Mean time } \\
\text { between } \\
\text { outages (hrs) }\end{array}$ \\
\hline $\begin{array}{l}\text { Excess dust due to } \\
\text { element and fail-safe } \\
\text { leaks }\end{array}$ & 0.78 & 240 & 2.14 & 10,998 \\
\hline $\begin{array}{l}\text { Excess dust due to } \\
\text { gasket leaks }\end{array}$ & 0.13 & 240 & 0.36 & 67,191 \\
\hline $\begin{array}{l}\text { Excess dust due to } \\
\text { metal structure leaks }\end{array}$ & 0.39 & 400 & 1.78 & 22,077 \\
\hline $\begin{array}{l}\text { Excess pressure drop } \\
\text { due to poor pulse } \\
\text { cleaning }\end{array}$ & 0.37 & 100 & 0.42 & 23,592 \\
\hline $\begin{array}{l}\text { Excess pressure drop } \\
\text { due to flow resistance } \\
\text { rise }\end{array}$ & 0.78 & 240 & 2.14 & 10,998 \\
\hline $\begin{array}{l}\text { Pulse cleaning system } \\
\text { failure }\end{array}$ & 0.24 & 24 & 0.07 & 36,501 \\
\hline $\begin{array}{l}\text { Ash removal system } \\
\text { failure }\end{array}$ & 2.00 & 60 & 1.37 & 4,323 \\
\hline Total System Results & 4.70 & 154 & 7.74 & 1,841 \\
\hline $\begin{array}{l}\text { Overall Filter System } \\
\text { Availability (\%) }\end{array}$ & & 92.26 & \\
\hline
\end{tabular}


Table 8.9 - Availability Estimates for Inverted Candle Cluster Filter in IGCC

\begin{tabular}{|l|c|c|c|c|}
\hline \multicolumn{1}{|c|}{$\begin{array}{c}\text { Shut Down } \\
\text { Occurrence }\end{array}$} & $\begin{array}{c}\text { Number } \\
\text { per year }\end{array}$ & $\begin{array}{c}\text { Mean } \\
\text { recovery } \\
\text { time (hrs) }\end{array}$ & $\begin{array}{c}\text { Outage } \\
\text { rate (\%) }\end{array}$ & $\begin{array}{c}\text { Mean time } \\
\text { between outages } \\
\text { (hrs) }\end{array}$ \\
\hline $\begin{array}{l}\text { Excess dust due to } \\
\text { element and fail-safe } \\
\text { leaks }\end{array}$ & 0.30 & 240 & 0.82 & 28,980 \\
\hline $\begin{array}{l}\text { Excess dust due to } \\
\text { gasket leaks }\end{array}$ & 0.20 & 240 & 0.55 & 43,590 \\
\hline $\begin{array}{l}\text { Excess dust due to } \\
\text { metal structure } \\
\text { leaks }\end{array}$ & 0.26 & 400 & 1.19 & 33,315 \\
\hline $\begin{array}{l}\text { Excess pressure drop } \\
\text { due to poor pulse } \\
\text { cleaning }\end{array}$ & 0.37 & 100 & 0.42 & 23,592 \\
\hline $\begin{array}{l}\text { Excess pressure drop } \\
\text { due to flow } \\
\text { resistance rise }\end{array}$ & 0.24 & 240 & 0.66 & 36,285 \\
\hline $\begin{array}{l}\text { Pulse cleaning } \\
\text { system failure }\end{array}$ & 0.24 & 24 & 0.07 & 36,501 \\
\hline $\begin{array}{l}\text { Ash removal system } \\
\text { failure }\end{array}$ & 0.50 & 60 & 0.34 & 17,472 \\
\hline $\begin{array}{l}\text { Total System } \\
\text { Results }\end{array}$ & 2.11 & 168 & 3.91 & 4,132 \\
\hline $\begin{array}{l}\text { Overall Filter } \\
\text { System Availability } \\
\text { (\%) }\end{array}$ & & 96.09 & \\
\hline
\end{tabular}


Table 8.10 - Availability Estimates for Sheet Filter in IGCC

\begin{tabular}{|l|c|c|c|c|}
\hline \multicolumn{1}{|c|}{$\begin{array}{c}\text { Shut Down } \\
\text { Occurrence }\end{array}$} & $\begin{array}{c}\text { Number } \\
\text { per year }\end{array}$ & $\begin{array}{c}\text { Mean } \\
\text { recovery } \\
\text { time (hrs) }\end{array}$ & $\begin{array}{c}\text { Outage } \\
\text { rate (\%) }\end{array}$ & $\begin{array}{c}\text { Mean time } \\
\text { between } \\
\text { outages (hrs) }\end{array}$ \\
\hline $\begin{array}{l}\text { Excess dust due to } \\
\text { element and fail-safe } \\
\text { leaks }\end{array}$ & 0.65 & 240 & 1.78 & 13,246 \\
\hline $\begin{array}{l}\text { Excess dust due to } \\
\text { gasket leaks }\end{array}$ & 0.13 & 240 & 0.36 & 67,191 \\
\hline $\begin{array}{l}\text { Excess dust due to } \\
\text { metal structure } \\
\text { leaks }\end{array}$ & 0.26 & 400 & 1.19 & 33,315 \\
\hline $\begin{array}{l}\text { Excess pressure drop } \\
\text { due to poor pulse } \\
\text { cleaning }\end{array}$ & 0.37 & 100 & 0.42 & 23,592 \\
\hline $\begin{array}{l}\text { Excess pressure drop } \\
\text { due to flow } \\
\text { resistance rise }\end{array}$ & 0.61 & 240 & 1.67 & 14,130 \\
\hline $\begin{array}{l}\text { Pulse cleaning } \\
\text { system failure }\end{array}$ & 0.24 & 24 & 0.07 & 36,501 \\
\hline $\begin{array}{l}\text { Ash removal system } \\
\text { failure }\end{array}$ & 0.72 & 60 & 0.49 & 12,115 \\
\hline $\begin{array}{l}\text { Total System } \\
\text { Results }\end{array}$ & 2.98 & 176 & 5.69 & 2,911 \\
\hline $\begin{array}{l}\text { Overall Filter } \\
\text { System Availability } \\
\text { (\%) }\end{array}$ & & 94.31 & \\
\hline
\end{tabular}


ceramic barrier filter systems have the potential for significantly improved filter system reliability and availability, with easier maintenance and lower operating costs. In IGCC, the total capital cost of the ceramic barrier filter system is a small fraction of the total power plant cost -- 3\% or less for this air-blown gasification case, and significantly less for oxygen-blown cases. For IGCC, the emphasis should be placed on improved hot gas filter system availability and ease of maintenance rather than on capital cost reduction.

The three inverted candle cluster configurations evaluated (individualencl osure clusters, complete-encl osure clusters, and complete-encl osure clusters with external support pipes) are all higher in capital cost than the standard candle cluster filter system. The inverted candle configurations using 2.0-m long inverted candles, 110-mm in OD, have the greatest cost potential. The ease of maintenance of the inverted candle filter systems range from comparable to the standard candle cluster filter system, for the individual-encl osure clusters configuration, to much easier for the complete-enclosure clusters configuration. The availability of the inverted candle filter configurations are potentially much higher than that of the standard candle cluster filter system if difficult ashes that are prone to bridging, and poor vessel hopper flow are characteristic of the IGCC application. If the IGCC environment is such that the availability of the standard candle cluster filter system is high, the inverted candle filter configurations still have the potential for significant maintenance advantages.

The sheet filter system evaluated has almost identical capital cost to the standard candle cluster filter system. It also has availability advantages over the standard candle cluster filter system if difficult ashes that are prone to bridging, and poor vessel hopper flow are characteristic of the IGCC application. The ease of maintenance of the sheet filter system is comparable to the standard candle cluster filter system. If the IGCC environment is such that the availability of the standard candle cluster filter system is high, the sheet filter configuration has the potential for comparable-to-better ease of maintenance and availability. 


\section{OPTION I PROGRAM ENGINEERING AND TEST PLANS}

In the Option I program, Bench-Scale Testing for the Resolution of Technical Issues, development activities will focus on the key issues for the two advanced ceramic barrier filter concepts, the inverted candle filter and the sheet filter, that have been identified in the Base Program. The Option I program will consist of 1 ) engineering activities related to inverted candle and sheet filter design and manufacturing, seals and el ement fixing, and fail-safe/regenerator adaptation to the advanced filter configurations; and 2) testing focused on the advanced filter element key issues. The testing will be conducted under simulated PFBC conditions and will utilize existing filter test facilities.

\subsection{TECHNICAL ISSUES}

The advanced ceramic barrier filter system evaluation has identified the major feasibility issues related to the two advanced ceramic barrier filter concepts. Key feasibility issues grouped into "engineering issues" and "performance issues subject to testing" are listed below. Each issue listed shows an indication of the ranking of the ability to resolve the issue in the Option I program. The ranking is based on the level of current engineering confidence, or certainty that the issues can be resolved. A "low " ranking means that it is uncertain if the issue can be resolved in the Option I program, whilea "high" ranking means that it is fairly certain that the issue can be resolved in the Option I program.

In the category of engineering issues:

\section{Inverted candle}

- flange design and inside membrane skin specification (ranking: high),

- gasket and holder design (ranking: high),

- candle placement guides design to hold candle tip (ranking: medium),

- manufacturing feasibility and cost for inverted candles 60-mm OD; 5 - 10-mm wall thickness; 1.5-m length (ranking: high),

- manufacturing feasibility and cost for inverted candles 110-mm OD; 5 - 10$\mathrm{mm}$ wall thickness; 1.5 and 2.0-m length (ranking: low), 


\section{Sheet filter}

- sheet filter element body features (wall thicknesses, internal ribs) (ranking: high),

- sheet filter element durable flange design (ranking: medium)

- gasket and holder design (ranking: medium),

- fixture design to keep sheet filter "locked" in position if it fails (ranking: medium)

- manufacturing feasibility and cost in the sizes conceived (1-ft by 1-ft) (ranking: medium).

In the category of performance issues subject to testing:

\section{Inverted candle}

- filtration and pulse cleaning performance (ranking: high),

- plugging and plug recovery performance (ranking: medium),

- filter element and gasket durability (ranking: medium),

- filter element self-sealing performance - that is, the ability of a fracture in the element to plug with dust (ranking: low-to-medium),

\section{Sheet filter}

- filtration and pulse cleaning performance (ranking: high),

- close-packed elements resistance to ash bridging (ranking: low-tomedium),

- filter element and gasket durability (ranking: low-to-medium),

- ability of fixture to keep filter element locked in position even if damaged (ranking: medium).

The thin-wall, inverted candle filter with inside membrane skin appears to be a geometry and manufacturing form closely related to the devel opment of commercial and advanced ceramic candles if the standard candle dimensions of 60$\mathrm{mm} \mathrm{OD}$ and 1.5-m length are maintained, and confidence is high that manufacturing feasibility of such elements can be resolved. The larger diameter (110-mm) and longer (2-m) inverted candle filter elements have a lower ranking of manufacturing feasibility resolution. Confidence is also relatively high that the flange, gasketing, and holding of the inverted candle filter elements will be a direct extrapolation of the technique used for the conventional candle filter elements and can be resolved in the Option I program. The manufacturing feasibility of the inside membrane on the inverted candles is possibly the largest manufacturing issue.

The engineering issues for the sheet filter generally rank lower than those for the inverted candle filter, reflecting the current state of design knowledge and test experiences with similar ceramic filter elements. The sheet filter is a more unusual and uncertain ceramic filter element design, and past experiences with the related 
cross-flow filter element raises concern that the flange, gasketing, holding, and fixturing to keep damaged sheet filters locked in position are critical to the success or failure of the sheet filter. Thus, the Option I program must focus considerable engineering consideration on the sheet filter element, with the Option I testing proceeding initially with the inverted candles, to be followed later by the sheet filter testing.

\subsection{ENGINEERING TASKS}

Option I engineering activities will address the following tasks:

\section{Task 1 - Inverted Candle Engineering}

\section{Task 1.1 - Manufacturing feasibility and cost evaluation}

Candidate ceramic filter element vendors for oxide-based, inverted ceramic candles with thin walls have been identified: Coors (40-mm ID, no inside membrane), Blasch (40-mm ID, no inside membrane), B\&W (50-mm ID, no inside membrane), DuPont. Discussions will be held with them to estimate the manufacturing feasibility and cost of the oxide-based, inverted ceramic candles in the sizes concei ved (60-mm and 110-mm OD; 5 - 10-mm wall thickness; 1.5 and 2.0$\mathrm{m}$ length, with inside membrane if required). Discussions will also be held with nonoxide ( $\mathrm{SiC}$ ), ceramic candle vendors (Pall, Schumacher, etc.) for the manufacturing feasibility and cost of thin-walled, SiC inverted candles, with and without inside membranes.

\section{Task 1.2 - Inverted candle hardware evaluation}

The inverted ceramic candle gasket and holder designs will be reviewed based on conventional ceramic candle filter element experience. The design of the inverted ceramic candle containment, placement guides and fail-safe regenerators will be conceptually evaluated.

\section{Task 1.3 - Inverted candle procurement}

Inverted, thin-walled ceramic candle specifications will be prepared, including flange design and inside membrane skin specification, based on current experience with conventional candle filters. Four sets of 10 ceramic inverted candle filter elements will be procured based on this specification from vendors selected based on the results of Task 1.1, as well as the interest of the vendors to participate in this development. These will all be standard candle dimensions (60-mm OD, 1.5$\mathrm{m}$ long). It is desired to include both oxide and non-oxide ceramic materials in the testing. Metal inverted candles will be considered for the Option I test program only as a fall-back position. 


\section{Task 2 - Sheet Filter Engineering}

\section{Task 2.1 - Sheet filter manufacturing feasi bility and cost evaluation}

The ceramic and metal sheet filter flange design and body features (wall thicknesses, internal ribs, etc.) will be assessed through finite element simulation of transient thermomechanical behavior. The ceramic sheet filter flange design will also be based on current experience with conventional candle filters as well as on past test and design evaluation conducted for cross-flow filter element flanges. Candidate ceramic and metal filter element vendors for the sheet filters will be identified and discussions held with them to estimate the manufacturing feasibility and cost of the sheet filters in the sizes conceived (1-ft x 1-ft).

\section{Task 2.2 - Sheet filter hardware evaluation}

The ceramic sheet filter gasket and holder designs will be reviewed based on conventional candle filter element experience, past testing and design of cross-flow filter elements, and the analyses conducted in Task 2.1. Fixture designs to keep the ceramic sheet filter locked in position if it is damaged will also be proposed and assessed. Similar considerations of gasket and holder design will be made for metal sheet filter elements. The sheet filter fail-safe/regenerator design will be reviewed and upgraded.

\section{Task 2.3 - Sheet filter procurement}

Specifications for the ceramic and metal sheet filter elements will be prepared. Three sets of 12 sheet filter elements each, two ceramic and one metal, will be procured from the vendors based on the Task 2.1 results. Blasch, B\&W are possible ceramic sheet filter supplies, and several metal filter vendor are candidates.

\subsection{TEST PROGRAM TASKS}

The Option I testing activities are organized into three major tasks: Task 3 NEPA, Task 4 - Inverted Candle Testing, and Task 5 - Sheet Filter Testing.

\section{Task 3 - NEPA}

The appropriate NEPA forms required for the Option I testing will be prepared and submitted. 


\section{Task 4 - Inverted Candle Testing}

\section{Task 4.1 - Cold flow tests}

A set of cold flow tests to visually observe inverted candle pulse cleaning will be conducted in an existing ceramic barrier filter Plexiglas test rig. A set of conventional Coors candles (3) will be installed using an existing inverted candle holding fixture. Coors candles are available at Westinghouse, and having no need for an inside membrane, represent an inverted candle that can be applied to test some key aspects of the issues.

The tests will address two cases:

- the Coors inverted candles pressure drop and pulse cleaning behavior at the reference PFBC design face velocity for the inverted candles $(9.1$ $\mathrm{ft} / \mathrm{min})$,

- a simulation of the performance of 100-mm ID inverted candles by dimensionally-scaling 40-mm ID inverted candles.

High-speed photographic records of pulse cleaning will be combined with pressure drop measurements to assess the performance. Test parameters will be the degree of ash load in the candles, and the pulse cleaning intensity. A completely plugged candle condition will also be tested. The 100-mm ID inverted candle simulation tests will show the influence of the inverted candle inlet velocity on the ash pulse cleaning performance. The dimensional-scaling of the 40-mm ID inverted candle will maintain the reference face velocity, inlet velocity, and L/D of the 100$\mathrm{mm}$ ID inverted candle.

\section{Task 4.2 - High-temperature tests}

A series of high-temperature tests on the three sets of inverted candles procured will be conducted in an existing high-temperature, high-pressure ceramic barrier filter test rig. Five inverted candles will be installed in the rig using the existing inverted candle holding fixture. The tests will be run in three series to address:

- steady-state filtration performance for the inverted candles (pressure drop and pulse cleaning) at PFBC reference design face velocity,

- simulation of 100-mm ID inverted candles performance,

- plugged filter element pulse cleaning performance,

- damaged inverted candle self-sealing performance. 
The outlet dust loading will be monitored to assess the self-sealing performance of the damaged inverted candle.

\section{Task 4.3 - Post test examinations}

Following the Task 4.1 and 4.2 testing, the inverted candle filter array will be inspected to assess the

- formation or elimination of ash bridges within either the inner bore of the candles, or within various locations of the array and ability to remove bridges;

- extent of dust cake removal along the filtration surface -- this will be monitored via post-test gas resistance measurements, and optically viewed via borescope inspection;

- operational efficiency of the gasket seals.

Post-test characterization of the inverted candle filters will be conducted to establish the

- residual room temperature gas flow permeability for comparison with new permeabilities,

- retention of fines along the internal filtration surface (i.e., absence of fines penetration into the filter wall),

- overall integrity of the filter body and flange (i.e., absence of crack formations; retention of the as-manufactured dimensional tolerances),

- residual bulk strength at room temperature and process operating temperature (i.e., compressive, tensile, hoop stress) and compared to conventional candles of the same material.

\section{Task 4.4 - Test data evaluation}

The inverted candle measured pressure drop performance will be compared to the projected performance, and the pressure drop and pulse cleaning performance of the candles will be assessed. The pressure drop and pulse cleaning/plugging performance of the 100-mm ID inverted candle will be projected from the simulation test data. The general influence of the inverted candle inlet velocity on the pulse cleaning performance will be identified. The relative durability of the four sets of inverted candles will be judged.

The inverted candle test data will be assessed with respect to success criteria to judge the feasibility of the inverted candle elements and the filter configuration concept. In particular, the test data will be applied to assess the pulse cleaning and plugging potential of the inverted candle filter elements, as well as their self-sealing, 
fail-safe potential. The inverted candle element estimated purchase cost will be applied to reassess the relative cost potential of the inverted candle filter system. A test report on the inverted candle tests will be prepared.

\section{Task 5 - Sheet Filter Tests}

\section{Task 5.1 - Design \& fabricate hardware}

The hardware required for the sheet filter tests (plenum pipe, flange holders, restraining fixtures) will be designed and fabricated. The sheet filter array will place 6 sheet filters in close proximity to each other and will duplicate key features expected in a commercial design.

\section{Task 5.2 - Cold flow tests}

A set of cold flow tests to visually observe sheet filter pulse cleaning, and filter cake buildup, and ash bridge accumulation will be conducted in an existing ceramic barrier filter Plexiglas test rig. A set of sheet filters (6) will be installed using the plenum fabricated in Task 5.1.

The tests will measure the sheet filter pressure drop and pulse cleaning behavior at the reference PFBC design face velocity for the sheet filter $(9.5 \mathrm{ft} / \mathrm{min})$. High-speed photographic records of pulse cleaning will be combined with pressure drop measurements to assess the performance. Test parameters will be the level of ash load on the sheet filters, and the pulse cleaning intensity. Damaged sheet filter simulations will also be conducted.

\section{Task 5.3 - High-temperature tests}

A series of high-temperature tests on the three sets of sheet filters procured will be conducted in the existing high-temperature, high-pressure ceramic barrier filter test rig. The tests will address:

- $\quad$ steady-state filtration performance of the sheet filter array operated at the PFBC reference face vel ocity (pressure drop and pulse cleaning),

- damaged sheet filter behavior tests.

The outlet dust load will be monitored to assess the damaged sheet filter stability of position in its fixture.

\section{Task 5.4 - Post test examinations}

The sheet filter assembly will be examined for signs of bridging between the filter elements and for patterns of pulse released ash. The sheet filter elements subjected to the high-temperature test conditions will be examined. The pattern of ash accumulation on the filter elements will be examined. The used sheet filter 
permeabilities will be measured and compared with the new permeabilities. Any degradation to the sheet filter flange or body will be characterized.

Post-test evaluation will be performed on selected sheet filters to identify the response and performance, particularly of new materials to the simulated PFBC gas environment. Specific attention will be given to the flange area of the elements to assure that the process and/or metal holder design has not induced the formation of cracks in this region of the filter element. In addition, the performance of the gasketing seals will be evaluated after the tests.

\section{Task 5.5 - Test data evaluation}

The sheet filter test data will be assessed with respect to success criteria to judge the acceptability of the sheet filter elements and the sheet filter configuration concept. In particular, the test data will be applied to assess the bridge potential and free-fall ash performance of the sheet filter configuration, the functionality of the restraining holder, and the short-term durability of the elements. The three vendors sheet filter products will also be compared and assessed. The sheet filter el ement estimated purchase cost will be applied to reassess the relative cost potential of the sheet filter system. A test report on the sheet filter tests will be prepared.

\subsection{DESCRIPTION OF TESTING}

\section{Inverted candle cold flow tests (Task 4.1)}

The cold flow test rig consists of a cylindrical Plexiglas vessel, pulse gas supply and control system, ash feed system, and instrumentation. The Plexiglas cylinder has 31-in inside diameter, is 108-in tall, and has $3 / 4-$ in wall thickness. It has been previously operated to test both candle filters and crossflow filters.

Three inverted Coors candles will be installed in the cold flow test rig and will be subjected to inside filtering of PFBC flyash. The cold flow test matrix is shown in Table 9.1 and addresses the two major aspects of the testing: 1) normal filtration, pressure drop, and pulse cleaning performance/ behavior of the Coors 40$\mathrm{mm}$ ID inverted candles; and 2) simulation of the performance of 100-mm ID inverted candles. The test conditions and variables are listed in Table 9.1, as well as the total number of tests and total number of 
Table 9.1 - Inverted candle cold flow test matrix

\begin{tabular}{|c|c|c|}
\hline & $\begin{array}{l}\text { 60-mm OD, 40-mm } \\
\text { ID, 1.5-m long } \\
\text { inverted candles }\end{array}$ & $\begin{array}{c}\text { Simulation of } 100- \\
\text { mm ID, } 1.5-m \text { long } \\
\text { inverted candles }\end{array}$ \\
\hline Temperature $\left({ }^{\circ} \mathrm{F}\right)$ & room & room \\
\hline Pressure (atm) & 1 & 1 \\
\hline Filter type & Coors & $\begin{array}{c}\text { Coors (60\% ID } \\
\text { surface blocked) }\end{array}$ \\
\hline Number of filters & 3 & 3 \\
\hline $\begin{array}{l}\text { Face velocity } \\
\text { (ft/min) }\end{array}$ & 9.1 & 9.1 \\
\hline $\begin{array}{l}\text { Filter inlet velocity } \\
\text { (ft/s) }\end{array}$ & 21.4 & 8.5 \\
\hline Gas flow (acfm) & 52 & 21 \\
\hline Ash type & Karhula Lakeland & Karhula Lakeland \\
\hline Ash flow (Ib/hr) & 1 & 1 \\
\hline Ash flow (ppmw) & 4,400 & 10,800 \\
\hline $\begin{array}{l}\text { Trigger pressure } \\
\text { drop (psi) }\end{array}$ & $\begin{array}{c}3 \text { variations }+ \\
\text { plugged condition }\end{array}$ & $\begin{array}{c}2 \text { variations }+ \\
\text { plugged condition }\end{array}$ \\
\hline Pulse intensity & 3 variations & $2-3$ variations \\
\hline Number of tests & 18 & 15 \\
\hline Hours of testing & 145 & 120 \\
\hline
\end{tabular}


hours of testing that are estimated to be accumulated in the program. The inlet dust loadings are estimates of the capabilities of the feed system with the selected PFBC fly ash material. In all cases, the maximum possible fly ash feed rate will be utilized to better simulate actual PFBC operation, as well as to allow faster accumulation of useful test data. Each test is assumed to be completed in a single 8-hour day. Several replicate tests and some tests with currently undefined test parameters are included. Potential test variations that the undefined parameter tests might be utilized for include alternative PFBC fly ash materials having finer particle size and lower flow permeability than the selected Karhula Lakeland fly ash.

The inverted filter elements will be operated with variations in the trigger pressure drop, and the pulse cleaning intensity. The data collected will be records of the pressure drop and pulse cleaning behavior. "Plugged" inverted candles will be tested by first allowing them to overfill at normal operating conditions until the pressure drop reaches an unacceptable value. High-speed movies will be made of several pulse cleaning events.

The 40-mm ID inverted Coors candle will be used to simulate the pressure drop and pulse cleaning behavior of 100-mm ID inverted candles. This will be done by blanking off the upper inside surface area and volume of the Coors candles to the extent needed (about 60\%) to give the length/inside diameter ratio of the $100-\mathrm{mm}$ ID inverted candle. This will result in the candle inlet velocity being that of the 100 $\mathrm{mm}$ ID inverted candle while the face velocity will be the PFBC reference design value (see Table 9.1).

\section{Inverted candle high-temperature tests (Task 4.2)}

Filter performance and short-term durability of the inverted candles will be evaluated in Westinghouse's pressurized fluidized-bed combustion (PFBC) simulator test facility. Feasibility testing in the Option I program will address the

- $\quad$ pressure drop performance and conditioned filter element pressure drop,

- filtration efficiency of the elements during steady state operation,

- dust cake pulse cleaning capability (normal operation and plugged recovery),

- response of the inverted candle elements to short-term exposure,

- short-term reliability of the gasket seal and mounting configuration,

- damaged inverted candle self-sealing performance.

High-temperature testing with the inverted candles will use available hardware, and the four sets of inverted ceramic filter el ements procured for the program. Table 9.2 shows the high-temperature test matrix and addresses the three major aspects of the testing: 1) normal filtration and pressure drop performance behavior of the inverted candles; 2) the self-sealing, fail-safe performance of damaged 
inverted candles; and 3) simulation of the performance of 100-mm ID inverted candles. The test conditions and variables are listed in Table 9.2, as well as the total number of tests and total number of hours of testing that are estimated to be accumulated in the program. The inlet dust loadings are estimates of the capabilities of the feed system with the selected PFBC fly ash material. In all cases, the maximum possible fly ash feed rate will be utilized to better simulate actual PFBC operation, as well as to allow faster accumulation of useful test data. Some replicate tests and several tests with currently undefined parameters are also provided for in the test plan. Potential test variations that the undefined parameter tests might be utilized for include alternative PFBC fly ash materials having finer particle size and lower flow permeability than the selected Karhula Lakeland fly ash.

In order to simulate the PF BC gas environment, natural gas will be combusted, producing a $6 \% \mathrm{O}_{2}, 7 \% \mathrm{CO}_{2}, 14 \% \mathrm{H}_{2} \mathrm{O}$, and $73 \% \mathrm{~N}_{2}$ gas stream which will then pass through the porous ceramic filter array at the reference design velocity of $9.1 \mathrm{ft} / \mathrm{min}$. Re-entrained PFBC filter ash will be delivered to the filter array to form a dust cake layer along the ID bore of the inverted candle filters. The dust cake layer will be removed by pulse cleaning at several $\Delta \mathrm{P}$ trigger set points (i.e., 30 in-wg over baseline). I sokinetic gas sampling of the exhaust gases will be conducted to establish outlet particle loading and to assure that the structural integrity of the filters and/or gasket seal have been maintained.

One inverted candle in each array will be fractured in-place and tested for its ability to self-seal with dust in the simulated PFBC environment. Steady-state operation will be achieved and the filter outlet dust loading will be measured to determine the degree of self-sealing. Differences in the self-sealing ability of the four ceramic inverted candles tested will be detected by the testing.

\section{Sheet filter cold flow tests (Task 5.2)}

The cold flow test rig will be used to test the sheet filter and its configuration. Six sheet filters will be installed in the cold flow test rig and will be subjected to filtering of PFBC fly ash. The same sheet filter plenum device designed and constructed for the high-temperature testing will be used for the cold flow testing.

The cold flow test matrix is shown in Table 9.3 and addresses the two major aspects of the testing: 1) normal filtration, pressure drop, pulse cleaning, and ash bridging performance/ behavior of the sheet filter; and 2) simulation of the stable, locked position performance of a damaged sheet filter. The test conditions and variables are listed in Table 9.3, as well as the total number of tests and total number of hours of testing that are estimated to be accumulated in the program. The inlet dust loadings are estimates of the capabilities of the feed system with 
Table 9.2 - Inverted candle high-temperature test matrix

\begin{tabular}{|c|c|c|c|}
\hline & $\begin{array}{l}\text { 60-mm OD, } 40 \text { to } \\
50-\mathrm{mm} \text { ID, } 1.5-\mathrm{m} \\
\text { long inverted } \\
\text { candles }\end{array}$ & $\begin{array}{c}\text { Damaged inverted } \\
\text { candle self-sealing } \\
\text { test }\end{array}$ & $\begin{array}{l}\text { Simulation of } 100- \\
\text { mm ID, } 1.5-m \text { long } \\
\text { inverted candles }\end{array}$ \\
\hline $\begin{array}{l}\text { Temperature } \\
\left({ }^{\circ} \mathrm{F}\right)\end{array}$ & 1550 & 1550 & 1550 \\
\hline Pressure (atm) & 10 & 10 & 10 \\
\hline Filter type & $\begin{array}{c}4 \\
\text { thin-wall, oxide } \\
\text { thin-wall, non- } \\
\text { oxide }\end{array}$ & 4 & 4 \\
\hline $\begin{array}{l}\text { Number of } \\
\text { filters }\end{array}$ & 5 & 5 (1 damaged) & 5 \\
\hline $\begin{array}{l}\text { Face velocity } \\
\text { (ft/min) }\end{array}$ & 9.1 & 9.1 & 9.1 \\
\hline $\begin{array}{l}\text { Filter inlet } \\
\text { vel ocity (ft/s) }\end{array}$ & $17.1-21.4$ & $17.1-21.4$ & 8.5 \\
\hline Gas flow (acfm) & $86-108$ & $86-108$ & $35-54$ \\
\hline Ash type & Karhula Lakeland & Karhula Lakeland & Karhula Lakeland \\
\hline Ash flow (lb/hr) & 5 & 5 & 5 \\
\hline Ash flow (ppmw) & $3,900-4,800$ & $3,900-4,800$ & $7,700-11,900$ \\
\hline $\begin{array}{l}\text { Trigger pressure } \\
\text { drop (psi) }\end{array}$ & $\begin{array}{c}3 \text { variations }+ \\
\text { plugged condition }\end{array}$ & 2 variations & $\begin{array}{c}2 \text { variations }+ \\
\text { plugged condition }\end{array}$ \\
\hline Pulse intensity & 3 variations & 2 variations & 2 variations \\
\hline Number of tests & 42 & 20 & 30 \\
\hline Hours of testing & 340 & 160 & 240 \\
\hline
\end{tabular}


the selected PFBC fly ash material. In all cases, the maximum possible fly ash feed rate will be utilized to better simulate actual PFBC operation, as well as to allow faster accumulation of useful test data. The sheet filter tests will have reasonably long, cumulative duration to allow substantial ash accumulation in the rig, and this will indicate if such accumulation might interfere with normal sheet filter operation.

The sheet filter elements will be operated with variations in the trigger pressure drop, and the pulse cleaning intensity. The data collected will be records of the pressure drop and pulse cleaning behavior. High-speed movies will be made of several pulse cleaning events, as well as of the damaged sheet filter tests. The residual ash accumulation between the sheet filters and on the support plenum will be measured. Simulation of the behavior of a severely damaged sheet filter element will be made to confirm that the holding fixture can maintain the element in its normal position.

\section{Sheet filter high-temperature tests (Task 5.3)}

An analogous series of high-temperature tests will be conducted using the sheet filter concept. Six sheet filters will be installed within a newly constructed array and tube sheet configuration. The array will then be lowered into the PFBC vessel and testing will be initiated in a manner similar to the inverted candle tests. The ability of the sheet filter configuration to avoid bridging will be assessed, and the ability of the sheet filter element to maintain its position even when damaged will be observed.

Filter performance and short-term durability of the sheet filters will be evaluated in the pressurized fluidized-bed combustion (PFBC) simulator test facility. Sheet filter testing in the program will address the

- $\quad$ ash bridging performance between the sheet filter elements,

- filtration efficiency of the elements during steady state operation,

- dust cake pulse cleaning capability,

- conditioned filter pressure drop,

- durability response of the sheet filter elements to short-term exposure,

- $\quad$ sort-term reliability of the gasket seal and mounting configuration.

High-temperature testing with the sheet filters will use newly fabricated plenum hardware, and three sets of sheet filter elements procured for the program. Table 9.4 shows the high-temperature test matrix and addresses the two major aspects of the testing: 1) normal filtration, pressure drop, pulse cleaning, ash bridging and accumulation performance/ behavior of the sheet filters; and 2) the stable fixing performance of damaged sheet filters. 
The test conditions and variables are listed in Table 9.4, as well as the total number of tests and total number of hours of testing that are estimated to be accumulated in the program. The sheet filter tests will have reasonably long, cumulative duration to allow substantial ash accumulation in the rig, and this will indicate if such accumulation might interfere with normal sheet filter operation.

The inlet dust loadings are estimates of the capabilities of the feed system with the selected PFBC fly ash material. In all cases, the maximum possible fly ash feed rate will be utilized to better simulate actual PFBC operation, as well as to allow faster accumulation of useful test data. Some replicate tests and several tests with currently undefined parameters are also provided for in the test plan. Potential test variations that the undefined parameter tests might be utilized for include alternative PFBC fly ash materials having finer particle size and lower flow permeability than the selected Karhula Lakeland fly ash.

\subsection{DATA INTERPRETATION AND SUCCESS CRITERIA}

In the bench-scale test program, the overall operating performance of both the inverted candle or sheet filters will be assessed in terms of:

- filtration efficiency of the elements during steady state operation,

- baseline pressure recovery and pulse cleaning requirement (gas quantity and pressure),

- effective dust cake removal al ong the filtration surface from the ID bore of the inverted candle filters, or OD surface of the sheet filter elements,

- self-sealing, fail-safe capability of damaged inverted candles,

- stable position of damaged sheet filter element,

- conditioned filter pressure drop,

- reliability of the gasket seal and mounting configuration.

The integrity of the filter elements as functional components will be assessed in terms of:

- elimination of ash plugs within the ID of the inverted candles,

- elimination of ash bridges between adjacent sheet filter el ements,

- retention of clean gasket seals,

- absence of fines penetration into the filter wall,

- overall integrity of the filter body and flange (i.e., absence of crack formations; retention of the as-manufactured dimensional tolerances),

- residual bulk strength at room temperature and process operating temperature (i.e., compressive, tensile, hoop stress) compared to conventional candles of the same material. 
Table 9.3 - Sheet filter cold flow test matrix

\begin{tabular}{|l|c|c|}
\hline & $\begin{array}{c}\text { Steady-state } \\
\text { operation }\end{array}$ & $\begin{array}{c}\text { Damaged sheet } \\
\text { filter simulation }\end{array}$ \\
\hline Temperature $\left.{ }^{\circ} \mathrm{F}\right)$ & room & room \\
\hline Pressure (atm) & 1 & 1 \\
\hline Filter type & $\begin{array}{c}\text { ceramic-types } \\
\text { metal-type }\end{array}$ & 3 \\
\hline Number of filters & 6 & $6(1$ damaged) \\
\hline $\begin{array}{l}\text { Face velocity } \\
\text { (ft/min) }\end{array}$ & 9.5 & 9.5 \\
\hline Gas flow (acfm) & 114 & 114 \\
\hline Ash type & Karhula Lakeland & Karhula Lakeland \\
\hline Ash flow (Ib/hr) & 1 & 1 \\
\hline Ash flow (ppmw) & 2,000 & 2,000 \\
\hline $\begin{array}{l}\text { Trigger pressure } \\
\text { drop (psi) }\end{array}$ & 2 variations & 2 variations \\
\hline Pulse intensity & 2 variations & 2 variations \\
\hline Number of tests & 16 & 14 \\
\hline Hours of testing & 130 & 110 \\
\hline
\end{tabular}


Table 9.4 - Sheet filter high-temperature test matrix

\begin{tabular}{|l|c|c|}
\hline & $\begin{array}{c}\text { Steady-state } \\
\text { testing }\end{array}$ & $\begin{array}{c}\text { Damaged filter } \\
\text { simulation }\end{array}$ \\
\hline Temperature ${ }^{\circ} \mathrm{F}$ ) & 1550 & 1550 \\
\hline Pressure (atm) & 10 & 10 \\
\hline Filter type & $\begin{array}{c}3 \\
\text { ceramic-types } \\
\text { metal-type }\end{array}$ & 3 \\
\hline Number of filters & 6 & 6 (1 damaged) \\
\hline Face velocity (ft/min) & 9.5 & 9.5 \\
\hline Gas flow (acfm) & 114 & 114 \\
\hline Ash type & $\begin{array}{c}\text { Karhula } \\
\text { Lakeland }\end{array}$ & $\begin{array}{c}\text { Karhula } \\
\text { Lakeland }\end{array}$ \\
\hline Ash flow (lb/hr) & 5 & 5 \\
\hline Ash flow (ppmw) & 3,600 & 3,600 \\
\hline $\begin{array}{l}\text { Trigger pressure drop } \\
\text { (psi) }\end{array}$ & 2 variations & 2 variations \\
\hline Pulse intensity & 2 variations & 2 variations \\
\hline Number of tests & 18 & 15 \\
\hline Hours of testing & 300 & 250 \\
\hline
\end{tabular}


The relative operating performance and durability of the alternative inverted candle types (oxide and non-oxide) and the alternative sheet filter types (ceramic and metal) will be compared.

Successful demonstration of the inverted candle and/or sheet filters to perform comparably with, or exceed the performance of Westinghouse's standard candle filter design is a key criteria in the evaluation process.

\subsection{OPTION I PROGRAM SCHEDULE}

The Option I program schedules for the two major activities, engineering and testing, are shown in Figure 9.1. 
Figure 9.1 - Option I Program Schedule

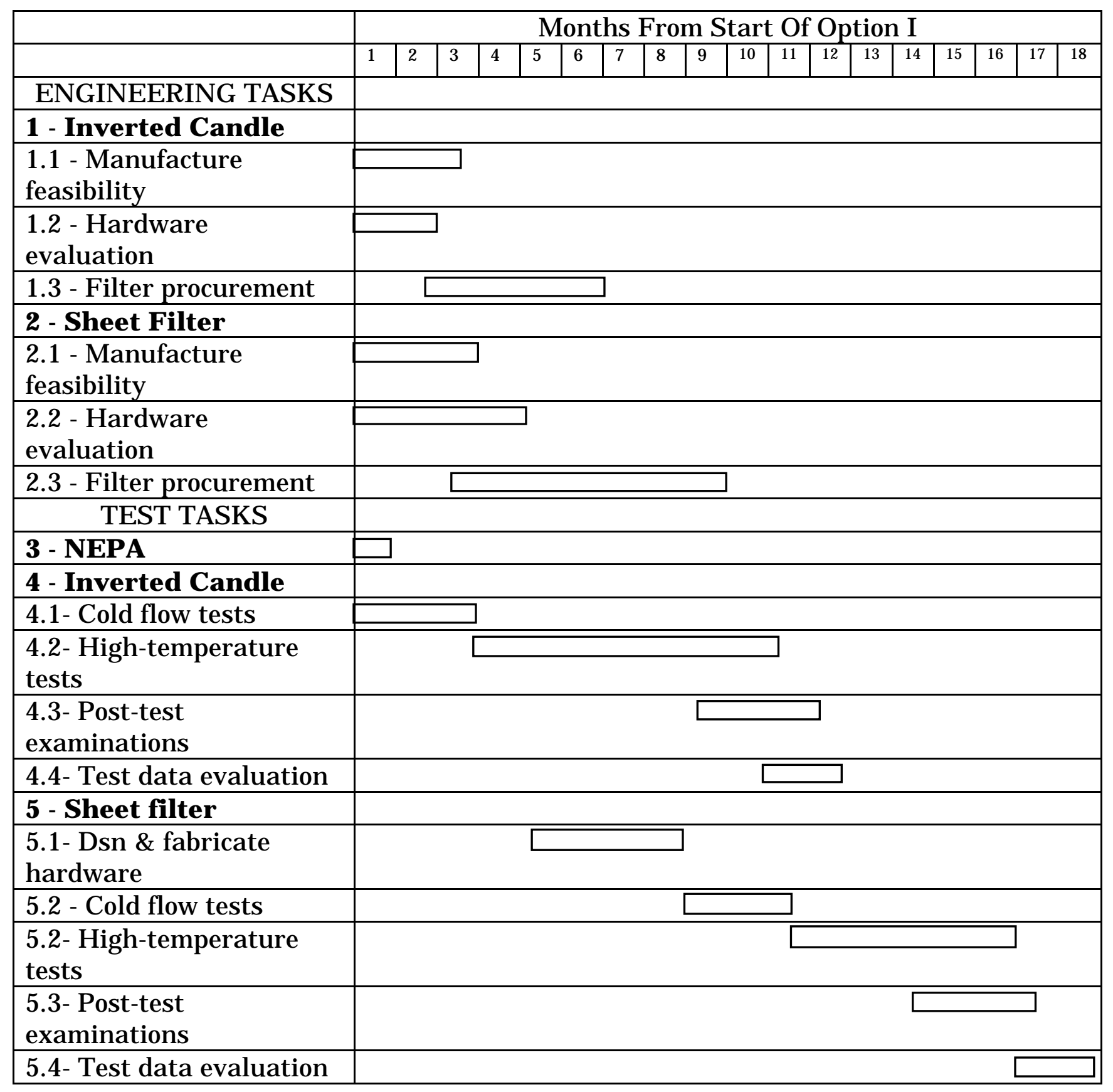


9-19 


\section{REFERENCES}

1. Alvin, M. A., T. E. Lippert, E. S. Diaz, E. E. Smeltzer and G. J . Bruck, "Filter Component Assessment, proceedings of the Advanced Coal Based Power and Environmental Systems '97 Contractors Review Meeting, Pittsburgh, PA, J uly, 1997.

2. Alvin, M. A. and T. E. Lippert, "Mechanical Analysis of a Cross Flow Filter Final Report", work performed under DOE Contract DE-AC21-86M C23252, 1996.

3. Brown, R. A., and A. J . Leitch, "Filtration of PFBC Dusts U sing a Rigid Ceramic Tube Type Filter", Proceedings of the $12^{\text {th }}$ International Conference on Fluidized Bed Combustion, 1993.

4. Delallo, M. R., et al., "Advanced Technol ogy Repowering, Parsons Power Report No. 3081, Final Report to DOE/FETC Under Contract No. DE-AC2194MC31166, 1997.

5. Higashi, K, N. , et al., "Operating Experiences of the Advanced Ceramic Tube Filter for the Wakamatsu 71 MW PFBC Demonstration Plant and Design Improvements for the Realization of Commercial Plants", Proceedings of the $14^{\text {th }}$ International Conference on Fluidized Bed Combustion, 1997, p.1201.

6. Ireson, W. G., and C. F. Coombs, "Handbook of Reliability Engineering and management," McGraw-Hill Book Company, New York, NY, 1966.

7. Lippert, T. E., and R. A. Newby, "High-Temperature Particulate Control", in Pressurized Fluidized Bed Combustion, E. J . Anthony Editor, Blackie Academic \& Professional, New York, 1995.

8. Newby, R. A., T. E. Lippert, M. A. Alvin, G. J . Bruck, and Z. N. Sanjana, "Status of Westinghouse Hot Gas Filters for Coal and Biomass Power Systems", paper presented at the $43^{\text {rd }}$ ASME Gas Turbine and Aeroengine Congress, Exposition, and Users Symposium, Stockholm, Sweden, J une, 1998. 
9. Weber, G. F., and G. L. Schelkoph, "Pilot Scale Performance/Durability Evaluations of 3M Company's High Temperature Nextel Fiber Bags", Final Project Report, Submitted to EPRI under EPRI Contract 1336-16, 1990. 


\section{APPENDIX A - SHEET FILTER MECHANICAL DESIGN ASSE SSMENT}

Preliminary mechanical analysis of the sheet filter was conducted to assess the feasibility of this new filter element and to identify its required mechanical features. The primary consideration made here was the ability of the sheet filter to withstand the stresses generated during back-pulse cleaning. It is estimated that a representative maximum pressure drop across the sheet filter plates during backpulse cleaning would be 5 psi, with a 15 psi design pressure drop providing a large mechanical design margin. Sheet filter dimensions, plate thickness, and internal ribbing features that provide a safe mechanical margin have been determined and appear to be feasible for ceramic fabrication. Further analysis of the transient thermal-mechanical behavior of the sheet filter, including the features of the flange, is required.

\section{EVALUATION OF PLATE STRESSES}

The initial evaluation of the sheet filter used standard stress equations to determine the maximum stresses in the plate. From Roark's Formula's for Stress \& Strain, Table 26, Case 4, the stresses for a rectangular plate with one side fixed, and 3 sides simply supported, with a uniform load over the entire plate are as follow:

$$
\begin{aligned}
& \operatorname{Max} \sigma=\beta q b^{2} / t^{2} \\
& \max y=-\alpha b q^{4} /\left(E t^{3}\right) \\
& \text { for }
\end{aligned}
$$

$\begin{array}{llllllll}\mathrm{a} / \mathrm{b} & 1 & 1.5 & 2.0 & 2.5 & 3.0 & 3.5 & 4.0 \\ \beta & 0.50 & 0.66 & 0.73 & 0.74 & 0.74 & 0.75 & 0.75 \\ \alpha & 0.03 & 0.046 & 0.054 & 0.056 & 0.057 & 0.058 & 0.058\end{array}$

where $a / b$ is the ratio of the plate width to the plate height ( $b$ is 12 -inches for all of the cases considered here). The values were based on Poisson's ratio $=0.3$.

To compare the effects of the various parameters, baseline calculations were made using the above equations for the following conditions:

plate depth $=12 "$

plate width $=12 ", 24 ", 36 ", 48$ " ( plate a/b ratios $=1,2,3$, and 4.)

plate thickness $=.19685 ", 0.3937 ", 0.5905 "(5 \mathrm{~mm}, 10 \mathrm{~mm}, 15 \mathrm{~mm})$

internal pressure $=5,10,20,40,60$ psi (developed during pulse cleaning). 
The results of the calculations are listed in Table A1. As seen by examining the equations, the Modulus of Elasticity affects the displacement, but not the values of maximum stress.

\section{Table A10.1 - Sheet Filter stress as a function of plate dimensions, thickness, and pulse pressure}

\begin{tabular}{|c|c|c|c|c|c|}
\hline $\begin{array}{c}\text { Thicknes } \\
\text { s } \\
\text { inches }\end{array}$ & $\begin{array}{c}\text { Pressure } \\
\text { psi }\end{array}$ & $12^{\prime \prime}$ & Plate & Width & $48 "$ \\
\hline \multirow{5}{*}{0.19685} & 5 & 9290 & 13564 & 13750 & 13936 \\
\hline & 10 & 18581 & 27128 & 27499 & 27871 \\
\hline & 20 & 37161 & 54256 & 54999 & 55742 \\
\hline & 40 & 74323 & 108511 & 109998 & 111484 \\
\hline & 60 & 111484 & 162767 & 164996 & 167226 \\
\hline \multirow{5}{*}{0.39370} & 5 & 2323 & 3391 & 3437 & 3484 \\
\hline & 10 & 4645 & 6782 & 6875 & 6968 \\
\hline & 20 & 9290 & 13564 & 13750 & 13936 \\
\hline & 40 & 18581 & 27128 & 27499 & 27871 \\
\hline & 60 & 27871 & 40692 & 41249 & 41807 \\
\hline \multirow{5}{*}{0.59055} & 5 & 1032 & 1507 & 1528 & 1548 \\
\hline & 10 & 2065 & 3014 & 3055 & 3097 \\
\hline & 20 & 4129 & 6028 & 6111 & 6194 \\
\hline & 40 & 8258 & 12057 & 12222 & 12387 \\
\hline & 60 & 12387 & 18085 & 18333 & 18581 \\
\hline
\end{tabular}

\section{EFFECTS OF POISSON'S RATIO}

Since the previous equations are based on a Poisson's ratio of 0.3 , the results do not include the effect of Poisson's ratio. To provide the effect of variations in Poisson's ratio, a simple finite element shell model of a 12" x 12" plate, 0.19685 " thick was made.

The Ansys model was run only for the 12 " square model. Three edges were held in plane, while the fourth edge was fixed (held in $x, y$, and $z$, and in rotation). For the case consisting of $0.19685^{\prime \prime}$ thickness, 5 psi, with Poissons ratio $=3$, the maximum stress was 9383 psi, which is slightly higher than the stress using the equations. Varying Poisson's ratio in the Ansys model gave the following stresses:

\begin{tabular}{|l|l|l|l|}
\hline Poisson's Ratio & $0.19685 "$ plate & $0.3937 "$ plate & $0.59055^{\prime \prime}$ plate
\end{tabular}




\begin{tabular}{|c|c|c|c|}
\hline 0.3 & $9383 \mathrm{psi}$ & $2359 \mathrm{psi}$ & $1054 \mathrm{psi}$ \\
\hline 0.25 & $9387 \mathrm{psi}$ & $2361 \mathrm{psi}$ & $1056 \mathrm{psi}$ \\
\hline 0.2 & $9391 \mathrm{psi}$ & $2364 \mathrm{psi}$ & $1058 \mathrm{psi}$ \\
\hline 0.18 & $9393 \mathrm{psi}$ & $2365 \mathrm{psi}$ & $1059 \mathrm{psi}$ \\
\hline
\end{tabular}

From these results it can be seen that the effect of Poisson's ratio is negligible; with only a $0.1 \%$ stress variation for the thinnest plate, and a $0.5 \%$ variation in stress for the $15 \mathrm{~mm}$ plate, with Poisson's ratio varying from 0.3 to 0.18 .

\section{D MODELS}

Because the simple plate model of the sheet filter does not include the effects of the sides and bottom which are also loaded by the pulse pressure, a 3D model provides greater accuracy in representing the filter behavior. The model was created with 12-inch x 12-inch plates, with a filter thickness of 1.0" (plate centers offset by one inch minus the thickness of the wall). The top is open, with the edges constrained in translation. The bottom is closed, with pressure applied. The analysis of 0.19685 " material with 5 psi pulse gave a maximum stress of 5635 psi, compared to the 9290 psi for the simple plate model. When the long top edges are constrained against rotation, (similar to the constraints of the plate model), the maximum stress is 6214 psi, occurring at the top center of the plate. Changes in the fixturing of the end have a significant effect on the stresses in the unribbed filter.

The maximum stresses in the model occur near the narrow ends, as the edges tend to act like hinges. To reduce the stresses, several design variations of internal ribs and external fins were modeled. The analyses were made using a 12" x 12" face, 1 " deep, with 0.19685 " thick material, with 5 psi pulse pressure. Comparison of the results of the design variation maximum stresses can be made using Table A2.

From these results, the ribs contribute more to the stress reduction than the fins do. The maximum stresses occur in the outer fiber of the plate material, due to the bending. The maximum stresses in the top, middle, and bottom of the plate, using the three rib/one fin case as an example, are 454 psi, 198 psi, and 419 psi, respectively.

The maximum pulse pressure design value is $15 \mathrm{psi}$. This will triple the stresses from the values in the preceding table. Plotting the stresses for both $5 \mathrm{psi}$ and 15 psi pulse pressures gives the results shown in Figure A1. 
Table A2 - Variation of Maximum Stresses with Rib and Fin Features

\begin{tabular}{|l|c|l|l|l|}
\hline Model & $\begin{array}{c}\text { Maximum } \\
\text { Stress, } \\
\text { translation } \\
\text { constraint } \\
\text { ksi }\end{array}$ & $\begin{array}{l}\text { location of max. } \\
\text { stress }\end{array}$ & $\begin{array}{l}\text { With } \\
\text { rotation } \\
\text { constraint }\end{array}$ & $\begin{array}{l}\text { location of } \\
\text { maximum } \\
\text { stress }\end{array}$ \\
\hline no ribs or fins & 5.635 & near side edge & 6.214 & at top center \\
\hline one rib & 1.751 & at rib & 1.727 & at rib \\
\hline two ribs & 0.783 & at rib & & \\
\hline three ribs & 0.447 & at rib & 0.446 & at rib \\
\hline four ribs & 0.287 & at rib & 0.286 & at rib \\
\hline one fin per side & 5.782 & outer edge of fin & & \\
\hline $\begin{array}{l}\text { three fins per } \\
\text { side }\end{array}$ & 3.666 & outer edge of fin & & \\
\hline $\begin{array}{l}\text { three ribs, one } \\
\text { fin }\end{array}$ & 0.454 & at rib & & \\
\hline
\end{tabular}

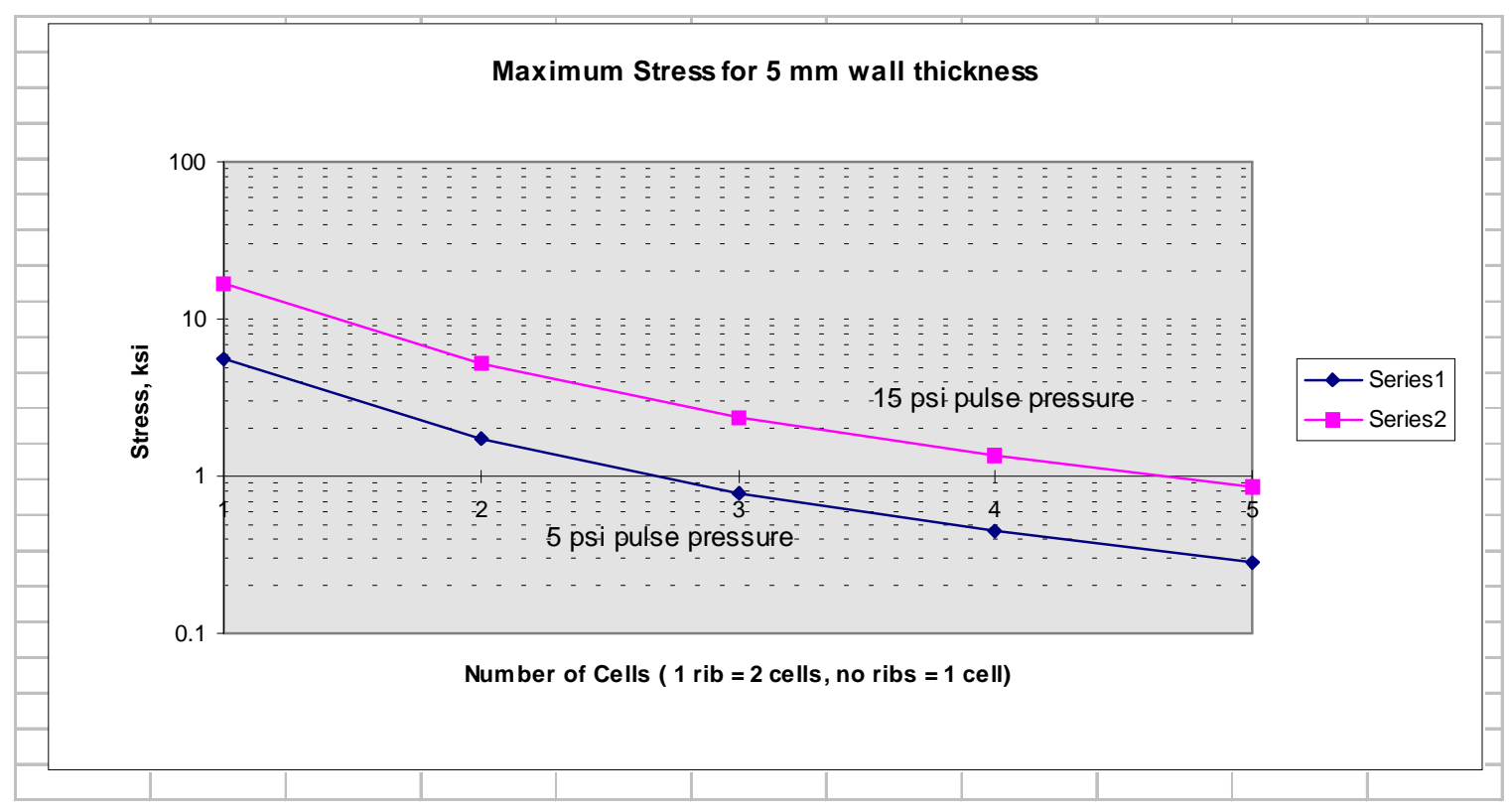

Figure A1 - Maximum Sheet Filter Stress with Internal Rib Construction 


\section{APPLICATION OF RESULTS}

Representative advanced ceramic materials have the properties listed in Table A3.

Table A3 - Sheet Filter Representative Material Mechanical Properties

\begin{tabular}{|l|l|l|l|l|}
\hline Material & $\begin{array}{l}\text { Mullite } \\
\text { Bonded } \\
\text { Alumina, } \\
\text { B-4-270-3 }\end{array}$ & $\begin{array}{l}\text { Mullite } \\
\text { Bonded } \\
\text { Alumina, } \\
\text { B-4-270-8 }\end{array}$ & $\begin{array}{l}\text { High Alumina, } \\
\text { BP95/6-P }\end{array}$ & $\begin{array}{l}\text { Larsenite, } \\
\text { BP85/6-AS }\end{array}$ \\
\hline $\begin{array}{l}\text { Ultimate Hoop } \\
\text { Stress, psi }\end{array}$ & & $1.60 \mathrm{e} 6 \mathrm{psi}$ & & \\
\hline $\begin{array}{l}\text { Elastic } \\
\text { Modulus, psi } x \\
10^{6}\end{array}$ & $2.12 \mathrm{e} 6 \mathrm{psi}$ & $376 \mathrm{psi}$ & & \\
\hline $\begin{array}{l}\text { Ultimate Hoop } \\
\text { Stress, psi }\end{array}$ & $410 \mathrm{psi}$ & & $4.2 \mathrm{ksi}$ & $2.6 \mathrm{ksi}$ \\
\hline $\begin{array}{l}\text { Modulus of } \\
\text { Rupture at } \\
\text { 1500F, psi }\end{array}$ & & & & \\
\hline
\end{tabular}

While the increase in pulse pressure from its expected maximum value of 5 psi to its design value of 15 psi increased the stress by a factor of 3, the stress can be reduced by a factor of 4 by using $10 \mathrm{~mm}(0.3937 ")$ material instead of $5 \mathrm{~mm}$ $(0.19685 ")$ material. The stress for 3 ribs, with 15 psi pulse pressure, would then be expected to be approximatel $\mathrm{y} 3 / 4 \times 0.447 \mathrm{ksi}=0.335 \mathrm{ksi}$.

A confirming Ansys run was made, using a 1.2" thick filter to keep a gap of about $0.6^{\prime \prime}$, resulted in 118 psi with 5 psi pulse pressure, or 353 psi with 15 psi pulse pressure, about $5 \%$ higher than projected. A 1.0" thick filter with 15 psi pulse pressure has a maximum stress of $351 \mathrm{psi}$, indicating that changes in thickness of the plate filter have little effect on the maximum stress. Using 4 ribs would provide even greater margin, with the maximum stress of 230 psi in a 4 rib, 15 psi pulse, 1.0 " thick filter with $10 \mathrm{~mm}$ ribs and walls. 